\title{
Mecanismos fisiopatogénicos involucrados en la patología ósea de la Enfermedad de Gaucher
}

\begin{abstract}
Resumen
La enfermedad de Gaucher (EG) es una patología genética de almacenamiento lisosomal, de herencia autosómica recesiva, causada por la deficiencia de la enzima lisosomal beta-glucosidasa (GCasa). Esta deficiencia lleva a la acumulación de glucosilceramida, principalmente en macrófagos.

Las manifestaciones clínicas principales son: anemia, trombopenia, hepatoesplenomegalia, fracturas óseas, dolores óseos, osteopenia, osteonecrosis.

Si bien el daño óseo es una característica común de la EG, los mecanismos de la injuria y destrucción tisular son desconocidos. Por otro lado se sabe que la inflamación es un factor clave en la patogénesis de la EG.

En el presente trabajo de tesis se propuso profundizar en los mecanismos celulares y moleculares que llevan al daño óseo en la EG.

Para el estudio de estos mecanismos se emplearon muestras de pacientes con EG y dos modelos in vitro, uno humano y uno murino, en los cuales la actividad de la GCasa es inhibida mediante el uso de un epóxido, el $C B E$, que inhibe irreversiblemente la enzima.

En el presente trabajo se pudo demostrar la participación de los osteoclastos en el daño óseo tanto en el caso de los modelos como también en los pacientes. Por otro lado se demostró que los linfocitos $\mathrm{T}$ estarían involucrados en el proceso de diferenciación y activación de los osteclastos en la enfermedad.

Pudo observarse también que la citoquina TNF-a sería uno de los principales mediadores involucrados en el aumento del proceso de resorción que llevaría al daño óseo en la enfermedad.
\end{abstract}




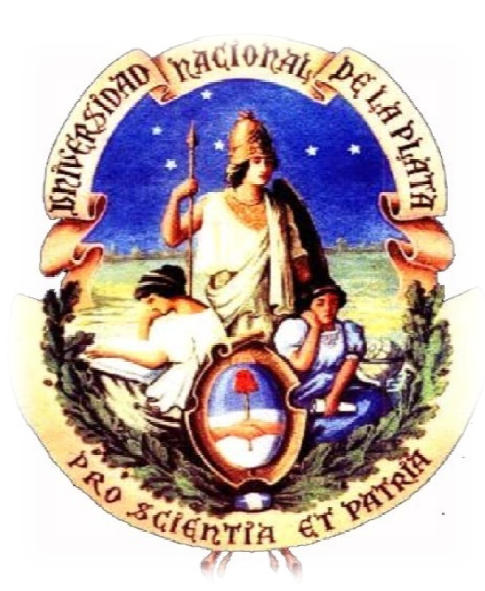

\title{
UNIVERSIDAD NACIONAL DE LA PLATA
}

Facultad de Ciencias Exactas Departamento de Ciencias Biológicas

Trabajo de tesis para optar por el grado de Doctor de la Facultad de Ciencias Exactas

\section{Mecanismos fisiopatogénicos involucrados en la patología ósea de la Enfermedad de Gaucher}

\author{
Directora: Dra. Paula Rozenfeld \\ Codirectora: Dra. María Victoria Delpino \\ Autor: Lic. Juan Marcos Mucci \\ Laboratorio de Investigaciones del Sistema Inmune \\ 2014
}




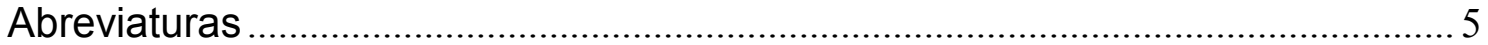

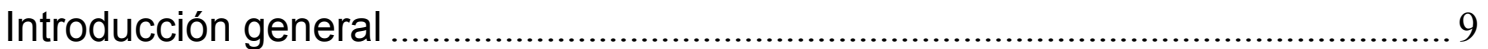

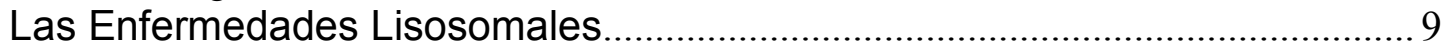

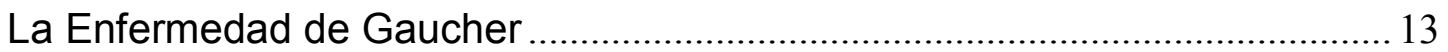

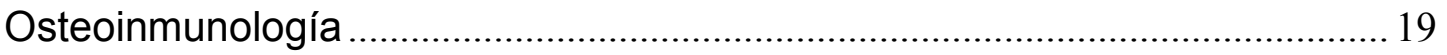

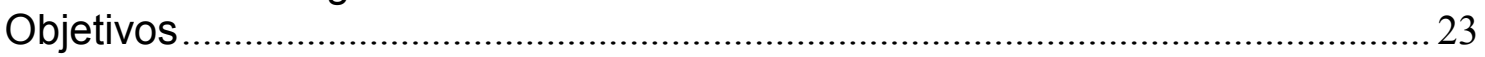

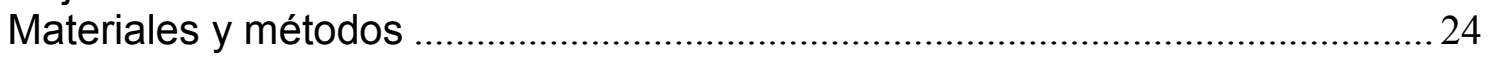

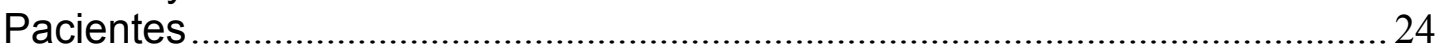

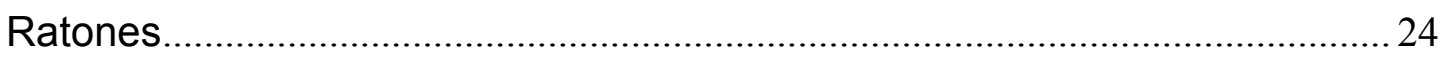

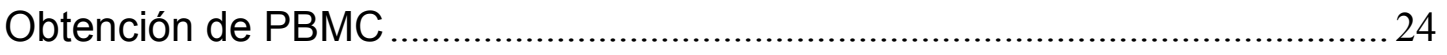

Preparación de sobrenadantes de cultivo condicionado .................................2. 25

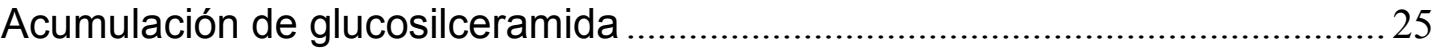

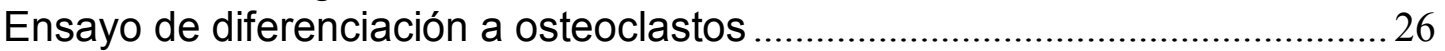

Evaluación de la expresión del receptor de vitronectina ..................................228

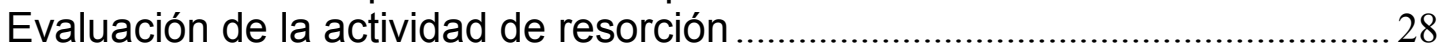

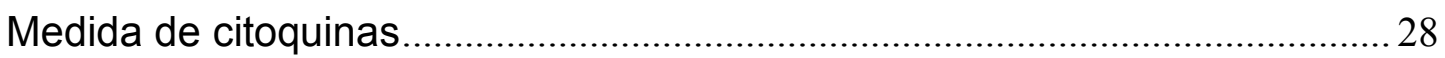

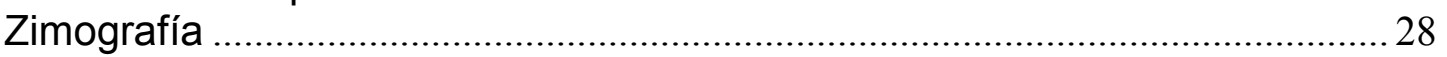

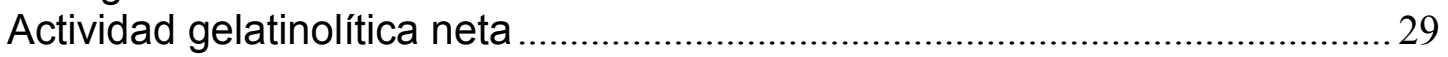

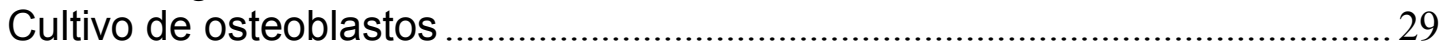

Cuantificación de la mineralización por tinción con Alizarina Roja (ARS) ...... 29

Cuantificación de la deposición de cólageno mediante tinción con Rojo Sirio

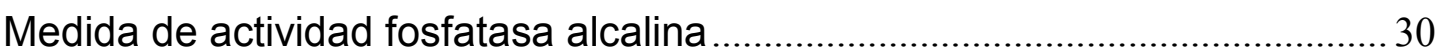

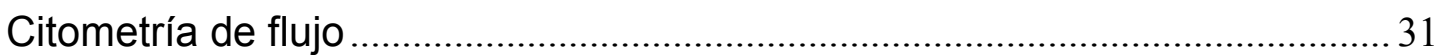

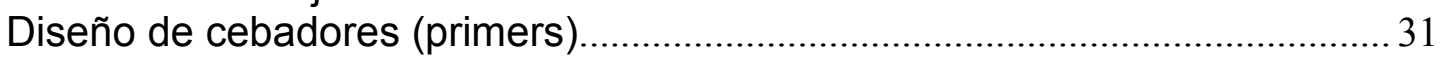

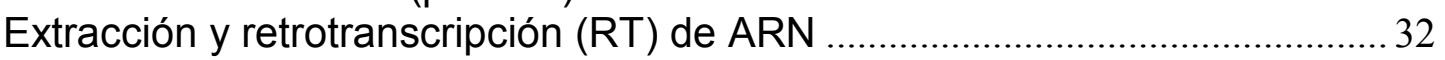

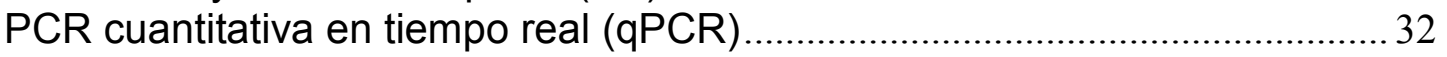

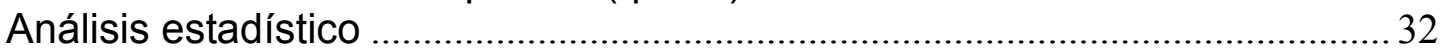

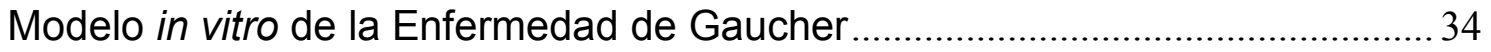

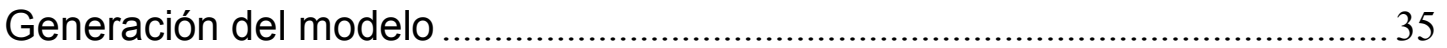

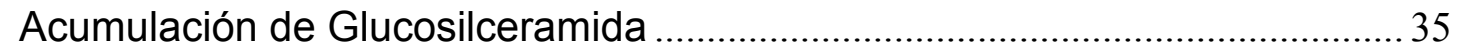

Inducción de la diferenciación de osteoclastos mediada por sobrenadante de

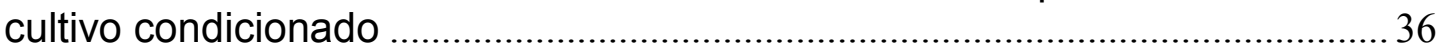

Determinación de citoquinas en sobrenadantes de cultivo condicionados .... 39

Actividad osteolítica ............................................................................................. 42

Secreción de citoquinas y marcadores de células de Gaucher por

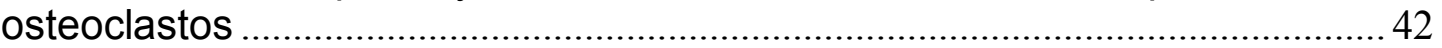

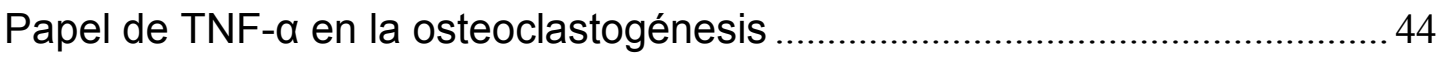

Participación de las células T en la osteoclastogénesis ................................... 45

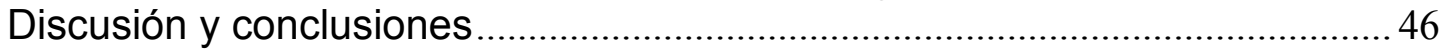

Modelo Murino in vitro de la Enfermedad de Gaucher ........................................ 49

Generación de los modelos in vitro murinos..................................................... 49

Inducción de la diferenciación de osteoclastos mediada por sobrenadante de

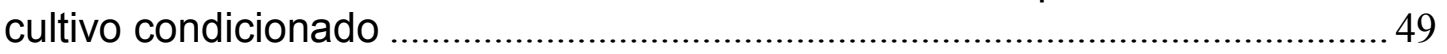

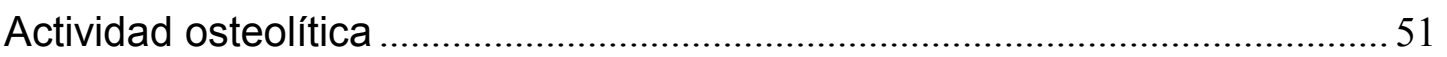

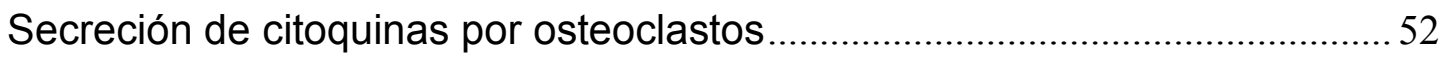

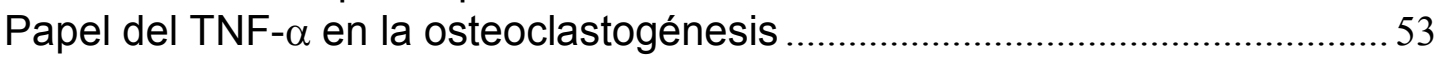

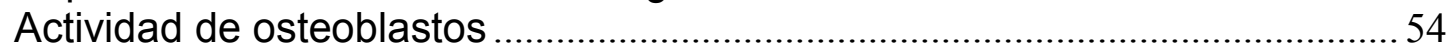

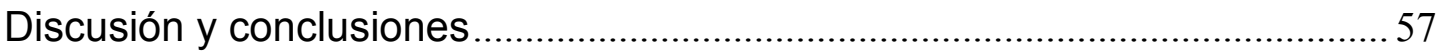

Osteoclastogénesis en pacientes con Enfermedad de Gaucher ...........................60 
Datos demográficos y clínicos de los pacientes estudiados

Perfíl inflamatorio de poblaciones en circulación de pacientes con EG

Niveles de precursores de osteoclastos en circulación de pacientes con enfermedad de Gaucher....

Medida de niveles de marcadores involucrados en la osteoclastogénesis en pacientes con enfermedad de Gaucher

Presencia de RANKL en células en circulación .................................................. 75

Diferenciación de precursores obtenidos de circulación ....................................... 77

Osteoclastogénesis mediada por moléculas solubles .................................... 78

Efecto del tratamiento in vitro con Velaglucerasa (rhGCasa) sobre la

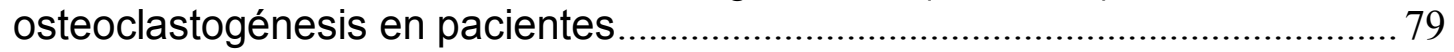

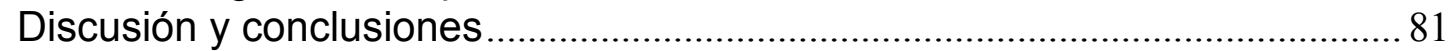

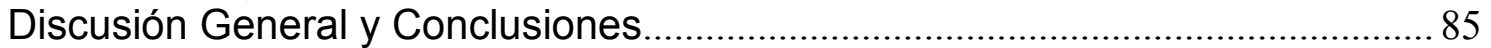

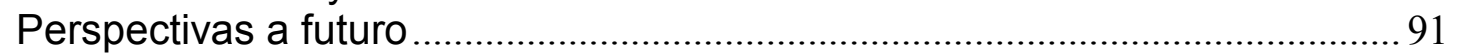

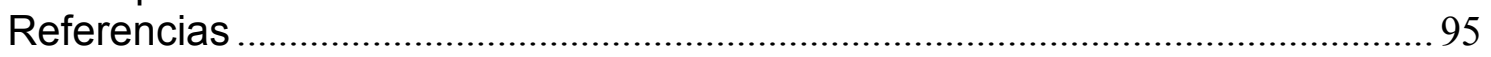




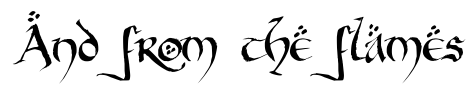

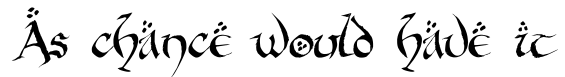

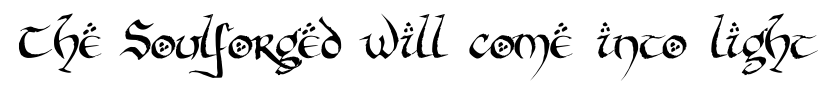

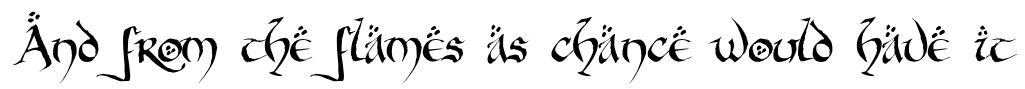

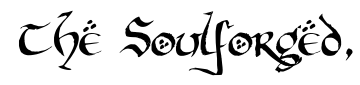

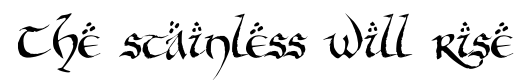

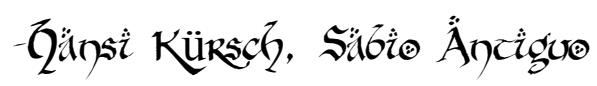


El presente trabajo de tesis no es el resultado del esfuerzo de una persona sino de un conjunto de personas que me apoyaron durante los momentos más difíciles. Por lo que les debo mi eterno agradecimiento y, a modo de pequeño homenaje, les dedico esta tesis.

A Paula, mi directora, por darme la oportunidad de trabajar con ella y por su eterna paciencia (la cual fue puesta a prueba más de una vez).

A Vic, mi codirectora, por el apoyo y la buena voluntad de responder a todas mis dudas en momentos de desesperanza.

A mis compañeros de grupo, los que están y los que pasaron: Romi (mi madre postiza), Florcita (mi compañera de emociones) y a Nico (mi maestro zen).

A toda la FAMILIA LISIN, con la cual compartí no solo es trabajo sino la vida en general. Y que me apoyaron durante los momentos más difíciles que tuve que atravesar. Gracias: Bel, Rodri, Facu, Coquita, Lu, Romi A, Paolín, Ceci, Costita, Fer, Andre, Yani, Martín, Loli, Dom, Agus Z, Gri, Herni, Dave, Alberto, Reni, Guille y Trejo. Y, por supuesta, a JC por ser la columna vertebral de nuestro laboratorio.

En especial a mis Padrinos Mágicos, por su apoyo y cariño incondicional frente a la adversidad.

A Agus por su amor, cariño, paciencia y por ser mí soporte a través de TODO.

A Nacho, por ser él.

A mi Mamá y mi Hermano ya que sin ellos no hubiera llegado a superar ningún obstáculo del camino.

A mis amigos, por mantenerse a mi lado a pesar de mis falencias.

Y, finalmente, a la Facultad de Ciencias Exactas y la Universidad Nacional de La plata, por brindarme la formación académica. Y a la ANPCyT y CONICET por otorgarme las becas para el desarrollo de mi tesis doctoral. 


\section{Abreviaturas}

ACTB - $\beta$-actina

ADN - Ácido desoxirribonucléico

MEM - Medio esencial mínimo

ARN - Ácido ribonucléico

ARS - Alizarina Roja

CBE - Conduritol- $\beta$-epóxido

CCL18 - Quemoquina con motivo C-C ligando 18

CCL2 - Quemoquina con motivo C-C ligando 2

CHIT - Quitotriosidasa

CM - Medio de cultivo condicionado

Ctl - Control

CtsK - Catepsina K

DC - Célula dendrítica

DMEM - Medio esencial mínimo modificado por Dulbecco

EG - Enfermedad de Gaucher

EL - Enfermedades lisosomales

ELISA - Ensayo de inmunoadsorción acoplado a enzima (Enzyme-Linked Immunosorbent Assay)

ER - Enzima recombinante

FACS - Citometría de flujo (Fluorescence-activated cell sorting)

FBS - Suero fetal bovino

FITC - Isotiocianato de fluoresceína

GBA - Glucocerebrosidasa (Gen)

GCasa - Glucocerebrosidasa o beta-glucosidasa ácida (Proteína)

GDI - Gen de interés

HLA-DR - Antígeno leucocitario humano DR

kDa - Kilodalton

IFN - Interferón

IL- Interleuquina

LB - Linfocitos B

LPS - Lipopolisacarido

LT - Linfocitos T

M-CSF - Factor de estimulación de colonias de macrófagos

MIP-1 - Proteína inflamatoria macrofáfica

$\mathrm{MMP} / \mathrm{s}$ - Metaloproteasa/s de matriz

MPS - Mucopolisacaridosis

NLRP3 - Receptor tipo NOD con dominio tipo pirina 3

OP - Precursor de osteoclasto

OPG - Osteoprotegerina

PBMC - Células mononucleares de sangre periférica

PBS - Buffer fosfato salino

qPCR - Reacción en cadena de la polimerasa en tiempo real

RANKL - Ligando del receptor activador del factor nuclear kappa-B

RANK - Receptor activador del factor nuclear kappa-B

S1P - Esfingosina-1-fosfato

SHN - Suero humano normal 
sRANKL - Ligando del receptor activador del factor nuclear kappa-B soluble

TBS - Buffer Tris salino

TGF - Factor de crecimiento tumoral

TLC - Cromatografía en capa fina

TNF - Factor de necrosis tumoral

TNFRp55KO - Knock out para la subunidad p55 del receptor de TNF

TRAP - Fosfatasa ácida resistente a tartrato

TRE - Terapia de reemplazo enzimático 


\section{Introducción general}

\section{Las Enfermedades Lisosomales}

Las enfermedades lisosomales comprenden actualmente un grupo de alrededor de 60 patologías de origen genético caracterizadas por la deficiencia de alguna de las proteínas que intervienen en la estructura y función normal de los lisosomas, lo que ocasiona la acumulación de sustratos en los mismos. Las enfermedades lisosomales son patologías multisistémicas, crónicas y progresivas, y los tipos celulares afectados en cada enfermedad, así como los órganos comprometidos son particulares de cada patología. La acumulación intralisosomal y/o tisular de uno o más compuestos, no permite explicar la fisiopatología subyacente en ellas, pudiendo existir una serie de eventos moleculares asociados a la alteración lisosomal que darían en conjunto el fenotipo observado en cada patología (Cox et al., 2012).

La incidencia estimada de todas estas enfermedades tomadas en conjunto varía de 1/4000 a 1/9000 nacidos vivos entre diferentes reportes bibliográficos (Fuller et al., 2006). El patrón de herencia más común entre las enfermedades lisosomales es el autosómico recesivo, aunque existen tres enfermedades cuyo patrón es ligado al cromosoma X.

La clasificación histórica de las enfermedades lisosomales se basaba principalmente en el tipo de sustrato que se acumula (esfingolipidosis, mucopolisacaridosis, etc.). En los últimos años la tendencia ha sido hacia una clasificación que involucre el defecto molecular asociado a cada una (Tabla 1) (Filocamo et al., 2011; Platt et al., 2012).

El primer paso para el diagnóstico de las enfermedades lisosomales es la sospecha clínica por parte del médico, y puede complementarse mediante diferentes técnicas como ser el diagnóstico por imágenes, la evaluación neurológica, el análisis de biopsias, etc. Invariablemente el diagnóstico se basa también en la evaluación bioquímica la cual puede ser, dependiendo del caso, orientativa o confirmatoria de la enfermedad. Entre los métodos orientativos se cuenta con la determinación de sustratos en suero u orina (glicosaminoglicanos, oligosacáridos, sulfátidos), y la búsqueda de rasgos distintivos en los tipos celulares afectados por microscopía o ultramicroscopía. Para el caso de las enfermedades lisosomales debidas a deficiencias enzimáticas la medida de la actividad enzimática es el método confirmatorio para el diagnóstico. Esta medida se realiza sobre leucocitos o fibroblastos obtenidos a partir de biopsias de piel. 
Tabla 1: Clasificación de las Enfermedades Lisosomales según el mecanismo de acumulación. Se incluyen varios ejemplos con su causa y órganos y sistemas afectados. Adaptado de (Platt, Boland, \& van der Spoel, 2012).

\begin{tabular}{|c|c|c|c|c|c|}
\hline $\begin{array}{l}\text { Mecanismo de } \\
\text { acumulación } \\
\text { lisosomal }\end{array}$ & $\begin{array}{l}\text { Ejemplos de } \\
\text { enfermedad }\end{array}$ & $\begin{array}{c}\text { Proteína lisosomal } \\
\text { deficiente (símbolo del } \\
\text { gen) }\end{array}$ & Sustrato(s) almacenados & $\begin{array}{c}\text { Principales órganos } \\
\text { periféricos } \\
\text { afectados }\end{array}$ & $\begin{array}{l}\text { Patología } \\
\text { del SNC }\end{array}$ \\
\hline \multirow{10}{*}{$\begin{array}{l}\text { Deficiencia de actividad } \\
\text { enzimática lisosomal } \\
\text { (mutación de enzima } \\
\text { lisosomal, enzima } \\
\text { activadora o cofactor } \\
\text { enzimático) }\end{array}$} & Aspartlglucosaminuria & $\begin{array}{c}\text { Aspartilglucosaminidasa } \\
\text { (glicosilasparaginasa, AGA) }\end{array}$ & $\begin{array}{l}\text { aspartilglucosamina ( } \mathrm{N} \text { - } \\
\text { acetilglucosaminil- } \\
\text { asparagina) }\end{array}$ & $\begin{array}{l}\text { Esqueleto, tejido } \\
\text { conectivo }\end{array}$ & + \\
\hline & Enf. de Fabry & a-Galactosidasa A (GLA) & $\begin{array}{l}\text { Globotriaosilceramida, } \\
\text { globlotriaosilesfingosina }\end{array}$ & $\begin{array}{l}\text { Riñón, corazón, } \\
\text { sistema vascular }\end{array}$ & - \\
\hline & $\begin{array}{l}\text { Enf. de Gaucher tipo 1, } \\
2 \text {, y } 3\end{array}$ & $\beta$-Glucocerebrosidasa (GBA) & $\begin{array}{l}\text { Glucosilceramida, } \\
\text { glucosilsesfingosina }\end{array}$ & $\begin{array}{l}\text { Bazo/hígado, médula } \\
\text { ósea, hueso }\end{array}$ & + \\
\hline & Gangliosidosis GM1 & $\beta$-Galactosidasa (GLB1) & $\begin{array}{l}\text { Gangliósido GM1, } \\
\text { oligosacáridos }\end{array}$ & Esqueleto, corazón & + \\
\hline & $\begin{array}{l}\text { Enf. de Krabbe } \\
\text { (Leucodistrofia de } \\
\text { células globoides) }\end{array}$ & $\begin{array}{l}\text { Galactocerebrosidasa } \\
\text { (GALC) }\end{array}$ & Galactosilceramida & Corazón & + \\
\hline & $\begin{array}{l}\text { Leucodistrofia } \\
\text { metacromática }\end{array}$ & Arilsulfatasa A (ARSA) & Sulfogalactosilceramida & & + \\
\hline & Mucopolisacaridosis & $\begin{array}{l}\text { Enzimas involucradas en el } \\
\text { catabolismo de } \\
\text { mucopolisacáridos }\end{array}$ & Mucopolisacáridos & $\begin{array}{l}\text { Cartílago, hueso, } \\
\text { corazón, pulmones }\end{array}$ & + \\
\hline & $\begin{array}{l}\text { Deficiencia múltiple de } \\
\text { sulfatasas }\end{array}$ & $\begin{array}{l}\text { SUMF1 (enzima generadora } \\
\text { de formilglicina, necesaria } \\
\text { para activar sulfatasas) }\end{array}$ & $\begin{array}{l}\text { Múltiples, incluyendo } \\
\text { glicosaminoglicanos } \\
\text { sulfatados }\end{array}$ & $\begin{array}{l}\text { Bazo/hígado, hueso, } \\
\text { piel }\end{array}$ & + \\
\hline & Enf. de Pompe & a-Glucosidasa (GAA) & Glucógeno & Músculo esquelético & - \\
\hline & Enf. de Sandhoff & $\begin{array}{c}\beta \text {-hexosaminidasa } A \text { y } B \\
(\mathrm{HEXB})\end{array}$ & Gangliósido GM2 & & + \\
\hline $\begin{array}{l}\text { Defecto en el tráfico de } \\
\text { enzimas lisosomales }\end{array}$ & $\begin{array}{l}\text { Mucolipidosis tipo II } \\
\text { (enf. de células I) y }\end{array}$ & $\begin{array}{l}\mathrm{N} \text {-acetilglucosamina fosforil } \\
\text { transferasa } \alpha / \beta \text { (GNPTAB) }\end{array}$ & $\begin{array}{l}\text { Carbohidratos, lípidos, } \\
\text { proteínas }\end{array}$ & Esqueleto, corazón & $\begin{array}{c}+(\text { II }) \\
+/-(\text { IIIA })\end{array}$ \\
\hline & $\begin{array}{l}\text { Mucolipidosis tipo IIIA } \\
\text { (polidistrofia pseudo- } \\
\text { Hurler) }\end{array}$ & & & & \\
\hline $\begin{array}{l}\text { Defectos en proteínas } \\
\text { lisosomales solubles no } \\
\text { enzimáticas }\end{array}$ & $\begin{array}{l}\text { Enf. de Niemann-Pick } \\
\text { tipo C2 }\end{array}$ & $\begin{array}{l}\text { NPC2 (proteína soluble } \\
\text { lisosomal que se une a } \\
\text { colesterol) }\end{array}$ & Colesterol y esfingolípidos & Hígado & + \\
\hline \multirow{5}{*}{$\begin{array}{l}\text { Defectos en proteínas } \\
\text { lisosomales de } \\
\text { membrana }\end{array}$} & Cistinosis & $\begin{array}{l}\text { Cistinosin (trasnportador de } \\
\text { cisteína, CTNS) }\end{array}$ & Cistina & Riñón, ojo & - \\
\hline & Enf. de Danon & $\begin{array}{c}\text { Proteína de membrana } \\
\text { asociada a lisosomas 2, } \\
\text { variante de splicing A } \\
\text { (LAMP2) }\end{array}$ & $\begin{array}{l}\text { Glucógeno y otros } \\
\text { componentes autofágicos }\end{array}$ & $\begin{array}{l}\text { Músculo cardiáco y } \\
\text { esquelético }\end{array}$ & + \\
\hline & $\begin{array}{l}\text { Desorden de } \\
\text { almacenamiento de } \\
\text { ácido siálico libre }\end{array}$ & $\begin{array}{l}\text { Sialina (transportador de } \\
\text { ácido siálico, SLC } 1 \text { 7A5) }\end{array}$ & Ácido siálico libre & $\begin{array}{l}\text { Hígado/bazo, } \\
\text { esqueleto }\end{array}$ & + \\
\hline & Mucolipidosis IV & Mucolipina-I (MCOLN1) & Mucopolisacáridos y lípidos & Ojo & + \\
\hline & $\begin{array}{l}\text { Enf. de Niemann-Pick } \\
\text { tipo } \mathrm{C} 1\end{array}$ & $\begin{array}{l}\text { NPC1 (proteína de } \\
\text { membrana involucrada en el } \\
\text { transporte de lípidos) }\end{array}$ & Colesterol y esfingolípidos & Hígado & + \\
\hline $\begin{array}{c}\text { Desórdenes } \\
\text { lisosomales de } \\
\text { etiología no elucidada }\end{array}$ & $\begin{array}{l}\text { Lipofuscinosis ceroide } \\
\text { neuronal (NCLs, } \\
\text { incluyendo la enf. de } \\
\text { Batten) }\end{array}$ & $\begin{array}{c}\text { Grupo diverso de } \\
\text { enfermedades con defectos } \\
\text { genéticos en genes } \\
\text { aparentemente no } \\
\text { relacionados, muchos de los } \\
\text { cuales no están asociados al } \\
\text { sistema lisosomal. Se } \\
\text { desconoce si estos genes } \\
\text { cooperan en vías celulares } \\
\text { comunes. } \\
\end{array}$ & $\begin{array}{c}\text { La lipofuscina } \\
\text { autofluorescente es una } \\
\text { característica común, con } \\
\text { signos clínicos } \\
\text { convergentes (por ej. } \\
\text { defectos visuales/ceguera) }\end{array}$ & & + \\
\hline
\end{tabular}


El diagnóstico puede complementarse mediante el estudio genético molecular, el cual se realiza sobre ADN obtenido a partir de sangre periférica o ARN aislado de leucocitos o fibroblastos. Estos estudios incluyen la búsqueda de mutaciones ya conocidas o la secuenciación de ADN genómico o ADN complementario en búsqueda de nuevas mutaciones patogénicas. Mediante la información brindada por estos estudios, además de confirmarse el diagnóstico, puede llevarse a cabo el consejo genético familiar y evaluar las opciones posibles de tratamiento (Filocamo et al., 2011). La presencia de rasgos comunes entre muchas enfermedades lisosomales, permitiría trasladar los hallazgos realizados para una a otras. Sin embargo, la amplia heterogeneidad presentada entre las distintas enfermedades y, a su vez, dentro de distintos pacientes de una misma enfermedad hace difícil una generalización de los mecanismos fisiopatogénicos asociados a las manifestaciones clínicas observadas para cada una de ellas.

En particular, para explicar la fisiopatología de varias enfermedades lisosomales se sugirió hace ya tres décadas la existencia de una estimulación crónica del sistema inmune (Shoenfeld et al., 1982). Esta respuesta inmune generaría una reacción inflamatoria que ocasionaría el daño celular y tisular. Diferentes estudios en la enfermedad de Gaucher han mostrado un aumento en la expresión de mediadores inflamatorios, tales como las interleuquinas (IL) IL-6, IL-1 $\alpha$, IL-1 $\beta$ como también TNF- $\alpha$, IFN-y, sCD14 (Barak et al., 1999; Hollak et al., 1997; Hong et al., 2006). En modelos de las enfermedades de Niemann Pick Tipo C (Wu et al., 2005), Tay-Sachs, Sandhoff y mucopolisacaridosis (Simonaro et al., 2001) se ha demostrado que el estado inflamatorio es el responsable de la fisiopatología observada.

En los últimos años se ha puesto de manifiesto la implicancia que tienen los procesos autofágicos en las enfermedades lisosomales (Ballabio et al., 2009; Settembre et al., 2008; Sun et al., 2010; Vitner et al., 2010). Dentro de estos procesos los lisosomas juegan un papel central donde cualquier desorden en los mismos puede llevar a alteraciones en las vías de autofagia.

En las enfermedades lisosomales, la acumulación de un sustrato primario por una deficiencia genética en particular puede repercutir de manera severa en la función lisosomal. Cuando una sustancia se acumula en los auto- y endolisosomas, puede inhibir enzimas catabólicas y transportadores, lo cual resulta en una acumulación secundaria de sustratos (Lamanna et al., 2011; Prinetti et al., 2011; Walkley et al., 2009). Esta acumulación de sustratos primarios y secundarios puede tener efectos, no sólo sobre la autofagia, sino también sobre otras organelas (mitocondrias, retículo endoplásmico, aparato de Golgi, peroxisomas, etc.), y en la función celular en general. 
Se han identificado y descripto alteraciones de las vías de fagocitosis y autofagia para más de quince enfermedades lisosomales (Lieberman et al., 2012), por lo que incluso se ha llegado a considerar a estas patologías como "desórdenes de la autofagia" (Settembre et al., 2008).

Hasta el año 1991, el único tratamiento existente para las enfermedades lisosomales era paliativo de las manifestaciones clínicas. A partir de ese momento surge el primer tratamiento específico, denominado terapia de reemplazo enzimático (TRE), consistente en la infusión intravenosa de la enzima recombinante, en la que son deficientes los pacientes con enfermedad de Gaucher. Este hito desencadenó un auge en cuanto a nuevas terapias para otras enfermedades de este grupo, lo que produjo una revolución, generando numerosos estudios de investigación clínica y básica.

Al momento actual, existen terapias basadas en reemplazo enzimático disponibles comercialmente para seis enfermedades lisosomales (enfermedad de Gaucher, enfermedad de Fabry, MPS I, MPS VI, MPS II y enfermedad de Pompe). Existen además, otros enfoques terapéuticos. Uno de ellos se denomina inhibición de síntesis de sustrato, y consiste en una terapia oral que apunta a reducir la acumulación lisosomal al inhibir la ruta de síntesis de la sustancia acumulada (Abe et al., 2000; McEachern et al., 2007).

Otro enfoque es la terapia con chaperonas químicas, que son moléculas pequeñas que logran mejorar el plegamiento y estabilizar la enzima mutada, impidiendo su degradación en el retículo endoplasmático. De esta manera, estas moléculas permiten la llegada de la enzima al lisosoma, donde cumple su función con la actividad enzimática residual que aún posea (Ishii et al., 2007; Yam et al., 2006). El uso de chaperonas puede aplicarse a casos de pacientes cuyas mutaciones sean las de cambio de sentido (missense), aunque no todas las mutaciones pueden ser tratadas favorablemente con estos fármacos. 


\section{La Enfermedad de Gaucher}

La enfermedad de Gaucher es una patología genética autosómica recesiva de almacenamiento lisosomal, causada por la deficiencia de la enzima lisosomal glucocerebrosidasa o beta-glucosidasa ácida (GCasa). La ausencia o deficiencia de esta enzima produce la acumulación de su sustrato glucosilceramida en los macrófagos. La enzima GCasa necesita un cofactor, la saposina C. Pueden existir casos de enfermedad de Gaucher por déficit del cofactor (Beutler et al., 1995).

Históricamente la enfermedad de Gaucher se clasificó en tres fenotipos clínicos dependiendo, principalmente, de la ausencia (Tipo I) o presencia de manifestaciones neurológicas y si dichas manifestaciones se presentaban de una manera aguda (Tipo II) o crónica (Tipo III). En la actualidad se acepta que la enfermedad de Gaucher presenta un continuo de fenotipos clínicos, variando desde aspectos clínicos leves hasta complicaciones neurológicas severas que llevan a la muerte antes del año de vida. A pesar de esto la clasificación en tres fenotipos sigue siendo de utilidad para la delineación de las formas clínicas básicas.

La enfermedad de Gaucher tipo I o forma crónica no neuropática es la de mayor frecuencia representando aproximadamente un $90 \%$ de los casos de enfermedad de Gaucher (Sawkar et al., 2006). Las manifestaciones clínicas son principalmente hematológicas, viscerales y óseas y se caracteriza por no presentar manifestaciones neurológicas. Tiene una alta incidencia en la población de judíos Ashkenazi, de 1/950 y una incidencia de 1/60000 nacidos vivos en el resto de la población (Elstein et al., 2002; Zimran et al., 2010). El inicio de los síntomas puede ocurrir a cualquier edad de los pacientes como también dentro de cualquier población; y los casos de presentación más temprana se acompañan de peor pronóstico. Es de destacar que en el pasado, la enfermedad de Gaucher tipo I fue definida como libre de manifestaciones neurológicas, pero en los últimos años se ha demostrado que algunos pacientes desarrollan una enfermedad extrapiramidal parecida al parkinsonismo, cuyas bases no se comprenden completamente (Capablo et al., 2008; Chérin et al., 2010). Más aún, se conoce que mutaciones en el gen de la glucocerebrosidasa (GBA), presentes en estado heterocigota en numerosos grupos étnicos, son los determinantes genéticos de mayor prevalencia para la enfermedad de Parkinson identificados hasta ahora en muchas poblaciones (Bultron et al., 2010). Las principales características clínicas de la enfermedad de Gaucher tipo I se detallan más adelante.

Las formas de tipo II y III son menos frecuentes, aparecen a edad más temprana, y se caracterizan por presentar manifestaciones neurológicas. La forma aguda de la enfermedad neurológica (enfermedad de Gaucher de tipo II) es un 
trastorno muy raro que puede causar la muerte en los primeros años de la vida; sus características principales son irritabilidad, parálisis bulbar, opistótonos, y un modesto aumento en el tamaño de las vísceras.

Menos del $10 \%$ de los pacientes con la enfermedad de Gaucher desarrolla la llamada forma neuropática crónica, o enfermedad de Gaucher tipo III, sus características clínicas son parálisis de la mirada y otras manifestaciones como epilepsia mioclónica y sordera nerviosa. Además presentan una participación sistémica variable y, a veces, prominente infiltración alveolar en los pulmones.

Los macrófagos de pacientes con Enfermedad de Gaucher adquieren un mayor tamaño y se los conoce como "célula de Gaucher", y pueden observarse en aspirados de médula ósea, o en biopsias de hígado o bazo. La morfología más comúnmente encontrada son células multinucleadas de gran tamaño con citoplasma tipo papel de seda arrugado. La célula de Gaucher tiene el lisosoma distendido por agregados de glicolípidos alineados en conformación cabeza-cola (Cox et al., 2012). No obstante, existen reportes de detección de macrófagos espumosos (Machaczka et al., 2012). A pesar de presentarse las células de Gaucher en los tejidos, no hay correlación con la alteración observada a nivel de los órganos: la masa esplénica puede estar aumentada 100 veces lo normal, sin embargo, el exceso de glucosilceramida sólo corresponde a menos del $2 \%$ del peso adicional del órgano (Cox et al., 2001). Esta discrepancia ilustra la complejidad de los mecanismos patogénicos que se desencadenan a partir del defecto bioquímico. De manera similar a lo encontrado en muchas enfermedades lisosomales, se detecta acumulación de metabolitos secundarios, no directamente relacionados al defecto primario, tanto en lisosomas como en sitios extralisosomales (Fuller et al., 2008; Hein et al., 2007).

La sospecha de enfermedad de Gaucher en pacientes puede basarse en una esplenomegalia inexplicada o como resultado de exámenes para el diagnóstico de pancitopenias o visceromegalias, donde pueden ser identificadas células de Gaucher en aspirados de médula ósea (en exámenes por esplenomegalia o citopenias) o en biopsias de hígado (en exámenes por hepatomegalia). Hay que enfatizar que la presencia de células de Gaucher en biopsias no es suficiente para el diagnóstico ya que las mismas pueden estar presentes debido a otras condiciones hematológicas, en este caso se trata de células denominadas "seudo Gaucher" las cuales poseen características similares. Por otro lado, la ausencia de células de Gaucher en biopsias no descarta la posibilidad de que el paciente tenga la enfermedad.

El diagnóstico confirmatorio de Enfermedad de Gaucher se realiza mediante determinación de la actividad de la enzima glucocerebrosidasa (GCasa) en leucocitos o fibroblastos. El estudio de mutaciones en pacientes Gaucher ha revelado la 
existencia de 4 mutaciones más frecuentes en el gen de la $\beta$-glucosidasa ácida (GBA) que dan cuenta del 95\% de las mutaciones en la población judía Ashkenazi y del $75 \%$ en la población general (Beutler et al., 2001). Esas mutaciones son: c.1226A>G (N370S), c.1448T>C (L444P), c.84_85dupG (84GG) y c.115+1G>A (IVS2+1), que se encuentran en los exones $9,10,2$ y 2, respectivamente. Por ello para encarar el estudio genético se procede partiendo en primer lugar por la búsqueda de esas 4 mutaciones frecuentes, principalmente en pacientes que pertenecen a dicha etnia. Ante la ausencia de esas mutaciones, se debe proseguir con la secuenciación completa del gen, que contiene 11 exones, para encontrar los dos alelos mutados.

Para el seguimiento clínico de la enfermedad se utilizan biomarcadores plasmáticos, los cuales se encuentran aumentados en pacientes con enfermedad de Gaucher y presentan cierta correlación con la severidad de los signos clínicos. La quitotriosidasa es una enzima secretada por macrófagos activados por la vía alternativa y en el caso de la enfermedad de Gaucher es producida en grandes cantidades por las células de Gaucher (Aerts et al., 2005). La actividad de la quitotriosidasa puede medirse fácilmente mediante el uso de un sustrato fluorescente. La medida de actividad de la quitotriosidasa tiene como desventaja la alta ocurrencia de una duplicación de 24 pares de bases en el gen de la enzima, lo que lleva a una deficiencia en la actividad de la misma (Boot et al., 1998). Debido a este inconveniente se propuso encontrar algún marcador alternativo para el seguimiento clínico de la enfermedad. Mediante la técnica de SELDI-TOF (un tipo especial de espectrometría de masa) pudo evidenciarse que las células de Gaucher producían grandes cantidades de la quemoquina CCL18/PARC la cual se encuentra aumentada entre 10 y 40 veces en el suero de pacientes con enfermedad de Gaucher, y sus niveles poseen una buena correlación con la severidad de la enfermedad (Aerts et al., 2005). La medida de los niveles de esta quemoquina mediante la técnica de ELISA es útil para monitorear la enfermedad, sobre todo en pacientes que no poseen actividad de la quitotriosidasa debido a mutaciones en la misma.

Los pacientes con Gaucher de tipo I presentan alteraciones hematológicas debidas al compromiso de la médula ósea, caracterizadas por anemia y trombopenia, hígado y bazo agrandados, que están infiltrados con macrófagos activados por la vía alternativa en los sinusoides esplénicos y reemplazando las células de Kupffer hepáticas. La alteración esplénica provoca un mayor secuestro de células sanguíneas contribuyendo a la anemia, trombopenia y leucopenia. Raramente ocurre también infiltración pulmonar severa y una calcificación de válvula cardíca (Grabowski et al., 2006). 
Los aspectos esqueléticos en la enfermedad de Gaucher incluyen alteraciones sintomáticas y radiológicas, las cuales en conjunto se encuentran presentes en más de un $90 \%$ de los pacientes con enfermedad de Gaucher (Wenstrup et al., 2002). La patología esquelética es variable, progresiva, no se resuelve espontáneamente, y se debe a alteraciones en la formación del hueso, en la resorción ósea y a lesiones óseas focales, generadas por la interrelación entre la afectación del tejido óseo y la médula ósea. El dolor óseo es común en los pacientes, y puede ser agudo o crónico. La deformidad radiológica en forma de "frasco de Erlenmeyer" es característica, pero no patognomónica; y se debe a una alteración en el remodelamiento de la metáfisis del fémur distal. El esqueleto sufre tumefacción, destrucción de hueso en lesiones osteolíticas, osteopenia, desmineralización generalizada, infartos medulares, expansión medular, adelgazamiento óseo cortical y osteoporosis con riesgo aumentado de fracturas. Los pacientes pueden tener osteosclerosis, como resultado del remodelamiento aberrante de un infarto óseo con deposición de calcio. La osteonecrosis o necrosis avascular (muerte ósea), se cree que es secundaria a isquemia por infarto crónico, y se observa generalmente en cabeza femoral, húmero proximal, rodilla y cuerpos vertebrales, alterando la función de las grandes articulaciones de la cadera, hombro y rodilla. El conjunto de manifestaciones óseas es la complicación más grave y se asocia a discapacidad y a una reducida calidad de vida. Si bien el daño óseo es una característica común de la enfermedad de Gaucher, las bases fisiopatológicas de las complicaciones óseas aún no se conocen y estarían involucrados mecanismos complejos (Cox et al., 2012).

En las descripciones clásicas de la fisiopatogenia de la enfermedad, las células de Gaucher eran la clave de la explicación. Sin embargo, actualmente se asume que la simple presencia de material de depósito dentro de las células no constituye la base para explicar las alteraciones observadas. El material acumulado dentro de los macrófagos representa sólo una fracción de la hiperplasia e hipertrofia de los órganos. Se ha sugerido que el depósito anormal de material desencadena la liberación de factores inflamatorios que llevan a una cascada de cambios patológicos (Aerts et al., 1997; Jmoudiak et al., 2005; Moran et al., 2000). Mediante inmunohistoquímica de biopsias de bazo de pacientes Gaucher se demostró que las células de Gaucher son macrófagos activados por la vía alterna, que expresan fosfatasa ácida, quitotriosidasa, CD68, CD14, CCL18 y HLA clase II, y que las células que las rodean secretan mediadores proinflamatorios (Boven et al., 2004). Los macrófagos activados alternativamente se inducen por las citoquinas de perfil Th2, IL-4 e IL-13, y secretan ellos mismos IL-4. Poseen un rol importante en la protección ante reacciones 
inflamatorias exageradas y en la reparación de tejidos en enfermedades inflamatorias crónicas como artritis reumatoidea (Varin et al., 2009).

Si bien el macrófago es la célula blanco característica, otras células del sistema inmune como los linfocitos T (LT), las células dendríticas (DC) y las células natural killer (NK), se ven alteradas en esta enfermedad. En 2012, utilizando el modelo murino condicional de la enfermedad de Gaucher, en el cual los exones 8-11 del gen GBA son eliminados luego del nacimiento (GBA KO), fue demostrada la presencia de alteraciones en las poblaciones de células en el timo, observándose un aumento en las células $\mathrm{CD}^{+}$junto con una disminución relativa de la población de precursores $\mathrm{CD} 4^{+} \mathrm{CD}^{+}$y un aumento en la presentación antigénica. Se encontró un incremento en el timo de células $\mathrm{B}$ activadas que expresan $\mathrm{MHCll}$, las mismas se encuentran relacionadas con la presentación antigénica por ellas mismas o a través de la activación de células presentadoras de antígeno. Todo esto lleva a una alteración en la maduración tímica de los linfocitos T (Liu et al., 2012).

En el mismo año, utilizando un modelo murino con la mutación D409V en el gen GBA Pandey y col. demostraron alteraciones en las poblaciones de linfocitos $T$, linfocitos $B$, células dendríticas, células polimorfonucleares y macrófagos, junto con un aumento en la expresión de moléculas coestimuladoras sobre estas células. Además observaron un aumento en los niveles séricos de citoquinas del perfil Th1/Th17 (Pandey et al., 2012).

En pacientes sin tratamiento las poblaciones de células dendríticas plasmacitoides y mieloides como también las células dendríticas derivadas de monocitos se presentan disminuidas. Por otro lado, los monocitos en circulación de pacientes con enfermedad de Gaucher presentan niveles aumentados de MHCII y CD1d en su superficie, lo que lleva a una activación aumentada de los linfocitos $T$, según se demostró en ensayos in vitro (Pandey et al., 2013).

Se ha observado una disminución en los niveles de células $\mathrm{CD}^{+}$y $\mathrm{CD}^{+}$en circulación de pacientes con enfermedad de Gaucher esplenectomizados (Pandey et al., 2013).

En distintos estudios de caso se ha observado que los pacientes con enfermedad de Gaucher presentan una predisposición a infecciones óseas difíciles de tratar. En dos estudios de caso se observó que pacientes con enfermedad de Gaucher presentaron casos de osteomielitis por infección con bacterias Gram negativas las cuales sólo pudieron resolverse cuando se realizó un tratamiento conjunto de antibióticos y terapia de reemplazo enzimático (Finkelstein et al., 1992; Margalit et al., 2002). 
Hasta el año 1990, no existía tratamiento específico, los pacientes recibían medidas paliativas o de soporte, como intervenciones ortopédicas de reemplazo de cadera o la esplenectomía para superar el efecto del hiperesplenismo. A partir del año 1991, se dispone del tratamiento mediante reemplazo enzimático (TRE), consistente en la administración intravenosa de la glucocerebrosidasa humana recombinante. En la actualidad existen 3 productos comercialmente disponibles: Cerezyme (Genzyme Corporation, Cambridge, USA), VPRIV (Shire HGT, Lexington, USA) y taliglucerasa alfa (Protalix BioTherapeutics, Israel) (Aviezer et al., 2009; Barton et al., 1991; Pastores, Elstein, Hrebícek, \& Zimran, 2007). La enzima logra ingresar a las células a través de la unión al receptor de manosa, y de allí es transportada a los lisosomas para degradar el sustrato acumulado. Más adelante, surgió otro enfoque terapéutico, que es la terapia por vía oral de reducción de sustrato (Miglustat, Actelion Pharmaceuticals, Switzerland) cuyo efecto es inhibir una enzima clave que participa en la biosíntesis de glucosilceramida (Heitner et al., 2002).

La TRE y la terapia de reducción de sustrato logran disminuir el número de macrófagos que infiltran la médula ósea y el hígado, revierten las citopenias (anemia y trombopenia), reducen los episodios de osteonecrosis y mejoran la mineralización ósea (Pastores et al., 2007; Sims et al., 2008; Weinreb et al., 2002). Sin embargo, las manifestaciones relacionadas a la injuria ósea no son totalmente eliminadas, manteniéndose principalmente las crisis de dolor óseo en aproximadamente un $40 \%$ de los pacientes (Sims et al., 2008). En la actualidad, luego de 2 décadas de experiencia con TRE, los especialistas ya no ven a la enfermedad de Gaucher como un desorden caracterizado por citopenias y visceromegalias sino como una patología principalmente esquelética con defectos en la estructura y metabolismo óseo (Deegan et al., 2011). Dado que los mecanismos inmunopatogénicos implicados en el daño óseo no han sido completamente dilucidados, no es posible establecer un tratamiento definitivo.

La inflamación es un factor clave en la patogénesis de la enfermedad de Gaucher (Shoenfeld et al., 1982), y está caracterizada por la producción de citoquinas tales como TNF- $\alpha$, IL-6, IL-1 $\beta$, IL-1 $\alpha$ (Barak et al., 1999; Hollak et al., 1997; Hong et al.,

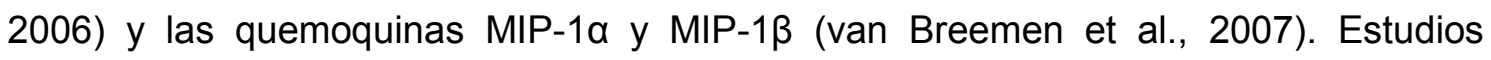
realizados en modelos murinos de enfermedad de Gaucher revelaron una mayor apoptosis y expresión de citoquinas proinflamatorias (Hong et al., 2004; Hong et al., 2006; Kacher et al., 2009). En el modelo condicional de la enfermedad de Gaucher, en el cual los exones 9-11 del gen GBA son eliminados durante la primera semana de vida de los ratones, se observó un aumento en los niveles séricos de las citoquinas IL-

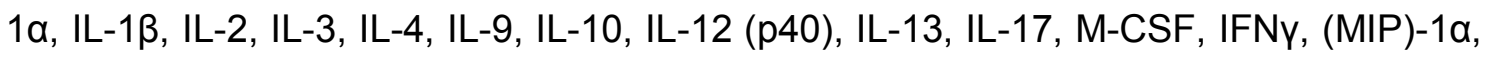


y MIP-1 $\beta$ (Liu et al., 2012). Por otro lado, el modelo murino que presenta la mutación D409V en el gen GBA presenta niveles aumentados de IFN $\gamma$, IL-12, TNF- $\alpha$ e IL-17 A/F, como también de las quemoquinas MCP-5, CXCL-2, CXCL-9, CXCL-10, CXCL11, CXCL-13, las cuales podrían causar la infiltración de leucocitos en los órganos de pacientes con enfermedad de Gaucher (Pandey et al., 2013, 2012)

En distintos trabajos se ha demostrado la presencia de marcadores que son indicadores de la existencia de alteraciones en el metabolismo óseo. En estudios realizados en células de pacientes Gaucher, se detectó el aumento en la expresión de marcadores fenotípicos de resorción ósea mediada por osteoclastos tales como Catepsina K (Moran et al., 2000) o la enzima fosfatasa ácida tartrato-resistente (TRAP) (Campeau et al., 2009a) a nivel transcripcional. Se demostró, además, un aumento en la expresión génica en células mesenquimales de la metaloproteasa de matriz MMP-2, que está involucrada en procesos de daño óseo por destrucción de la matriz extracelular (Campeau et al., 2009a). La expresión de la quemoquina CCL2 (o MCP-1) está elevada y podría producir alteraciones óseas indirectamente al atraer monocitos a la zona ósea. Estos monocitos generarían daño mediante la secreción de citoquinas proinflamatorias, así como también por su capacidad de diferenciarse ellos mismos a osteoclastos. Recientemente, el trabajo de Lecourt y col mostró que las células mesenquimales expuestas a conduritol- $\beta$-epóxido (CBE), un inhibidor específico de la GCasa, secretarían factores que promueven la resorción ósea (Lecourt et al., 2012).

\section{Osteoinmunología}

El hueso es un tipo de tejido conectivo especializado que provee un sistema de soporte interno a todos los vertebrados superiores. El soporte no es la única función que desempeña, sino que posee un rol central en el mantenimiento de la homeostasis del calcio en el cuerpo funcionando como fuente del mismo.

El hueso se encuentra formado por un $50-70 \%$ de matriz mineral en su mayoría hidroxiapatita en forma de cristales $\left[\left(\mathrm{Ca}_{10}\left(\mathrm{PO}_{4}\right)_{6}(\mathrm{OH})_{2}\right]\right.$, con pequeñas cantidades de carbonato, magnesio y fosfato ácido (Clarke et al., 2008). El 20-40\% de la masa ósea se compone de matríz orgánica compuesta, a su vez, de un $90 \%$ por proteínas colágenas, en su mayoría por colágeno tipo I con trazas de colágeno tipo III y V. EI restante $10 \%$ está compuesto por proteoglicanos, como el condroitín y el queratánsulfato, por glicoproteínas, como la osteonectina y la fibronectina, por proteínas con grupos $\gamma$-carboxiglutámicos, como la osteocalcina, y por citoquinas como el factor de crecimiento transformante- $\beta$ (TGF- $\beta$ ) y las proteínas morfogenéticas óseas (Clarke et 
al., 2008). El resto de los componentes del hueso se divide entre un $5-10 \%$ de agua y aproximadamente un $3 \%$ de lípidos.

El hueso se encuentra en un estado de continuo remodelamiento que le permite por un lado la reparación de lesiones derivadas de la fatiga normal del hueso y por otro la adaptación del sistema a cambios en los requerimientos físicos. En el proceso de remodelado participan dos tipos celulares: los osteoclastos y los osteoblastos, siendo un proceso complejo y altamente regulado en el cual la matriz ósea es degradada para que nuevo hueso sea generado dando como resultado la reparación del hueso.

El tipo celular responsable del proceso de degradación de la matriz ósea son los osteoclastos. Los osteoclastos son células multinucleadas gigantes que se forman a partir de la fusión de precursores del linaje monocito/macrófago en un proceso denominado osteoclastogénesis (Teitelbaum et al., 2000). Los precursores de osteoclastos migran desde la médula ósea hacia la circulación, y de esta hacia los sitios de degradación mediante la formación de lamelipodios (Li et al., 2006). En el sitio de degradación comienza lo que se conoce como fase degradativa en la cual los osteoclastos se polarizan a través de una reorganización del citoesqueleto, lo cual resulta en la formación de un borde rugoso con profundos pliegues por donde se secretan iones $\mathrm{H}^{+}$, y se produce la exocitosis, mediada por vesículas, de las enzimas catepsina $\mathrm{K}$ y metaloproteasas de matriz. El microambiente ácido generado por los iones $\mathrm{H}^{+}$disuelve la matriz mineral y las enzimas, con un $\mathrm{pH}$ óptimo ácido, degradan la matriz proteica. El compartimento ácido se encuentra aislado del resto de la superficie del hueso mediante un anillo rico en filamentos de actina dentro de los osteoclastos que rodea la zona rugosa sellando así el sitio de degradación (Väänänen et al., 1995). El proceso de osteoclastogénesis requiere la presencia de dos factores clave: el factor estimulante de colonias macrofágicas (M-CSF) y el ligando del receptor activado del factor nuclear $\kappa B($ RANKL). El M-CSF es producido por los osteoblastos y se une a su receptor c-fms en la superficie de los precursores de osteoclastos, de esta manera promueve la sobrevida y proliferación de los mismos (Hodge et al., 2007).

RANKL posee dos formas: puede encontrarse en la superficie de los osteoblastos 0 ser liberado en su forma soluble. Se ha documentado que los fibroblastos, los linfocitos B y T y las células dendríticas también son productores de RANKL (Kawai et al., 2006; Takayanagi et al., 2000). Por otro lado su actividad biológica se encuentra regulada por el inhibidor natural osteoprotegerina (OPG) que actúa como un receptor soluble señuelo de RANKL inhibiendo su unión a su receptor RANK el cual se expresa en la superficie de los precursores de osteoclastos (Yasuda et al., 1998).

A medida que los osteoclastos degradan la matriz mineral ósea se liberan factores inmersos en la misma los cuales podrían actuar sobre los osteoblastos para promover 
la formación del hueso, por ejemplo los factores de crecimiento insulínico (IGFs) I y II y el TGF- $\beta$ (Centrella et al., 1991). Por otro lado la interacción célula-célula a través de la proteína transmembrana ephrinB2 expresada en osteoblastos y EphB4 en los osteoclastos promueve la diferenciación de osteoblastos e inhibe la diferenciación de los osteoclastos (Martin et al., 2010; Zhao et al., 2006).

Los osteoblastos son las únicas células responsables de la formación del hueso y residen a lo largo de la superficie del hueso en zonas de formación ósea activa. Se originan a partir de células mesenquimales diferenciándose primero a preosteoblastos y luego a osteoblastos maduros frente a los estímulos adecuados (Neve et al., 2011; Pittenger et al., 1999).

Los osteoblastos maduros secretan colágeno tipo I y proteínas no colágenas incluyendo osteocalcina, osteopontina, sialoproteína y fosfatasa alcalina (las cuales ejercen funciones de regulación del recambio óseo y control de la mineralización) (Neve et al., 2011).

Luego de cumplir su función en la generación de hueso los osteoblastos pueden tener distintos destinos: pueden morir por apoptosis, pueden quedar embebidos en la matriz ósea y diferenciarse a osteocitos o pueden transformarse en células de revestimiento en la superficie del hueso (Eriksen et al., 2010).

Dos de las vías más importantes en la generación del hueso son la de la Wnt/ $\mathrm{H}$ catenina y la de la superfamilia TGF- $\beta$. La primera estimula la proliferación, diferenciación y sobrevida de los osteoblastos y osteocitos (Hu et al., 2005). La segunda es importante en la diferenciación de osteoblastos e involucra no solo al TGF$\beta$ sino también a las proteínas morfogenéticas óseas (Chen et al., 2012).

Los osteoblastos poseen una acción regulatoria sobre los osteoclastos, como ya mencionamos, mediante la expresión de M-CSF, RANKL y OPG, actuando sobre la diferenciación de los mismos. Además de esto los osteoblastos pueden secretar factores quimioatractantes que reclutan a los precursores de osteoclastos a los sitios de remodelación ósea. Por un lado los osteoblastos pueden generar la proteína quimioatractante de monocitos-1 (MCP-1) la cual ha sido involucrada en la migración de precursores de osteoclastos ( $\mathrm{Li}$ et al., 2007). Por otro lado los osteoblastos producen osteocalcina y colágeno de tipo I, los cuales quedan embebidos en la matriz ósea durante la formación del hueso y son liberados cuando los osteoclastos degradan la misma, atrayendo así más precursores de osteoclastos al sitio de resorción activa (Malone et al., 1982).

Durante un proceso inflamatorio ya sea causado por una infección bacteriana de los huesos o en enfermedades que poseen un componente inflamatorio crónico el balance 
de la formación y degradación del hueso puede verse afectado. En enfermedades que presentan daño óseo las citoquinas TNF- $\alpha$, IL-1 $\beta$ e IL- 6 han sido implicadas en el aumento de la degradación ósea. Los mecanismos que llevan a un aumento en la degradación del hueso pueden incluir un aumento en la diferenciación de osteoclastos ya que se ha documentado que las citoquinas TNF- $\alpha$ e IL-6 pueden inducir directamente la osteoclastogénesis (Azuma et al., 2000; Kobayashi et al., 2000; Kudo et al., 2003b), como también un aumento en la expresión de RANKL en la superficie de osteoblastos (Nakashima et al., 2000).

Por otro lado se ha demostrado que las citoquinas proinflamatorias pueden inducir la producción de metaloproteasas de matriz en varios tipos celulares incluyendo osteoblastos y fibroblastos sinoviales (Moret al., 2005; Rifas et al., 1994). Además, los macrófagos y neutrófilos reclutados a sitios de inflamación pueden liberar MMPs en respuesta a estos estímulos inflamatorios (Chakrabarti et al., 2005; Heidinger et al., 2006).

Por último las citoquinas TNF- $\alpha$ e IL-1 $\beta$ pueden inducir la apoptosis de los osteoblastos e inhibir su actividad de generación de la matriz ósea (Lacey et al., 2009; Tomomatsu et al., 2009).

Como mencionamos, el conjunto de manifestaciones óseas de la enfermedad de Gaucher es la complicación más grave y se asocia a discapacidad y a una reducida calidad de vida de los pacientes. Aunque la terapia de reemplazo enzimático logra disminuir los problemas óseos observados en los pacientes, un porcentaje alto de los mismos mantienen parte de los síntomas, principalmente las crisis de dolores óseos (Sims et al., 2008). A pesar de esto las bases fisiopatológicas de las complicaciones óseas aún no se conocen y estarían involucrados mecanismos complejos (Cox et al., 2012). Por lo tanto, el estudio de los mecanismos celulares y moleculares asociados esta problemática podría llevar al desarrollo de terapias coadyuvantes específicas para la problemática ósea que mejoren la calidad de vida de los pacientes. 


\section{Objetivos}

Teniendo en cuenta los reportes que documentan un estado proinflamatorio y el aumento de marcadores asociados a patología ósea en pacientes con Enfermedad de Gaucher, proponemos como hipótesis central a ser analizada en este trabajo que la enfermedad de Gaucher puede causar inflamación a nivel óseo, la cual podría estar desencadenada, por lo menos en parte, por la acumulación de glicolípidos en los lisosomas. Dicha inflamación podría causar la destrucción ósea mediante diversos mecanismos: la inducción de la producción de metaloproteasas de matriz, el estímulo de la diferenciación de monocitos/macrófagos a osteoclastos y/o alteración en la mineralización ósea por osteoblastos.

Nuestro objetivo general es:

Analizar si la alteración celular generada por la enfermedad de Gaucher es la responsable de las alteraciones óseas e investigar los mecanismos que llevan al estado proinflamatorio y su relación con la destrucción ósea.

Nuestros objetivos específicos son:

-Desarrollar modelos químicos in vitro humanos y murinos de la enfermedad de Gaucher.

-Estudiar la osteoclastogénesis en dichos modelos in vitro y los posibles mecanismos involucrados.

-Analizar el estado proosteoclastogénico y proinflamatorio en pacientes con enfermedad de Gaucher.

-Estudiar el efecto del tratamiento con Velaglucerasa sobre la osteoclastogénesis en pacientes con enfermedad de Gaucher. 


\section{Materiales y métodos}

\section{Pacientes}

Se incluyeron para este trabajo muestras de sangre de 24 pacientes con Enfermedad de Gaucher, tanto varones como mujeres (edad media: 32,16 \pm 19,66 años, rango etario: 10 - 77 años). El diagnóstico de la enfermedad de Gaucher se estableció mediante examen clínico, medida de actividad enzimática y estudio genético. Todos los pacientes se hallaban bajo terapia de reemplazo enzimático (TRE) con glucocerebrosidasa recombinante imiglucerasa (Cerezyme, Genzyme-Sanofi, USA) o velaglucerasa (VPRIV, Shire, USA) en el momento del estudio. El protocolo fue aprobado por el comité de ética del Instituto de Biología y Medicina Experimental (IBYME) de acuerdo con lo dispuesto en la Declaración de Helsinki en 1995. La naturaleza y el propósito del estudio se explicaron a todos los voluntarios y todos los pacientes dieron su consentimiento informado antes de participar en este estudio. Individuos sanos (edad media: 27,93 \pm 12,10, rango etario: 10 - 65 años) emparejados por edad y sexo sirvieron como controles.

\section{$\underline{\text { Ratones }}$}

Se utilizaron ratones de la cepa salvaje C57BI/6 (WT) y TNFRp55KO (knock out para el receptor de $55 \mathrm{kDa}$ de TNF- $\alpha$ ) de 8 semanas de edad (los cuales fueron amablemente provistos por la Dra. Di Genaro de la Universidad Nacional de San Luis). Los ratones se mantuvieron en un bioterio acondicionado en base a sus necesidades, con agua y alimento ad libitum.

El sacrificio de los ratones se realizó mediante dislocación cervical.

\section{Obtención de PBMC}

Las muestras de sangre periférica $(10 \mathrm{ml})$ se obtuvieron por punción venosa en heparina como anticoagulante, y se procesaron inmediatamente. Las células mononucleares de la sangre entera (PBMC) se aislaron por sedimentación en gradiente de Ficoll Hypaque (Sigma, St. Louis, MO, EE.UU.). 


\section{Preparación de sobrenadantes de cultivo condicionado}

Se cultivaron PBMC de controles sanos en medio DMEM (Invitrogen, Carlsbad, CA, EE.UU.) adicionado con $10 \%$ de suero fetal bovino (SFB), $100 \mathrm{U} / \mathrm{ml}$ de penicilina y 100 $\mu \mathrm{g} / \mathrm{ml}$ de streptomicina (medio completo) a $37^{\circ} \mathrm{C}$ en una atmósfera conteniendo $5 \%$ $\mathrm{CO}_{2}$ a razón de $10^{6}$ células $/ \mathrm{ml}$ durante $72 \mathrm{~h}$ en presencia o ausencia de $500 \mathrm{mM}$ de conduritol- $\beta$-epóxido (CBE) (Sigma, St Louis, MO, EE.UU.). El CBE es un inhibidor específico de la glucocerebrosidasa (GCasa) el cual se une irreversiblemente al sitio catalítico de la misma inhibiendo su actividad. En los casos mencionados, se añadió además lipopolisacárido (LPS) de E. coli en una concentración de $500 \mathrm{ng} / \mathrm{ml}$ en las últimas $24 \mathrm{~h}$ del cultivo. Después de las $72 \mathrm{~h}$ se obtuvo el sobrenadante de cultivo condicionado por centrifugación.

Por otro lado, PBMC de pacientes con enfermedad de Gaucher y de los correspondientes controles se cultivaron durante 3 días en medio completo. Al finalizar el cultivo el sobrenadante condicionado se separó por centrifugación.

Los ratones de la cepa C57BI/6 se inocularon por vía intraperitoneal con $1 \mathrm{ml}$ de tioglicolato $3 \%$. Luego de 4 días se obtuvieron los macrófagos peritoneales por lavado intraperitoneal con medio DMEM fresco. Las células se centrifugaron y resuspendieron en medio completo a razón de $10^{6}$ células $/ \mathrm{ml}$ en presencia o ausencia de $500 \mathrm{mM}$ de CBE. Luego de $72 \mathrm{~h}$ el sobrenadante condicionado se separó por centrifugación.

Por otro lado se obtuvo el bazo de ratones de la misma cepa, se homogeneizó y se filtró utilizando mallas metálicas. Los esplenocitos obtenidos por centrifugación se cultivaron a razón de $10^{6}$ células $/ \mathrm{ml}$ en presencia o ausencia de $500 \mathrm{mM}$ de CBE durante $72 \mathrm{~h}$ luego de las cuales se obtuvo el sobrenadante condicionado por centrifugación.

\section{$\underline{\text { Acumulación de glucosilceramida }}$}

Para determinar si las células tratadas con CBE presentaban el fenotipo característico de la enfermedad de Gaucher se determinó la acumulación de glucosilceramida dentro de las mismas.

Para ello, PBMC de controles sanos expuestas o no a CBE durante $72 \mathrm{~h}$ de cultivo se recogieron mediante centrifugación y se extrajeron los glicolípidos de acuerdo con el método de Vance y Sweeley (1967) con modificaciones. Brevemente, se agregaron 3 $\mathrm{ml}$ de cloroformo:metanol en relación $2: 1 \mathrm{v} / \mathrm{v}$ y $0,8 \mathrm{ml}$ de agua sobre el sedimento de células. Las muestras se homogeneizaron utilizando un vortex durante $30 \mathrm{~s}$ y se 
incubaron en hielo durante $15 \mathrm{~min}$. Se agregó $1 \mathrm{ml}$ de cloroformo y $1 \mathrm{ml}$ de agua mezclando por vortex nuevamente durante $30 \mathrm{~s}$. Para mejorar la separación de fases los tubos fueron centrifugados, la fase acuosa superior fue retirada y la fase inferior se evaporó por aplicación de calor bajo campana. Se añadieron $1 \mathrm{ml}$ de metanol y $0,1 \mathrm{ml}$ de $\mathrm{NaOH} 1 \mathrm{M}$ sobre el residuo seco, y se incubaron a $37^{\circ} \mathrm{C}$ toda la noche. Se adicionaron $2 \mathrm{ml}$ de cloroformo y $0,5 \mathrm{ml}$ de agua y las fases se separaron mediante centrifugación. Se eliminó la fase superior y la fase inferior, que corresponde al extracto de glicolípido, se evaporó. Los glicolípidos fueron disueltos en cloroformo:metanol 2:1 v/v y separados mediante la técnica de cromatografía en capa fina (TLC) utilizando una placa de sílica 60. La TLC se realizó utilizando cloroformo:metanol:agua 70:30:4, v/v/v como fase móvil y los glicolípidos se detectaron pulverizando la placa con el reactivo orcinol. Se utilizaron como estándar tres microgramos de glucosilceramida pura (Matreya, Pleasant Gap, PA).

\section{Ensayo de diferenciación a osteoclastos}

Se sembraron células de la línea monocítica humana THP-1 a razón de $5 \times 10^{5}$ células/pocillo sobre placas de cultivo de 24 pocillos y se mantuvieron durante $72 \mathrm{~h}$ a $37^{\circ} \mathrm{C}$ en atmósfera conteniendo $5 \%$ de $\mathrm{CO}_{2}$ en medio esencial mínimo a (a-MEM) suplementado con $2 \mathrm{mM}$ de L-glutamina, $10 \%$ de suero fetal bovino inactivado por calor (Gibco-BRL, Life Technologies, Grand Island, NY), $100 \mathrm{U} / \mathrm{ml}$ de penicilina y 100 $\mu \mathrm{g} / \mathrm{ml}$ de streptomicina (medio mínimo completo), adicionado con $30 \mathrm{ng} / \mathrm{ml}$ de M-CSF (R y D, Minneapolis, MN, EE.UU.). Las células no adherentes se retiraron mediante lavados con medio fresco y las células adherentes se utilizaron para los ensayos de diferenciación a osteoclastos. Para todos los ensayos las células se cultivaron en medio completo y sobrenadante condicionado en una proporción de 1:1 suplementado con M-CSF por 7 días reemplazando el medio cada 48 h. Para los experimentos realizados con sobrenadantes condicionados proveniente de cultivos adicionados con Lipopolisacárido (LPS) de Escherichia coli (Sigma, St Louis, MO, EE.UU.) se agregaron también $2 \mathrm{mg} / \mathrm{ml}$ de sulfato de polimixina-B para evitar la inhibición del LPS sobre la formación de osteoclastos (Mistry et al., 2010). Durante las últimas 48 horas de cultivo el medio se sustituyó con medio mínimo completo sin agregados y el sobrenadante se reservó para evaluar la presencia de citoquinas y biomarcadores de la enfermedad de Gaucher. Como control positivo de la formación de osteoclastos se adicionaron $50 \mathrm{ng} / \mathrm{ml}$ de RANKL humano (Millipore, Billerica,MA, EE.UU.).

Para evidenciar el papel del TNF- $\alpha$ en la osteoclastogénesis, el ensayo de inducción de osteoclastos se llevó a cabo en presencia de un 
anticuerpo anti-TNF- $\alpha$ en una concentración final de $2 \mathrm{ng} / \mathrm{ml}$ (BD Pharmingen, San Diego, CA) para neutralizar esta citoquina o un control de isotipo (BD Pharmingen, San Diego, CA). Para analizar la participación de las células $T$ en la osteoclastogénesis,el ensayo de formación de osteoclastos se realizó utilizando sobrenadante condicionado producido a partir de PBMC depletadas de células $\mathrm{CD}^{+}$. La depleción de células $\mathrm{CD}^{+}$ se realizó utilizando el reactivo RosetteSep ${ }^{\circledR}$ Human CD3 Depletion Cocktail (Stem Cell Tecnologies, Vancouver, Canadá), según el protocolo del fabricante. La eliminación completa de células $\mathrm{CD}^{+}$se evaluó mediante citometría de flujo, observándose menos de un $0,1 \%$ de células positivas en las muestras tratadas con el kit.

Se extrajeron precursores de médula ósea de ratones C57BL/6 WT o TNFRp55KO y se sembraron a razón de $5 \times 10^{5}$ células/pocillo, sobre placas de cultivo de 24 pocillos, manteniéndose durante $48 \mathrm{~h}$ a $37^{\circ} \mathrm{C}$ en una atmósfera con $5 \%$ de $\mathrm{CO}_{2}$ en medio completo adicionado con $30 \mathrm{ng} / \mathrm{ml}$ de M-CSF (R\&D, Minneapolis, MN, EE.UU.). Las células no adherentes se eliminaron mediante lavados con medio fresco y las células adherentes se utilizaron para los ensayos de diferenciación de osteoclastos. Para todos los ensayos las células adherentes se cultivaron durante 7 días en presencia de medio condicionado y medio mínimo completo en una proporción de 1:1 suplementado con M-CSF, reemplazando el medio de cultivo cada $48 \mathrm{~h}$. El sobrenadante de los osteoclastos se recogió para evaluar la presencia de MMP. Como control positivo los ensayos de formación de osteoclastos se realizaron en presencia de $50 \mathrm{ng} / \mathrm{ml}$ de RANKL o TNF- $\alpha$ recombinante murino (Millipore, Billerica, MA, EE.UU.).

Se sembraron PBMC de los pacientes con enfermedad de Gaucher y los controles sanos a razón de $5 \times 10^{5}$ células/pocillo, en placas de 24 pocillos, y se cultivaron durante 7 días a $37^{\circ} \mathrm{C}$ en una atmósfera con $5 \%$ de $\mathrm{CO}_{2}$ en medio completo adicionado con $30 \mathrm{ng} / \mathrm{ml}$ de M-CSF (R\&D, Minneapolis, MN, EE.UU) o con $30 \mathrm{ng} / \mathrm{ml}$ de M-CSF y $50 \mathrm{ng} / \mathrm{ml}$ de RANKL humano en ausencia o presencia de 1,5 U/ml de Velaglucerasa (rhGCasa) (Shire, USA).

Para la identificación de los osteoclastos, las células se fijaron con paraformaldehído al $4 \%$ y se tiñeron para revelar la presencia de la fosfatasa ácida resistente a tartrato (TRAP, Sigma Aldrich) y se colorearon utilizando hematoxilina de Meyer. Las células positivas para TRAP y multinucleadas (más de 3 núcleos) se definieron como osteoclastos realizándose un recuento mediante microscopía de fase. 


\section{Evaluación de la expresión del receptor de vitronectina}

La expresión del receptor de vitronectina (CD51) se determinó mediante microscopía de fluorescencia utilizando anticuerpos anti-CD51 humano o murino (según corresponda) conjugados con FITC, (BD Pharmingen, San Diego, CA). Las células CD51 positivas y multinucleadas (más de 3 núcleos) se definieron como osteoclastos.

\section{Evaluación de la actividad de resorción}

La actividad de resorción mediada por los osteoclastos diferenciados se determinó mediante el uso de placas de cultivo recubiertas con una matriz de dentina (BD Pharmingen, San Diego, CA), sobre las cuales se llevaron a cabo los experimentos de diferenciación de osteoclastos como se explicó antes. Luego del cultivo las células se lisaron por tratamiento hipotónico y se realizó el recuento del número de áreas de resorción mediante microscopía de fase.

\section{Medida de citoquinas}

Las concentraciones de IL-1 $\beta$, IL-6, TNF- $\alpha$, TGF- $\beta$, IL-4, IL-12, IFN- $\gamma$ (BD Pharmingen, San Diego, CA), IL-13 e IL10 (eBiosciences, San Diego, EE.UU.) se determinaron por ELISA de captura en sobrenadantes de cultivo.

\section{Zimografía}

Los niveles de metaloproteasas (MMP) con actividad gelatinolítica se analizaron mediante zimografía de acuerdo con el método de Hibbs et al. (1985). Brevemente, 20 $\mu \mathrm{l}$ de medio condicionado de osteoclastos se mezcló con $5 \mu \mathrm{l}$ de buffer de siembra $(0,25 \mathrm{M}$ de Tris [pH 6,8], 50\% de glicerol, 5\% SDS y cristales de azul de bromofenol) y se sometieron a una corrida electroforética en geles de SDS-PAGE 10\% conteniendo $0,1 \%$ de gelatina (Sigma-Aldrich, Argentina). Luego de la electroforesis, los geles se lavaron con la solución A (50 mM de Tris- $\mathrm{HCl}(\mathrm{pH} 7,5), 2,5 \%$ de Tritón X-100) durante 30 min luego de los cuales se lavó por otros $30 \mathrm{~min}$ con la solución B (50 mM de Tris$\mathrm{HCl}(\mathrm{pH} 7,5), 2,5 \%$ de Triton X-100, $\mathrm{CaCl}_{2} 5 \mathrm{mM}, 1 \mathrm{mM} \mathrm{ZnCl}$ ). Luego de los lavados el gel se incubó con Buffer Colagenasa (50 mM de Tris-HCl $(\mathrm{pH} 7,5), 2,5 \%$ Tritón X-100, $\left.\mathrm{CaCl}_{2} 10 \mathrm{mM}, \mathrm{NaCl} 200 \mathrm{mM}\right)$ durante 48 hs a $37^{\circ} \mathrm{C}$. Esta etapa de desnaturalización/renaturalización promueve la actividad de MMP sin la escisión proteolítica de pro-MMP-9. La actividad gelatinasa se visualizó por tinción del gel con 
0,5\% de Coomassie Blue. La presencia de bandas sin teñir indicaron la actividad gelatinasa, y su posición relativa indicó el peso molecular de las enzimas implicadas.

\section{Actividad gelatinolítica neta}

La actividad gelatinasa en los sobrenadantes de cultivo en condiciones nativas se midió mediante el uso de un kit fluorométrico para la medida de gelatinasa/colagenasa (EnzChek; Invitrogen, Carlsbad, CA) de acuerdo a las instrucciones del fabricante. El kit EnzChek contiene gelatina $\mathrm{DQ}$, una gelatina conjugada con altas concentraciones de fluoresceína de modo que la fluorescencia se encuentra reprimida. Cuando este sustrato es digerido por gelatinasas o colagenasas se generan péptidos altamente fluorescentes de modo que el incremento de fluorescencia es proporcional a la actividad proteolítica. Como control positivo se utilizó una colagenasa purificada a partir de Clostridium histolyticum proporcionado en el kit de ensayo. La lectura de fluorescencia se realizó en placas opacas de 96 pocillos en un fluorómetro (Victor3, Perkin-Elmer, Waltham, MA).

\section{Cultivo de osteoblastos}

Se cultivaron osteoblastos de la línea celular MC3T3 murina en medio completo y estimulados con los sobrenadantes de cultivo condicionado correspondientes en relación $1: 1$ a $37^{\circ} \mathrm{C}$ en atmósfera con $5 \%$ de $\mathrm{CO}_{2}$. Además se agregaron los suplementos necesarios para inducir la diferenciación a osteoblastos, glicerofosfato de sodio $1 \mathrm{mM}$ y L-ascorbato $50 \mathrm{mM}$ (Sigma-Aldrich). El medio de cultivo fue reemplazado cada 3-4 días.

\section{Cuantificación de la mineralización por tinción con Alizarina Roja (ARS)}

Los osteoblastos se cultivaron en placas de 6 pocillos los cuales fueron lavados con buffer fosfato salino (PBS) y fijados con $10 \%$ (v/v) de formaldehído (Sigma-Aldrich) a temperatura ambiente durante $15 \mathrm{~min}$ y se lavaron dos veces con $4 \mathrm{ml}$ de $\mathrm{H}_{2} \mathrm{O}$ destilada. Luego se adicionó $1 \mathrm{ml}$ de ARS $40 \mathrm{mM}(\mathrm{pH} \mathrm{4,1).} \mathrm{Las} \mathrm{placas} \mathrm{se} \mathrm{incubaron} \mathrm{a}$ temperatura ambiente durante 20 min con agitación suave. El colorante no incorporado se aspiró y los pocillos se lavaron cuatro veces con $4 \mathrm{ml}$ de $\mathrm{H}_{2} \mathrm{O}$ destilada con agitación durante $5 \mathrm{~min}$. Se añadieron a cada pocillo $800 \mu \mathrm{l}$ de ácido acético $10 \%(\mathrm{v} / \mathrm{v})$ 
y la placa se incubó a temperatura ambiente durante 30 min con agitación. La monocapa, ahora pegada ligeramente a la placa, se levantó de la placa con un rastrillo para células (Fisher Lifesciences) y se transfirió a un tubo de microcentrífuga de 1,5 $\mathrm{ml}$. Luego de agitar el tubo con vórtex durante $30 \mathrm{~s}$ la suspensión se cubrió con $500 \mu \mathrm{l}$ de aceite mineral (Sigma-Aldrich), se calentó a $85^{\circ} \mathrm{C}$ durante $10 \mathrm{~min}$ y se transfirió a hielo durante $5 \mathrm{~min}$. A continuación, la suspensión se centrifugó a $20.000 \mathrm{~g}$ durante 15 $\min$ y $500 \mu \mathrm{l}$ del sobrenadante se retiraron a un nuevo tubo. Se añadieron $200 \mu \mathrm{lde}$ $10 \%(v / v)$ de hidróxido de amonio para neutralizar el ácido. En algunos casos, se midió el $\mathrm{pH}$ en este punto para asegurar que el mismo se encontraba entre 4,1 y 4,5. Se realizó la medida de absorbancia a $505 \mathrm{~nm}$ sobre alícuotas de $150 \mu \mathrm{l}$ por triplicado.

\section{Cuantificación de la deposición de cólageno mediante tinción con Rojo Sirio}

Los osteoblastos cultivados sobre placas de cultivo de 24 pocillos se lavaron 3 veces con PBS y se fijaron durante $1 \mathrm{~h}$ utilizando $250 \mu \mathrm{l}$ de fluido de Bouin, preparado al momento de uso mezclando $15 \mathrm{ml}$ de ácido pícrico saturado y $5 \mathrm{ml}$ de formaldehído $35 \% \mathrm{v} / \mathrm{v}$. Las células fijadas se lavaron 3 veces con exceso de agua destilada y se secaron por unos minutos. Se agregó $1 \mathrm{ml}$ de Rojo Sirio 0,1\% (Sigma-Aldrich) en ácido pícrico y se incubó a temperatura ambiente durante $18 \mathrm{~h}$ con agitación suave. Luego de la incubación se realizaron 5 lavados con $\mathrm{HCl}$ 0,01 $\mathrm{N}$ para eliminar el exceso de colorante. Para la cuantificación se agregaron $200 \mu \mathrm{l}$ de $\mathrm{NaOH} \mathrm{0,1} \mathrm{N} \mathrm{y} \mathrm{se} \mathrm{incubó}$ durante 30 min con agitación para disolver el colorante. La absorbancia de la solución se midió a $550 \mathrm{~nm}$ por triplicado.

\section{Medida de actividad fosfatasa alcalina}

La monocapa de osteoblastos, cultivados en placas de 24 pocillos, fue lavada con buffer tris salino (TBS) 4 veces, cubierta con $200 \mu$ de BCIP (5-bromo-4-cloro3indolilfosfato)/NBT (azul de nitro-tetrazolio) e incubada durante 10-15 min a temperatura ambiente. Durante la incubación la generación de color fue seguida mediante microscopia de fase de modo que no se llegara al punto de saturación de color. La reacción se detuvo mediante el agregado de agua destilada. Para cuantificar se realizó la medida de la relación entre el área coloreada y el área total ocupada por células mediante el programa de procesamiento de imágenes Image J (Image $\mathrm{J}$ software; National Institutes of Health). 


\section{Citometría de flujo}

PBMC de los pacientes con enfermedad de Gaucher y los controles sanos se incubaron en PBS conteniendo $10 \%$ de suero humano normal por 20 min a $4^{\circ} \mathrm{C}$ luego de los cuales se centrifugaron y se resuspendieron en $50 \mu \mathrm{l}$ de PBS y $10 \%$ de suero humano normal conteniendo los distintos anticuerpos conjugados. En todos los casos se incubaron las células por $25 \mathrm{~min}$ a $4^{\circ} \mathrm{C}$, luego se realizó un lavado con PBS filtrado y se analizaron en un citómetro FACSCalibur (BD Biosciences, San Diego, CA). Se utilizaron los siguientes anticuerpos: anti-CD51-FITC, anti-CD16-PE y anti-CD14PECy5.5 para evidenciar los precursores de osteoclastos como células CD $51^{+} \mathrm{CD} 16^{+} \mathrm{CD} 14^{+}$anti-CD3-FITC, anti-RANKL-PE y anti-CD20-PerCP para evaluar los niveles de RANKL en linfocitos $T$ (células $C D 3^{+} R A N K L^{+} C D 20^{-}$) y linfocitos $B$ (células $\mathrm{CD}^{-} \mathrm{RANKL}^{+} \mathrm{CD} 20^{+}$) y Lin1-FITC (un coctel de anticuerpos que contiene CD3, CD14, CD16, CD19, CD20 y CD56), anti-RANKL-PE y antiHLA-DR-PECy7 para analizar los niveles de RANKL en células dendríticas (células Lin1'RANKL ${ }^{+} H L A-D R^{+}$). En todos los casos los anticuerpos fueron provistos por BD Biosciences, San Diego, CA. Para el caso de la tinción intracitoplasmática luego de realizar la tinción de las moléculas de superficie correspondientes, siguiendo el mismo protocolo detallado antes, las células se fijaron y permeabilizaron utilizando el kit Citofix/Citoperm (BD Biosciences, San Diego, CA) según las especificaciones del fabricante. Luego del paso de permeabilización se realizó la tinción intracitoplasmática utilizando los siguientes anticuerpos específicos: Foxp3-PE, IL-1 $\beta-A P C$, IL-6-APC, TNF- $\alpha-A P C$ (BD Biosciences, San Diego, CA) en 50 ul de buffer Wash/Perm incluido en el kit. La tinción se realizó a $4^{\circ} \mathrm{C}$ durante $25 \mathrm{~min}$, luego de los cuales se realizaron dos lavados con PBS filtrado y se analizaron las células en el citómetro de flujo.

\section{Diseño de cebadores (primers)}

Los cebadores (primers) utilizados para la determinación de expresión génica fueron diseñados mediante el programa PerIPrimer. Las secuencias fueron elegidas de modo tal que tuvieran una temperatura de hibridación de alrededor de $60^{\circ} \mathrm{C}$ y una longitud de 20-22 pb. La especificidad de las secuencias se verificó mediante la herramienta Primer-BLAST del National Center for Biotechnology Information (NCBI, National Library of Medicine, National Institutes of Health, EE.UU., http://www.ncbi.nlm.nih.gov/tools/primer-blast/), y se comprobó la ausencia de 
estructuras secundarias en las zonas de hibridación de la secuencia blanco de cDNA mediante la herramienta bioinformática mFold (http://mobyle.pasteur.fr/cgibin/portal.py?\#forms::mfold) (Zuker, 2003).

Para todos los cebadores se realizó una curva de eficiencia en qPCR con controles positivos apropiados y se verificó el tamaño del amplicón por electroforesis en gel de agarosa.

\section{Extracción y retrotranscripción $(R T)$ de $A R N$}

La extracción de ARN se realizó utilizando kits de columnas MiniSpin® (GE Healthcare, Buckinhamshire, Reino Unido) y se retro-transcribió utilizando como cebadores una mezcla de hexámeros generados al azar y un kit de reactivos de RT (M-MLV RT, dNTPs, DTT, RNase-Out y First-Strand buffer) según las especificaciones del fabricante (Invitrogen, Carlsbad, CA, EE.UU.), utilizando el siguiente programa: 10 $\min$ a $25^{\circ} \mathrm{C}, 50 \min$ a $37^{\circ} \mathrm{C}, 15 \mathrm{~min}$ a $70^{\circ} \mathrm{C}$. Las reacciones se llevaron a cabo en un termociclador Mastercycler Gradient (Eppendorf AG, Hamburgo, Alemania).

\section{$\underline{P C R}$ cuantitativa en tiempo real ( $q P C R)$}

La determinación de la expresión génica sobre muestras de ADN complementario (cDNA) se realizó en un termociclador iQ5 (BioRad, Hercules, CA, EE.UU.) por qPCR con SYBR Green, utilizando una mezcla de reacción compuesta por $10 \mu \mathrm{l}$ de cDNA, 1 $\mu \mathrm{l}$ de cada primer (forward y reverse), y $12 \mu \mathrm{l}$ de $\mathrm{iQ}^{\mathrm{TM}}$ SYBR ${ }^{\circledR}$ Green Supermix (BioRad, Hercules, CA, EE.UU.). El programa de reacción utilizado fue: 2 min a $50^{\circ} \mathrm{C}$, $10 \mathrm{~min}$ a $95^{\circ} \mathrm{C}, 50$ ciclos de $15 \mathrm{~s}$ a $95^{\circ} \mathrm{C}$ y $60 \mathrm{~s}$ a $60^{\circ} \mathrm{C}$, con una curva final de desnaturalización de $55^{\circ} \mathrm{C}$ a $95^{\circ} \mathrm{C}$ (en pasos de $0,5^{\circ} \mathrm{C} / 10 \mathrm{~s}$ ). Las medidas se realizaron por duplicado por cada gen y muestra.

Para el cálculo del nivel expresión de un gen de interés (GDI) en particular se utilizó el gen de $\beta$-actina (ACTB) como normalizador interno en cada muestra, y utilizando los valores promedio de ciclo al punto de intesección (Ct, cycle threshold) obtenidos para ambos genes se calculó la expresión (en unidades arbitrarias) según la fórmula:

$$
\operatorname{Exp}_{G D I}=2^{-\Delta C t}=2^{-\left(C t_{g d i}-C t_{A C T B}\right)}
$$

\section{$\underline{\text { Análisis estadístico }}$}


Los análisis estadísticos se realizaron mediante el programa GraphPad Prism 4.0 aplicando el test $t$ o ANOVA de una vía seguido del post-test de Tuckey. Para los estudios de niveles de fluorescencia media por citometría se utilizó un test $t$ de una muestra, comparando los datos con un valor hipotético de 1. Los datos se presentan como la media \pm variación estándar de la media. 


\section{Modelo in vitro de la Enfermedad de Gaucher}

Los resultados de esta sección fueron publicados en una revista internacional indexada: "Induction of osteoclastogenesis in an in vitro model of Gaucher disease is mediated by T cells via TNF-a", Mucci JM, Scian R, De Francesco PN, Suquelli Garcia F, Ceci R, Fossati CA, Delpino MV, Rozenfeld PA. Gene 2012 Nov 1;509(1):51-9. doi: 10.1016/j.gene.2012.07.071.

Como se mencionó en la introducción general el metabolismo del hueso es un proceso complejo y muy controlado. En los individuos sanos existe un balance continuo entre la degradación y la formación de hueso nuevo. Los osteoclastos son las únicas células encargadas de degradar la matriz del hueso. Los mismos se originan a partir de la fusión de precursores pertenecientes al linaje monocito/macrófago, lo cual resulta en la generación de células multinucleadas gigantes con la capacidad de resorber hueso, mediante la secreción de protones (disolución de matriz mineral) y de enzimas proteolíticas (degradación de matriz orgánica). La degradación de la matriz orgánica involucra principalmente dos clases de enzimas: las cisteína proteasas lisosomales como la catepsina K (Drake et al., 1996), y las MMPs incluyendo principalmente MMP9 (Reponen et al., 1994).

La diferenciación de los osteoclastos requiere de la presencia de dos factores críticos: el factor estimulante de colonias macrofágicas (M-CSF) y el ligando del receptor activador de NF-KB (RANKL). RANKL es expresado en la superficie de los osteoblastos o bien puede ser liberado en forma soluble, aunque también se ha documentado su expresión por otros tipos celulares como fibroblastos, linfocitos B y $T$ activados (Horwood et al., 1999; Takayanagi et al., 2000; Yeo et al., 2011). Su actividad biológica está regulada por el inhibidor natural osteoprotegerina (OPG) que actúa como un receptor soluble de RANKL que inhibe en forma competitiva la unión de este último a su receptor RANK en la superficie de los precursores de osteoclastos (Yasuda et al., 1998).

Tanto la forma transmembrana como la soluble de RANKL inducen la formación de osteoclastos in vitro cuando los precursores de estas células son cultivados con el factor estimulante de colonias macrofágicas (M-CSF) (Quinn et al., 1998). Sin embargo, la diferenciación de los osteoclastos también puede ocurrir por un proceso independiente de la interacción RANKL-RANK. Se ha reportado que TNF- $\alpha$ (Azuma et al., 2000) e IL-6 (Kudo et al., 2003a) también son capaces de inducir en forma directa la formación de osteoclastos in vitro, en presencia de M-CSF. Esto sugiere que ambas citoquinas proinflamatorias juegan un rol importante en la osteoclastogénesis. 
En las enfermedades inflamatorias crónicas del hueso, se ha demostrado que tanto RANKL como las citoquinas proinflamatorias TNF- $\alpha$, IL-1 $1 \beta$ e IL-6 son importantes en la progresión de la enfermedad y destrucción ósea (Dickerson et al., 2012; Kotake et al., 1996; Romas et al., 2002). Es importante destacar que los macrófagos en los tejidos inflamados no solo tienen la capacidad de diferenciarse a osteoclastos (Adamopoulos et al., 2006), sino que pueden acelerar la degradación del hueso a través de la producción de citoquinas proinflamatorias (Chu et al., 1992; Takasugi et al., 2006).

\section{Generación del modelo}

Para la generación del modelo in vitro de la enfermedad de Gaucher se cultivaron PBMC de controles normales en presencia del inhibidor específico de la Glucocerebrosidasa (GCasa), Conduritol- $\beta$-epóxido (CBE). El CBE se une irreversiblemente a la enzima inhibiendo su actividad y produciendo la acumulación de su sustrato, glucosilceramida.

En paralelo se llevaron a cabo experimentos que incluían el agregado de LPS durante las últimas $24 \mathrm{~h}$ de cultivo. Estos estudios tienen como propósito evaluar las posibles alteraciones en el equilibrio óseo en pacientes con enfermedad de Gaucher que cursan infecciones por bacterias Gram negativas.

El cultivo se llevó a cabo durante tres días, luego de los cuales se guardó el sobrenadante para ser usado como medio de cultivo condicionado en posteriores ensayos. Las células fueron utilizadas para determinar la acumulación de glucosilceramida.

\section{Acumulación de Glucosilceramida}

Para evidenciar si la presencia del inhibidor producía la acumulación del sustrato de la GCasa, glucosilceramida, se realizó la extracción de los glicolípidos a partir de PBMC cultivadas. Se separaron los mismos mediante TLC junto con un estándar. Se observó que la presencia del inhibidor producía una acumulación de glucosilceramida y que dicha acumulación era específica para este glicolípido (Fig.1) 


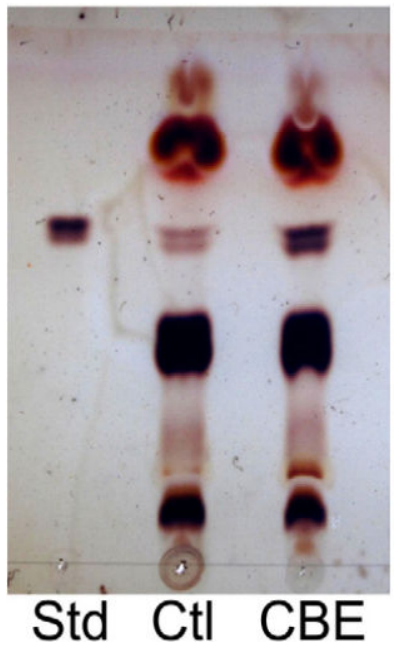

Fig.1 TLC de glicolípidos extraídos de PBMC tratadas con CBE (CBE) o sin tratar (Ctl). Se utilizó glucosilceramida como estándar (Std)

\section{Inducción de la diferenciación de osteoclastos mediada por sobrenadante de cultivo condicionado}

Para evaluar si existen factores solubles liberados por las células del modelo in vitro de la enfermedad de Gaucher capaces de inducir la diferenciación a osteoclastos, tratamos células de la línea monocítica THP-1 con M-CSF para obtener células precursoras de osteoclastos, las cuales fueron expuestas a los sobrenadantes condicionados.

La exposición al sobrenadante condicionado proveniente de células tratadas con CBE (PBMC/CBE) produjo un aumento significativo en la cantidad de osteoclastos evidenciados como células multinucleadas que expresan fosfatasa ácida resistente a tartrato (TRAP) respecto del control (sobrenadante de cultivo de PBMC que no recibieron tratamiento) (Fig. 2A). A su vez el tratamiento con CBE y LPS (PBMC/CBE+LPS) indujo un aumento aún más marcado en este efecto; esto nos indicaría una mayor diferenciación de osteoclastos mediada por las células del modelo respecto del control (sobrenadante de cultivo de PBMC que fueron tratados con LPS).

Como los osteoclastos diferenciados secretan la metaloproteasa de matriz (MMP)-9 decidimos analizar si estas células multinucleadas que expresan TRAP eran capaces de producir y secretar MMP-9. La producción de MMPs fue determinada en los sobrenadantes de cultivo por zimografía utilizando como sustrato gelatina (Fig. 2B). Los precursores que fueron tratados con medio condicionado proveniente de PBMC/CBE+LPS produjeron cantidades significativas de MMP-9 respecto del control (precursores tratados con sobrenadantes de PBMC/LPS). Por otro lado, las células 
tratadas con PBMC/CBE no mostraron diferencias significativas en cuanto a la producción de MMP-9 respecto del control.

La actividad de las MMPs in vivo está altamente regulada y se encuentra contrarrestada por la actividad de inhibidores tisulares específicos denominados TIMPs. Por lo tanto, la actividad proteolítica neta, depende del balance entre la actividad de las MMPs y de las TIMPs (Brinckerhoff et al., 2002). Esta actividad neta podría no ser detectada por zimografía ya que los complejos MMP-TIMP podrían disociarse durante la electroforesis. Por lo tanto, decidimos determinar la actividad gelatinolítica neta en el sobrenadante de cultivo de osteoclastos diferenciados bajo las distintas condiciones incubándolos con un conjugado de gelatina-FITC que no fluoresce cuando la molécula está integra, pero sí cuando la misma es degradada por la acción de proteasas. Se observó un incremento significativo en la actividad neta en los sobrenadantes provenientes de precursores diferenciados con sobrenadante condicionado de PBMC/CBE como también de PBMC/CBE+LPS comparados con sus respectivos controles (Fig. $2 \mathrm{C}$ ). 
A

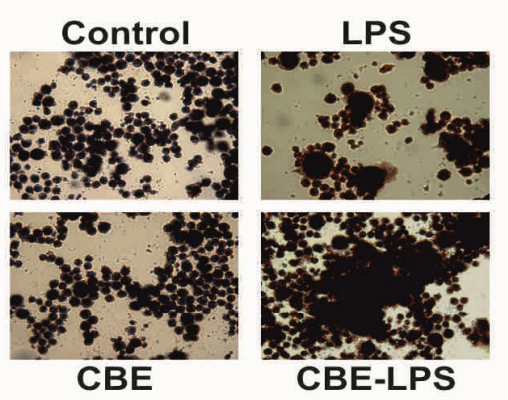

B CtI CBE LPS LPS RANKL

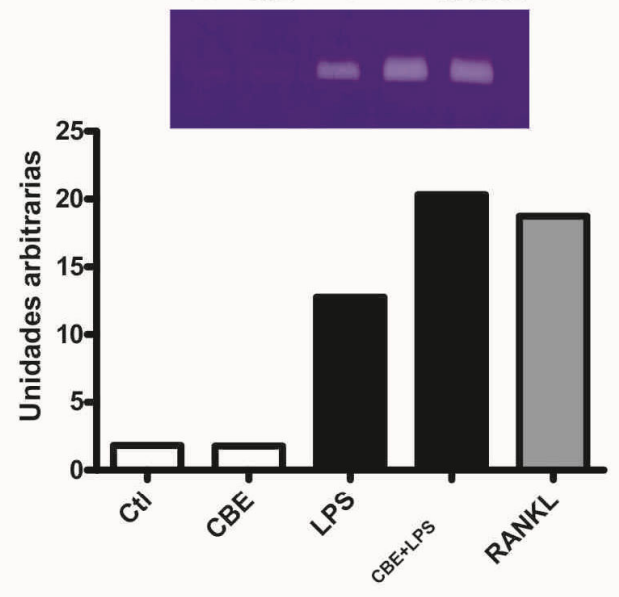

D
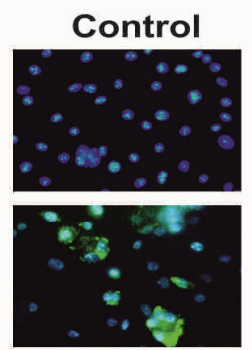

CBE
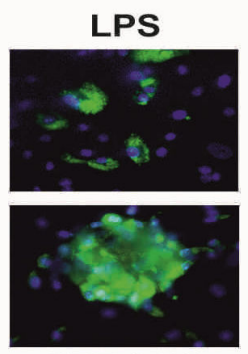

CBE-LPS
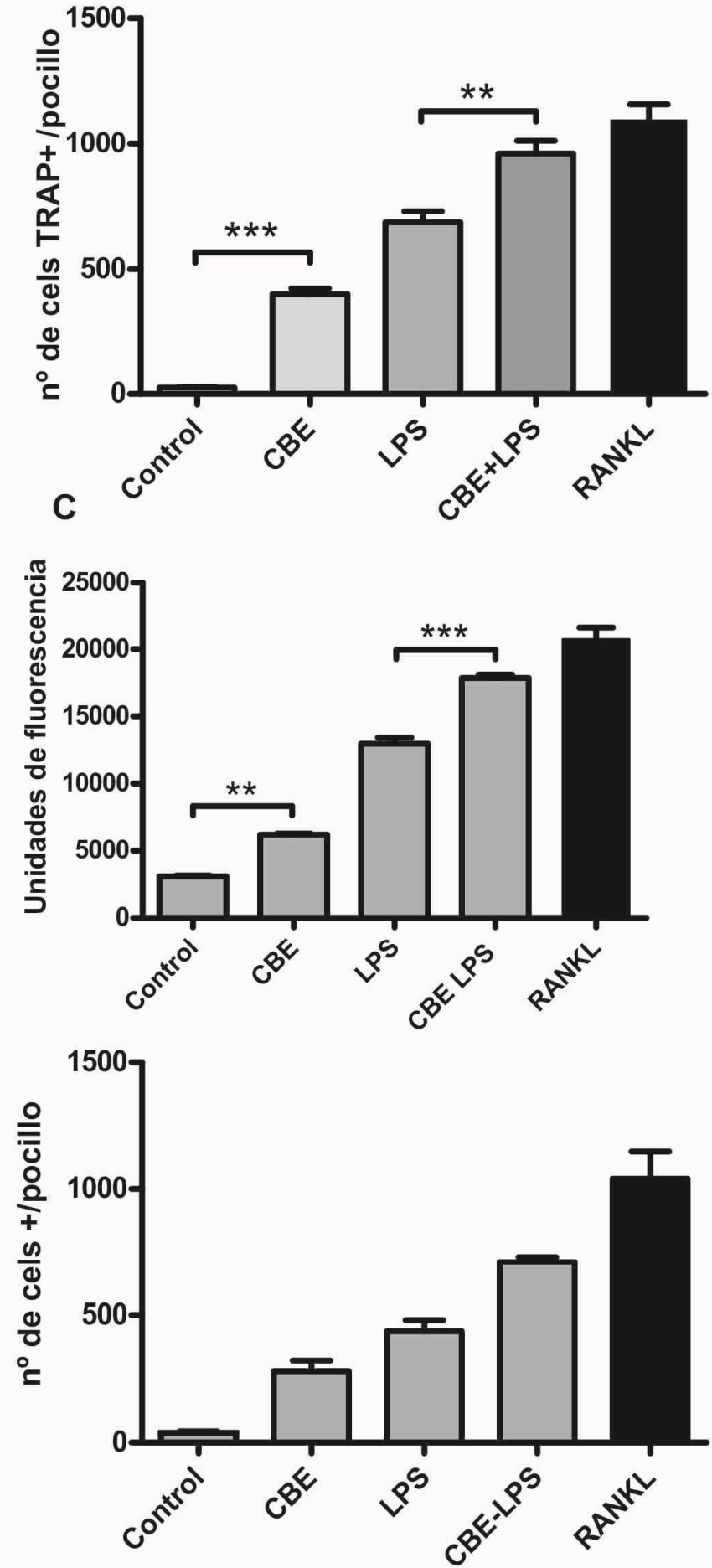

Fig. 2 Inducción de osteoclastogénesis mediada por sobrenadante condicionado. Las células precursoras fueron tratadas con distintos sobrenadantes y analizadas para los siguientes marcadores: 2 A Células TRAP ${ }^{+}$multinucleadas. 2 B Niveles de MMP-9 mediante zimografía. 2 C actividad gelatinolítica neta mediante fluorometría. 2 D expresión del receptor de vitronectina por inmunofluorescencia. ${ }^{* *} \mathrm{p}<0,01{ }^{*} \mathrm{p}<0,001$ ANOVA de una vía.

Para corroborar que las células diferenciadas eran verdaderos osteoclastos se analizó la expresión del receptor de CD51 en la superficie de las células multinucleadas (Fig 2 D). Los niveles de células multinucleadas que expresaban CD51 fue mayor para los 
precursores tratados con sobrenadante condicionado proveniente de PBMC/CBE, y $\mathrm{PBMC/CBE+LPS} \mathrm{en} \mathrm{comparación} \mathrm{a} \mathrm{sus} \mathrm{respectivos} \mathrm{controles.}$

De esta manera pudimos concluir que la inhibición de la enzima GCasa sobre células mononucleares generaría la secreción de factores solubles por parte de estas células que promueven la diferenciación de precursores a osteoclastos maduros y que los mismos liberan mayores niveles de MMPs. Este efecto se vio aumentado ante el agregado de LPS.

\section{Determinación de citoquinas en sobrenadantes de cultivo condicionados}

A continuación nos propusimos determinar algunos de los posibles mediadores solubles que podrían estar participando en la inducción de la diferenciación de osteoclastos en nuestro modelo. Además, está descripto que, los pacientes con enfermedad de Gaucher presentan niveles alterados de citoquinas y quemoquinas (Pandey et al., 2013). Por lo tanto decidimos evaluar si la inhibición de la GCasa en nuestro modelo in vitro producía un aumento en la producción de citoquinas, en particular de aquellas que podrían estar involucradas en los procesos de resorción y síntesis de matriz ósea.

El tratamiento de PBMC de individuos sanos con CBE no modificó la secreción de las citoquinas estudiadas respecto de los controles sin tratar, excepto para la producción de IL-4, para la cual se observa una tendencia al aumento en la secreción de esta citoquina cuando las células son tratadas con CBE respecto a los controles sin tratar. En cambio, el agregado de LPS además de CBE indujo un aumento significativo en la secreción de TNF- $\alpha(p=0,0004)$ y una tendencia al aumento de IL-6, IL-1 $\beta$ e IL-12 comparadas con los sobrenadantes de cultivo de aquellas células que fueron tratadas sólo con LPS. En contraste, las concentraciones de las citoquinas IL-13, IL-10 y TGF- $\beta$ mostraron una tendencia a menores niveles en aquellos sobrenadantes correspondientes a las células tratadas con LPS y CBE respecto de aquellos provenientes de células tratadas con LPS solo (Fig. 3). La medida de RANKL en los sobrenadantes no presentó niveles apreciables ni diferencia entre los tratamientos (datos no mostrados).

Estos resultados muestran que, en nuestro modelo in vitro, la inhibición de la GCasa durante tres días no induciría un aumento en la producción de las citoquinas estudiadas. En presencia de LPS la inhibición de la GCasa produce un aumento significativo en la producción de TNF- $\alpha(p<0,001)$ y una tendencia al aumento de la secreción de IL-6, IL-1 $\beta$ e IL-12 y disminución de los niveles de las citoquinas anti- 
inflamatorias IL-10 y TGF- $\beta$. Por otro lado, los niveles aumentados de IL-4 podrían relacionarse a la activación alternativa de macrófagos observada en los pacientes con enfermedad de Gaucher (Boven et al., 2004). 
IL-1 $\beta$

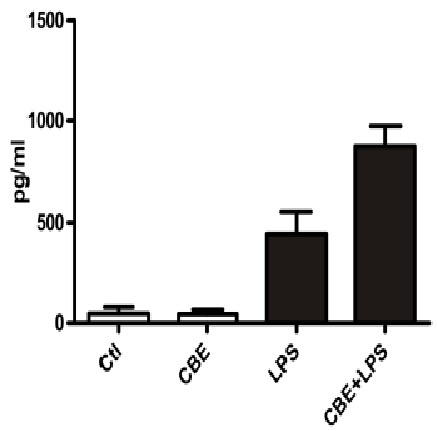

IL-10

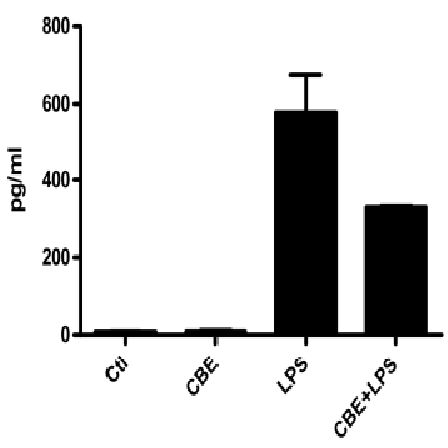

IL-13

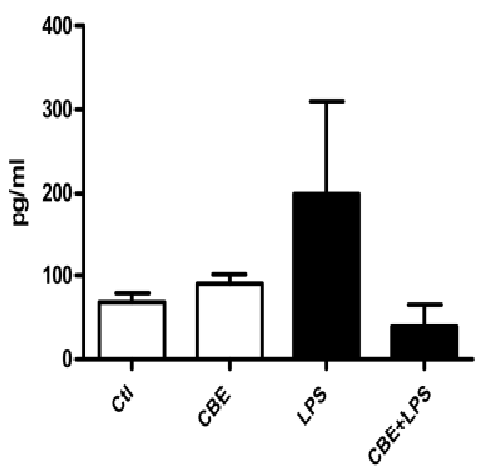

IL-6

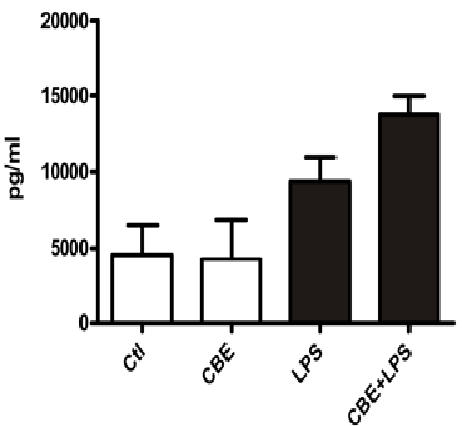

IFN-y

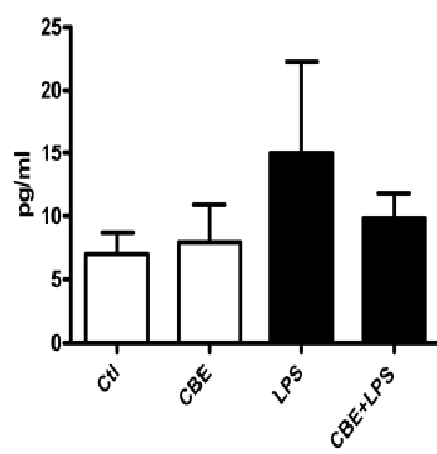

TGF- $\beta$

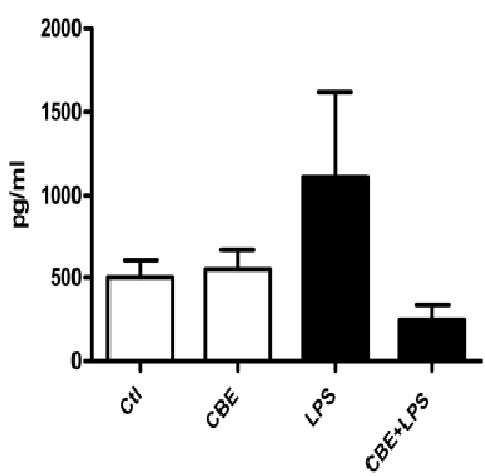

TNF- $\alpha$

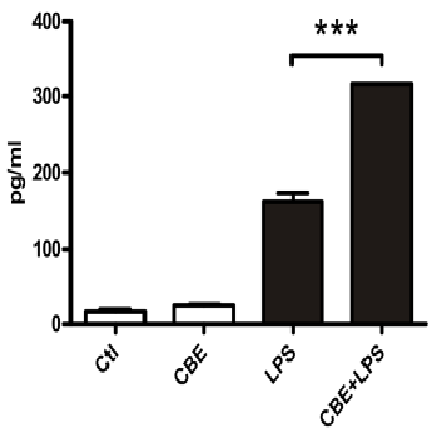

IL-4

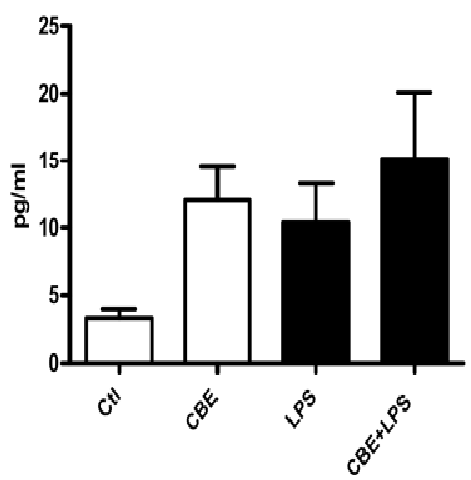

IL-12

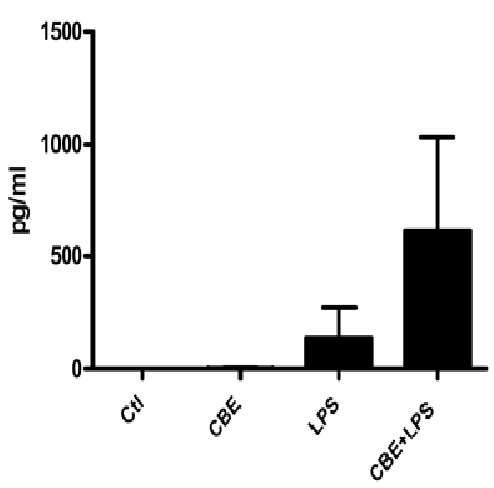

Fig. 3 Concentración de citoquinas en sobrenadantes de cultivo de PBMC tratadas con CBE y/o LPS mediante ELISA. $* * * \mathrm{p}<0,01$ ANOVA de una vía. 


\section{Actividad osteolítica}

Nuestra hipótesis se basa en que la enfermedad de Gaucher podría crear un microambiente inflamatorio que promovería una mayor generación de osteoclastos provocando pérdida ósea. Por lo tanto, evaluamos la actividad funcional de los osteoclastos formados en respuesta a los distintos medios condicionados mediante su habilidad para degradar dentina. Para llevar a cabo este objetivo se realizaron los experimentos de diferenciación de osteoclastos sobre una matriz de dentina.

Los osteoclastos diferenciados a partir del tratamiento con los sobrenadantes de cultivo de PBMC estimulados con CBE y CBE+LPS indujeron un aumento significativo en la degradación de dentina en comparación con sus respectivos controles (Fig. 4).

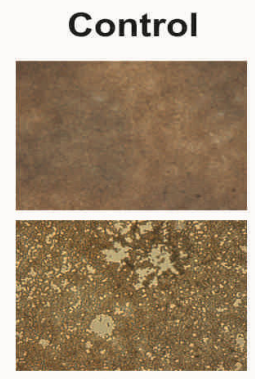

CBE
LPS

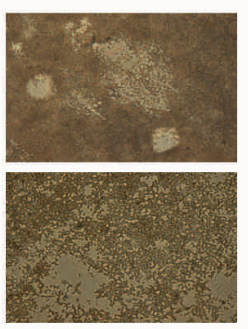

CBE-LPS

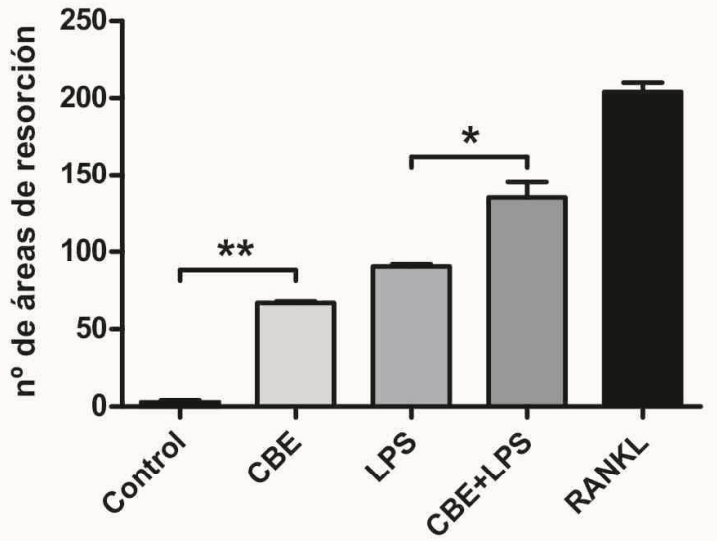

Fig. 4 Actividad de resorción de las células TRAP $^{+}$. Recuento de áreas de resorción inducidas por distintos sobrenadantes condicionados sobre una matriz comercial. ${ }^{*} \mathrm{p}<0,05 *{ }^{*} \mathrm{p}<0,01$ ANOVA de una vía.

Por lo tanto los osteoclastos diferenciados por los factores solubles presentes en los sobrenadantes condicionados poseen una mayor actividad de resorción en el caso del tratamiento con CBE, el cual aumenta en presencia del LPS.

\section{Secreción de citoquinas y marcadores de células de Gaucher por osteoclastos}

Nos propusimos evidenciar si los osteoclastos activados eran capaces de inducir ellos mismos un microambiente inflamatorio mediante la secreción de citoquinas. Para esto se midieron los niveles de las citoquinas IL-1 $\beta$, TNF- $\alpha$ e IL-6 en los sobrenadantes de cultivo de los osteoclastos diferenciados mediante ELISA. Con este fin se reemplazó el 
medio de cultivo de los osteoclastos por medio completo fresco sin el agregado de sobrenadante condicionado durante las últimas 24 hs del cultivo, de este modo se evitó la interferencia con citoquinas presentes en los sobrenadantes de medio condicionado de PBMC. Los osteoclastos liberaron mayores niveles de IL-1 $\beta$ y TNF- $\alpha$ cuando fueron estimulados a partir de sobrenadante condicionado proveniente de PBMC/CBE y este efecto es estadísticamente significativo cuando proviene de PBMC/CBE+LPS (Fig. 5A).

Se ha demostrado que la enzima quitotriosidasa $(\mathrm{CHIT})$ es producida por las células de Gaucher (Hollak 1994) y también es un marcador de activación alternativa de macrófagos. La medida de la actividad para esta enzima fue significativamente mayor en los sobrenadantes de los osteoclastos diferenciados por medio condicionado proveniente de PBMC/CBE y de PBMC/CBE+LPS en comparación con sus controles (Fig. 5B).

A
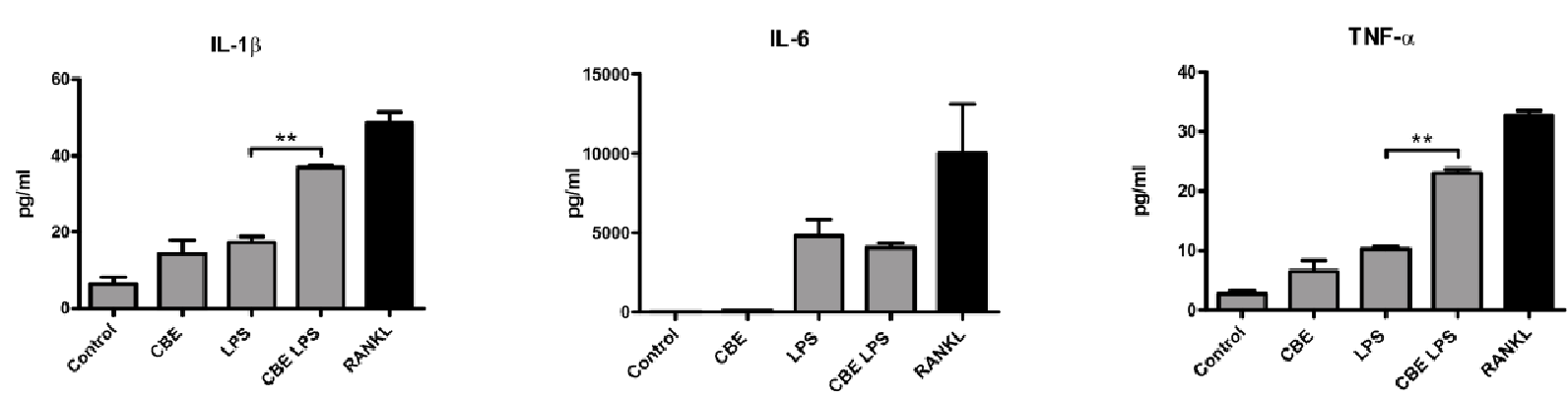

B

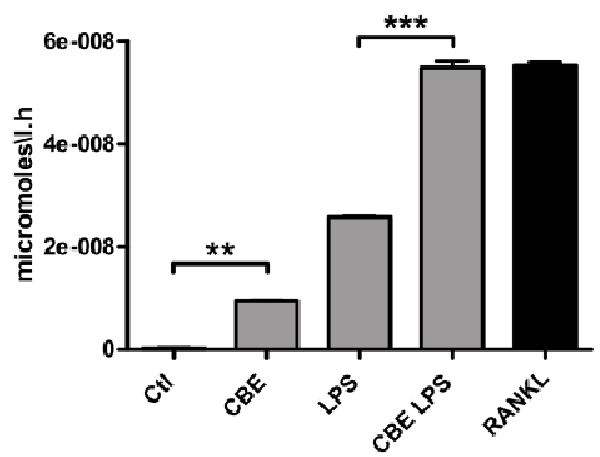

Fig. 5 Caracterización de las citoquinas y marcadores de la enfermedad de Gaucher secretados por osteoclastos diferenciados. A Niveles de Citoquinas proinflamatorias en sobrenadantes de cultivo de osteoclastos diferenciados con distintos sobrenadantes condicionados. B Actividad de Quitotriosidasa mediante fluorometría. $* * \mathrm{p}<0,01 * * * \mathrm{p}<0,001$ ANOVA de una vía.

Por lo tanto los osteoclastos diferenciados liberarían citoquinas que podrían favorecer el mantenimiento y diferenciación de otros osteoclastos. Además los osteoclastos diferenciados a partir de sobrenadantes de PBMC tratadas con CBE presentan una 
mayor actividad de quitotriosidasa, la cual es una característica distintiva de la enfermedad de Gaucher.

\section{Papel de TNF- $\alpha$ en la osteoclastogénesis}

La diferenciación de los osteoclastos requiere la presencia de dos factores críticos: el factor estimulante de colonias macrofágicas (M-CSF) y el ligando del receptor activador de NF-KB (RANKL). RANKL es expresado en la superficie de los osteoblastos o bien puede ser liberado en forma soluble, aunque también se ha documentado su expresión por otros tipos celulares como fibroblastos, linfocitos $B$ y $T$ activados (Takayanagi et al., 2000; Yeo et al., 2011). Su actividad biológica está regulada por el inhibidor natural osteoprotegerina (OPG) que actúa como un receptor soluble de RANKL que inhibe en forma competitiva la unión de este último a su receptor RANK en la superficie de los precursores de osteoclastos (Yasuda et al., 1998).

Tanto la forma transmembrana como la soluble de RANKL inducen la formación de osteoclastos in vitro cuando los precursores de estas células son cultivados con el factor estimulante de colonias macrofágicas (M-CSF) (Quinn et al., 1998). Sin embargo, la diferenciación de los osteoclastos también puede ocurrir por un proceso independiente de la interacción RANKL-RANK.

En las enfermedades inflamatorias crónicas del hueso, se ha demostrado que tanto RANKL como las citoquinas proinflamatorias TNF- $\alpha$, IL-1 $1 \beta$ e IL- 6 son importantes en la progresión de la enfermedad y destrucción ósea (Haynes, 2004; Nair et al., 1996).

Los resultados de nuestro modelo in vitro de la enfermedad de Gaucher, indican que la osteoclastogénesis dependería de la presencia de citoquinas proinflamatorias y teniendo en cuenta que TNF- $\alpha$ es una molécula clave implicada en la osteoclastogénesis independiente de RANKL (Azuma et al., 2000; Kobayashi et al., 2000), nuestra hipótesis es que TNF- $\alpha$ podría ser la principal citoquina involucrada en el fenómeno de osteoclastogénesis observado.

Para evidenciar este proceso se realizaron experimentos de osteoclastogénesis inducida por sobrenadante de cultivo condicionado en presencia de un anticuerpo neutralizante anti-TNF- $\alpha$ o un control de isotipo. La incubación de los precursores con sobrenadante de cultivo condicionado y en presencia de anti-TNF- $\alpha$ redujo significativamente el número de células multinucleadas que expresan TRAP así como también la cantidad de áreas de resorción, mientras que el control de isotipo no mostró efecto alguno (no mostrado). El TNF-a recombinante $(50 \mathrm{ng} / \mathrm{ml})$ usado como control positivo indujo osteoclastogénesis (Fig. 6). 


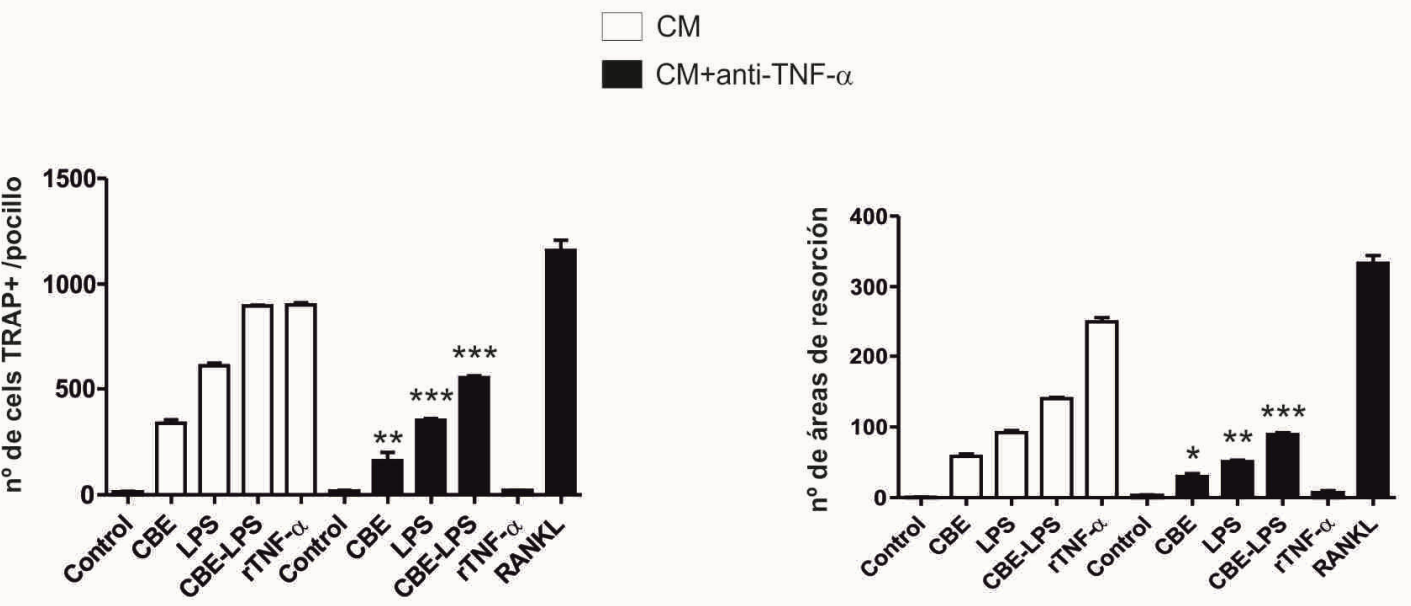

Fig. 6 Recuento de células multinucleadas TRAP+ y áreas de resorción inducidas por sobrenadante condicionado (CM) en presencia o ausencia de un anticuerpo neutralizante de TNF- $\alpha$ (anti- TNF- $\alpha$ ). ${ }^{*}$ p $<0,05 * * p<0,01 * * * p<0,001$ ANOVA de una vía.

Por lo tanto el TNF- $\alpha$ sería una de las moléculas involucradas en el proceso de inducción de osteoclastogénesis en nuestro modelo de la enfermedad de Gaucher.

\section{Participación de las células T en la osteoclastogénesis}

En las enfermedades óseas inflamatorias crónicas, el reclutamiento de células inmunes puede contribuir a la pérdida de hueso. RANKL y las citoquinas proinflamatorias tales como, TNF- $\alpha, \mathrm{IL}-1 \beta, \mathrm{IL}-6$ e IL-17 han sido importantes para la progresión de la enfermedad y la pérdida de hueso (Kotake et al., 1996; Mclnnes \& Schett, 2007). Los linfocitos T y B contribuyen también a la aceleración en el proceso de pérdida ósea. Específicamente las células $T$ activadas pueden inducir la destrucción ósea en condiciones patológicas, tales como la artritis reumatoidea (Y. Y. Kong et al., 1999) convirtiéndose en una fuente de RANKL y TNF- $\alpha$. Aunque RANKL ha sido indicado como la principal citoquina que regula la diferenciación de osteoclastos, los linfocitos $\mathrm{T}$, también podrían secretar citoquinas que inhiben la osteoclastogénesis tales como, IFN- $\gamma$, IL-4 e IL-10 (Hiroshi Takayanagi, 2007).

Por lo tanto para evaluar la participación de las células $T$ en nuestro modelo de inducción de osteoclastogénesis realizamos la inmunodepleción de células CD3 previo a los cultivos de PBMC (Fig. 7). Como se observa en la Fig. 7 A la ausencia de células $T$ reduce significativamente los niveles de citoquinas proinflamatorias en respuesta a la estimulación con CBE y CBE+LPS. En concordancia, la inducción de osteoclastogénesis mediada por sobrenadantes condicionados tratados con CBE y CBE+LPS fue menor con respecto al control sin depleción (Fig. 7 B). En vista de estos 
resultados los linfocitos T jugarían un papel central en el proceso de inducción de osteoclastogénesis en nuestro modelo in vitro de la enfermedad de Gaucher, liberando factores solubles que inducen la maduración de osteoclastos.

A
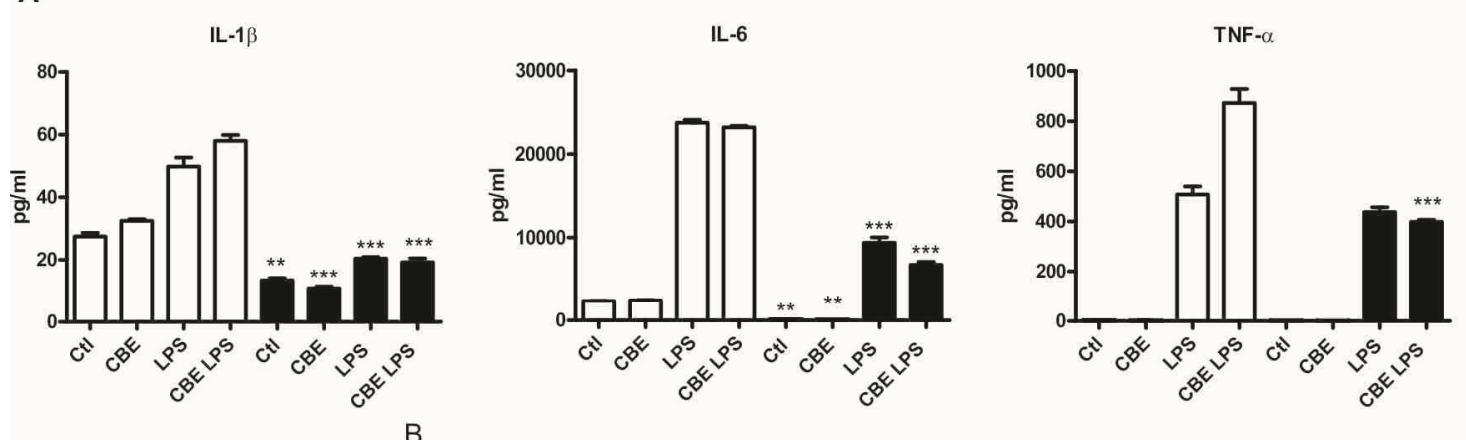

B

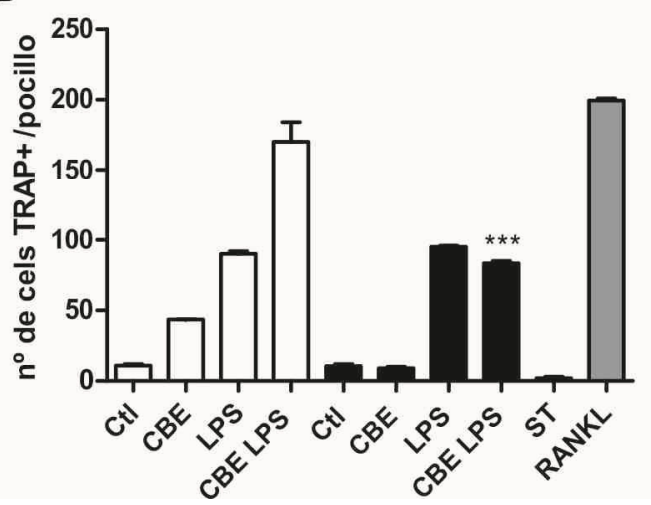

CONTROL

CD 3 INMUNODEPLETADA

Fig. 7 Niveles de citoquinas (A) e inducción de células TRAP ${ }^{+}$, mediante sobrenadante condicionado proveniente de células tratadas con $\mathrm{CBE}$ o CBE+LPS e inmunodepletadas para $\mathrm{CD}^{+}(\mathbf{B}) .{ }^{* *} \mathrm{p}<0,01 * * * \mathrm{p}<0,001$ ANOVA de una via.

\section{Discusión y conclusiones}

En esta sección describimos uno de los mecanismos inmunes implicados en la degradación inflamatoria del hueso en la enfermedad de Gaucher. La inflamación es un factor importante en esta enfermedad, por lo tanto nuestra hipótesis es que durante un proceso inflamatorio de los huesos el balance existente entre la formación y la degradación del hueso puede verse afectado. Las citoquinas proinflamatorias TNF- $\alpha$, IL-1 $\beta$ e IL-6 han sido implicadas en la progresión de enfermedades inflamatorias crónicas del hueso con un aumento en la degradación ósea.

Para analizar esta hipótesis nos propusimos evidenciar la capacidad de mediadores solubles secretados por las células de nuestro modelo in vitro de la enfermedad de Gaucher para inducir la diferenciación de osteoclastos. Demostramos que existen moléculas solubles secretadas por PBMC tratadas con CBE que son capaces de generar la diferenciación de precursores hacia osteoclastos maduros y activos, los cuales poseen una mayor actividad de degradación de hueso. El tratamiento con CBE no indujo un aumento significativo en las citoquinas implicadas en los procesos de 
osteoclastogénesis estudiadas. Por lo tanto el/los mediadores solubles liberados por las células de nuestro modelo, que inducen la diferenciación inicial de los osteoclastos, aún no se han dilucidado completamente. Una de las posibilidades es que el mediador sea la interleuquina-17 (IL-17). Se han documentado evidencias de que tanto esta citoquina como la población de linfocitos $T$ que la secretan (Th17) producen la diferenciación de osteoclastos (Kotake et al., 1999; Noonan et al., 2010; Sato et al., 2006).

En concordancia con nuestros hallazgos, utilizando una estrategia similar, Lecourt et al. (2012) demostraron que el sobrenadante de cultivo de células mesenquimales tratadas con CBE induce la diferenciación a osteoclastos a partir de sus precursores. Por otro lado el tratamiento directo con CBE de los precursores de osteoclastos, no indujo la diferenciación de los mismos indicando que mediadores solubles secretados por las células mesenquimales tratadas con CBE serían los responsables de dicho fenómeno.

Para analizar las posibles complicaciones de los pacientes con enfermedad de Gaucher durante un proceso de infección los experimentos se llevaron a cabo en presencia de LPS. Nuestros resultados indican que el LPS induce un incremento en el número de osteoclastos en nuestro modelo de la enfermedad. Esto sugiere que el daño óseo podría ser mayor en aquellos pacientes que además presenten infecciones bacterianas, al menos aquellas debidas a bacterias Gram negativas. Clínicamente podría relacionarse con la predisposición que poseen los pacientes a infecciones óseas difíciles de tratar. En dos estudios de caso se observó que pacientes con enfermedad de Gaucher presentaron casos de osteomielitis por infección con bacterias Gram negativas. En el primer caso se estudió un paciente con enfermedad de Gaucher que presentaba casos de osteomielitis debido a una infección con Prevotella melaninogenica (Finkelstein et al., 1992). El segundo caso presentaba múltiples focos de osteomielitis luego de un episodio de sepsis con salmonella del grupo C. En este caso el tratamiento antibiótico no tuvo efecto considerable sino hasta que se administró en conjunto con la terapia de reemplazo enzimático con GCasa recombinante (Margalit et al., 2002).

En las enfermedades inflamatorias crónicas del hueso como la artritis reumatoidea, se ha demostrado que las citoquinas proinflamatorias TNF- $\alpha$, II-1 $\beta$ e IL-6, así como también RANKL y TGF- $\beta$, son importantes en la progresión de la enfermedad y en la inducción patológica de osteoclastogénesis (Chu et al., 1992; Haynes, 2004; Kotake et al., 1996; Merkel et al., 1999; Nair et al., 1996; Ukai et al., 2008). Por otro lado, ha sido demostrado que TNF- $\alpha$ estimula la osteoclastogénesis mediante un mecanismo independiente de RANKL (Azuma et al., 2000; Kobayashi et al., 2000). En nuestro 
estudio la neutralización de TNF- $\alpha$ en los experimentos redujo en forma significativa la diferenciación de osteoclastos y su actividad osteolítica. Esto sugeriría al TNF- $\alpha$ como uno de los mediadores solubles que promueven la osteoclastogénesis, aunque podrían existir otros. Aunque el tratamiento de PBMC con CBE no produjo un aumento significativo en los niveles de TNF- $\alpha$ en los sobrenadantes condicionados, los precursores de osteoclastos sometidos al tratamiento con sobrenadante de PBMC/CBE secretaron mayores niveles de esta citoquina en comparación a su control. Por lo tanto, como dijimos antes, el mediador soluble que inicia el proceso de osteoclastogénesis e induce la producción de TNF- $\alpha$ por los precursores de osteoclastos no se ha dilucidado. A pesar de esto, TNF- $\alpha$ secretado por los precursores de osteoclastos podrían participar en la amplificación y mantenimiento de la diferenciación de osteoclastos en nuestro modelo in vitro de la enfermedad de Gaucher.

Los linfocitos $T$ tienen la capacidad de activar la osteoclastogénesis mediante mecanismos dependientes e independientes de RANKL (Kotake 2001). Se ha demostrado que los LT pueden secretar RANKL así como también citoquinas proinflamatorias e inductoras de la osteoclastogénesis como TNF- $\alpha$ e IL-17.

Desde hace mucho tiempo se ha reconocido el compromiso de los LT en los pacientes con enfermedad de Gaucher (Lacerda et al., 1999). Para analizar la relevancia de estas células en nuestro modelo se realizó la inmunodepleción de células $\mathrm{CD}^{+}$a partir de PBMC para estudiar el papel que desempeñan los LT en la inducción de osteoclastogénesis. Estos experimentos revelaron que la osteoclastogénesis inducida por CBE y por CBE+LPS es en parte dependiente de la presencia de LT. Esto indicaría que este tipo celular participa tanto en el daño óseo debido a la enfermedad de Gaucher, como también en aquellos que presentan infecciones bacterianas concomitantes.

Por lo tanto, nuestros resultados sugieren que la deficiencia in vitro de la GCasa y la concomitante acumulación de glucosilceramida genera un estado proosteoclastogénico mediado en parte por citoquinas, en especial el TNF- $\alpha$. Además los linfocitos T estarían involucrados en este proceso. 


\section{Modelo Murino in vitro de la Enfermedad de Gaucher}

Los resultados de esta sección fueron publicados en una revista internacional indexada: "Uncoupling of osteoblast-osteoclast regulation in a chemical murine model of Gaucher disease." Mucci JM, Suqueli García F, de Francesco PN, Ceci R, Di Genaro S, Fossati CA, Delpino MV, Rozenfeld PA. Gene. 2013 Dec 15;532(2):186-91. doi: 10.1016/j.gene.2013.09.072.

En esta sección, decidimos realizar experimentos equivalentes a los de la primera parte utilizando dos modelos in vitro de cultivo primario de células de ratón. De esta manera intentamos poner de manifiesto similitudes y diferencias entre el modelo humano y el modelo murino de modo de evaluar la utilidad de este último como reflejo de la condición en humanos. Esto nos permitirá determinar si el modelo murino es útil para estudiar el daño óseo en la enfermedad de Gaucher. Para esto ya contamos en el laboratorio con los ratones modelo de la enfermedad que se ha utilizado para estudiar otros aspectos de la misma. Los mismos se encuentran en estos momentos en nuestro laboratorio gracias a la amable colaboración del Dr. Karlsson (Enquist et al., 2006). Por otro lado, en esta sección nos abocamos únicamente a la problemática ósea en condiciones de pérdida de la actividad de la GCasa, dejando de lado las posibles afectaciones durante una infección.

\section{Generación de los modelos in vitro murinos}

Para la generación de los modelos murinos se partió de dos cultivos primarios distintos a partir de ratones de la cepa C57BI/6: por un lado se obtuvieron los macrófagos peritoneales reclutados por inyección intraperitoneal de tioglicolato y posterior lavado con medio de cultivo. Por otro lado se separaron los esplenocitos desde el bazo de los ratones mediante homogeneización del mismo. Se realizó el cultivo de las células con CBE por tres días, siguiendo el mismo protocolo usado para el modelo con células humanas. Luego del cultivo se reservó el sobrenadante de cultivo condicionado para realizar los análisis.

\section{Inducción de la diferenciación de osteoclastos mediada por sobrenadante de cultivo condicionado}

De la misma manera que en la sección anterior se midieron los niveles de las citoquinas proinflamatorias IL-1 $\beta$, IL-6 y TNF- $\alpha$ en los sobrenadantes condicionados mediante ELISA, este ensayo no arrojó diferencias entre las células (macrófagos 
peritoneales y esplenocitos) tratadas con CBE con respecto al control sin tratar (datos no mostrados).

Para evidenciar la presencia de mediadores solubles pro-osteoclastogénicos en estos modelos se separaron precursores de médula ósea a partir del fémur de ratones los cuales se trataron durante 7 días con M-CSF para obtener precursores de osteoclastos. Estos precursores fueron cultivados luego en presencia de M-CSF y sobrenadante de cultivo condicionado por otros 7 días. La formación de osteoclastos a partir de sus precursores fue demostrada por la presencia de células multinucleadas que expresan TRAP.

Pudimos apreciar un aumento significativo en el número de células multinucleadas que expresan TRAP cuando los precursores fueron tratados tanto con sobrenadantes de esplenocitos/CBE como de macrófagos peritoneales/CBE, con respecto a los controles correspondientes sin tratar (Fig. 8).

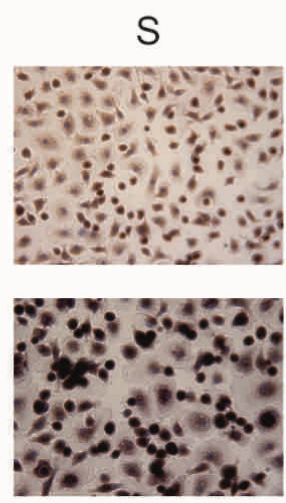

PM

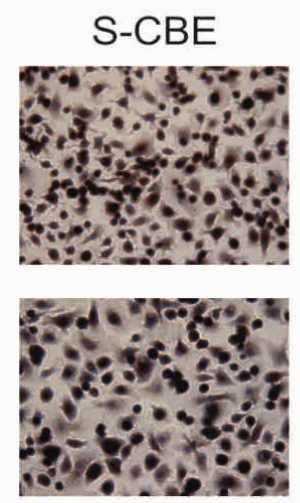

PM-CBE

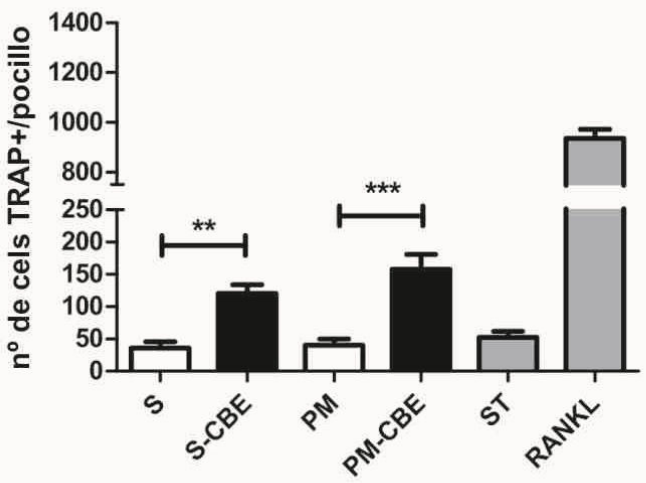

Fig.8 Recuento de células TRAP ${ }^{+}$inducidas por tratamiento con sobrenadante condicionado proveniente de esplenocitos (S) y macrófagos peritoneales (PM) tratados con CBE. **p $<0,01 * * * \mathrm{p}<0,001$ test $\mathrm{t}$.

Para caracterizar en mayor profundidad las células multinucleadas RRAP $^{+}$ diferenciadas se determinó mediante inmunofluorescencia la presencia de células multinucleadas CD51 positivas. Se observó un mayor número de células CD51 positivas multinucleadas cuando se trataron los precursores con sobrenadantes provenientes de esplenocitos/CBE y macrófagos peritoneales/CBE, (Fig. 9A) corroborando la identidad de las células multinucleadas TRAP positivas como verdaderos osteoclastos.

Por otro lado se ensayó la actividad de la MMP-9, mediante zimografía como siguiente paso de la caracterización. Los niveles de MMP-9 fueron mayores en el caso del tratamiento de precursores tratados con sobrenadante condicionado proveniente de esplenocitos/CBE y macrófagos peritoneales/CBE (Fig. 9B). Por lo tanto los 
osteoclastos diferenciados mediante los sobrenadantes condicionados serían maduros y poseerían una mayor actividad de degradación de matriz extracelular.

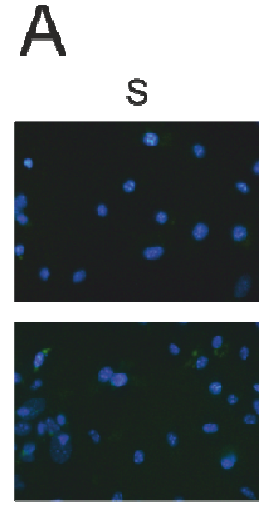

PM
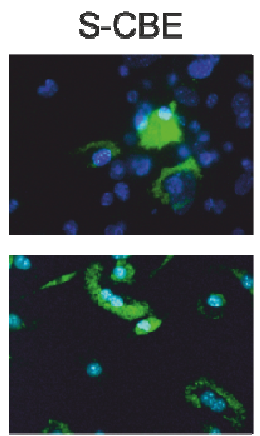

PM-CBE

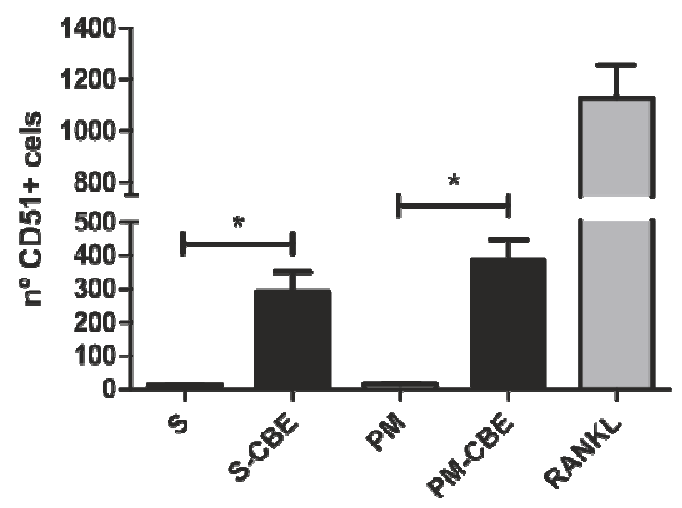

B

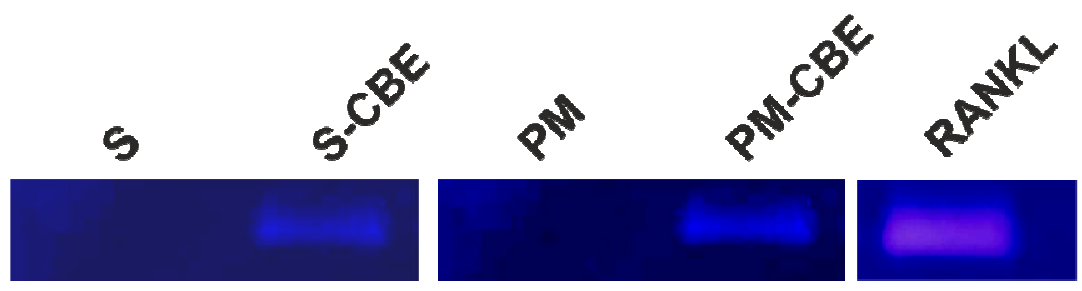

Fig.9 Recuento de células multinucleadas $\mathrm{CD} 51^{+}$inducidas por tratamiento con sobrenadante condicionado de esplenocitos (S) y macrófagos peritoneales (PM) con CBE mediante inmunofluorescencia (A). Zimografía de sobrenadantes de cultivo de osteoclastos diferenciados (B). ${ }^{*} \mathrm{p}<0,05$ test $\mathrm{t}$.

\section{Actividad osteolítica}

Como expusimos en la primera parte, el objetivo de nuestro trabajo es dilucidar si los problemas óseos en la enfermedad de Gaucher se deben, por lo menos en parte, a una mayor actividad de los osteoclastos. Nuevamente realizamos los experimentos de osteoclastogénesis sobre una matriz ósea comercial. Ambos tipos de modelo murino presentaron una mayor actividad de resorción visualizada como áreas degradadas de la matriz inorgánica cuando los precursores fueron diferenciados con medio condicionado derivado del tratamiento con CBE con respecto a su control (Fig. 10). 


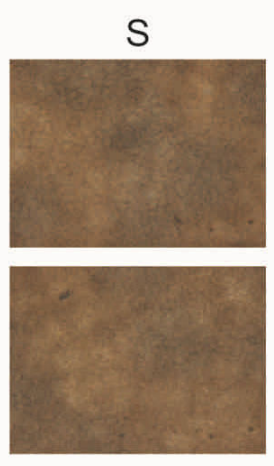

PM
S-CBE

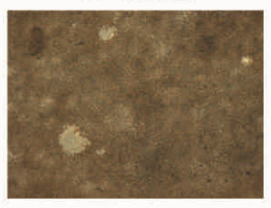

PM-CBE

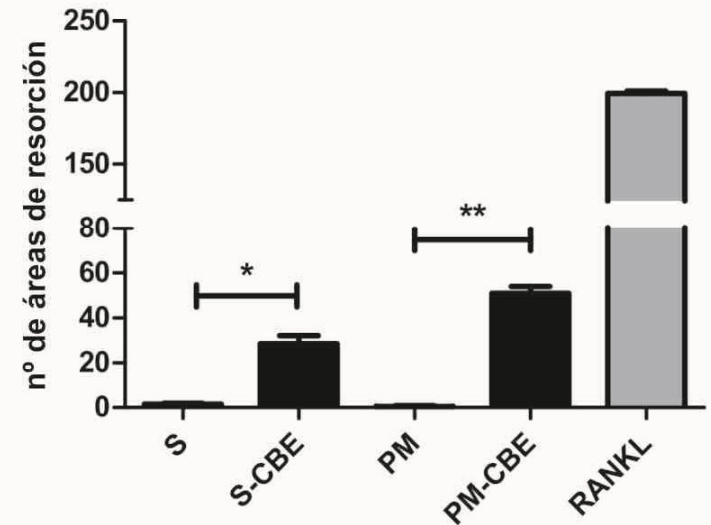

Fig.10 Actividad de osteoclastos diferenciados por tratamiento con sobrenadantes condicionados proveniente de esplenocitos (S) y macrófagos peritoneales (PM) tratados con CBE. *p<0,05**p<0,01 test t.

Los sobrenadantes condicionados provenientes de macrófagos peritoneales y esplenocitos tratados con $\mathrm{CBE}$ indujeron un mayor número de osteoclastos funcionalmente activos.

\section{Secreción de citoquinas por osteoclastos}

Nuevamente nos propusimos evidenciar si los osteoclastos activados secretaban citoquinas. Para esto se midieron los niveles de las citoquinas IL-1 $\beta$, TNF- $\alpha$ e IL-6 en los sobrenadantes de cultivo de los osteoclastos diferenciados mediante ELISA. Para esto se reemplazó el medio de cultivo de los osteoclastos por medio completo fresco sin el agregado de sobrenadante condicionado durante las últimas $24 \mathrm{hs}$ del cultivo, de este modo se evitó la interferencia con citoquinas presentes en los sobrenadantes de medio condicionado de esplenocitos y macrófagos peritoneales.

Para los esplenocitos se observó un aumento en la producción de las tres citoquinas por los precursores de osteoclastos cuando los mismos fueron tratados con sobrenadante condicionado de esplenocitos/CBE con respecto a su control (Fig. 11A) esta diferencia fue significativa para IL-1 $\beta$ e IL-6.

En el caso de los macrófagos peritoneales se presentaron aumentos en la secreción de IL-6 y TNF- $\alpha$ mediante los precursores cuando se trataron con sobrenadante de macrófagos/CBE, siendo la diferencia significativa para IL-6 (Fig. 11B).

Por lo tanto para ambos modelos los precursores de osteoclastos y/o los osteoclastos maduros liberan citoquinas involucradas en el proceso de diferenciación de osteoclastos cuando son expuestos a sobrenadantes condicionados provenientes de células tratadas con CBE. De esta manera los precursores aumentan y mantienen el estado de diferenciación de osteoclastos observado en el modelo. 

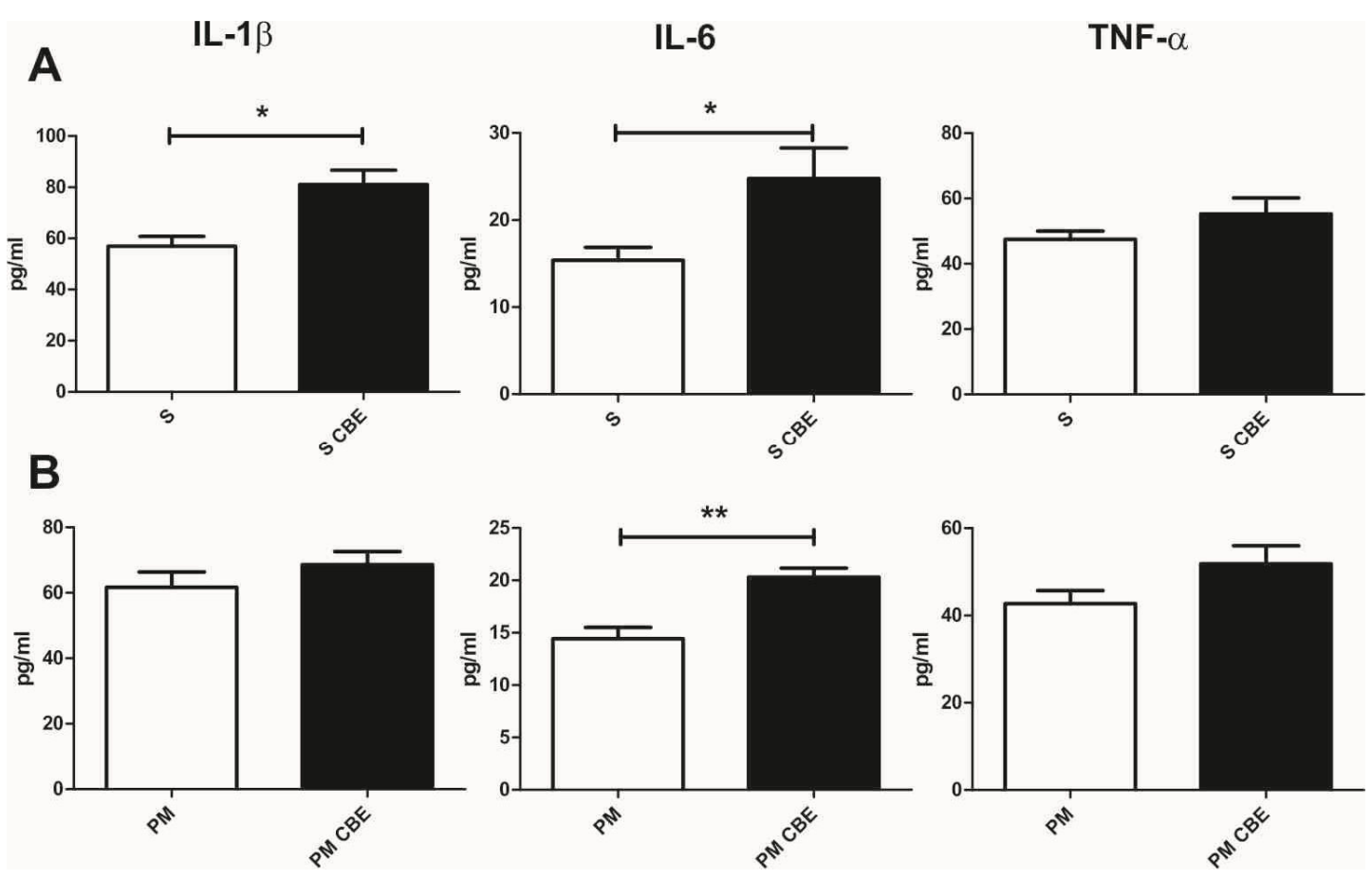

Fig. 11 Determinación de citoquinas secretadas por osteoclastos diferenciados por tratamiento con sobrenadante condicionado de esplenocitos (S) y esplenocitos/CBE (S CBE) (A) o de macrófagos peritoneales (PM) y macrófagos peritoneales/CBE (PM CBE) (B), mediante ELISA. *p $<0,05 *$ * $<<0,01$ test-t

\section{Papel del TNF- $\alpha$ en la osteoclastogénesis}

Debido a que en el modelo que desarrollamos in vitro utilizando células humanas, TNF- $\alpha$ era una de las citoquinas involucradas en los fenómenos de osteoclastogénesis decidimos evaluar la importancia de la misma en el modelo murino.

Para evidenciar esto se obtuvieron los precursores de osteoclastos a partir de médula ósea de ratones C57BI/6 deficientes para el receptor de TNF- $\alpha$ (TNFRp55KO).

Estos precursores se trataron con sobrenadantes condicionados provenientes de esplenocitos/CBE y macrófagos peritoneales/CBE y se determinó la presencia de células multinucleadas TRAP positivas. Como control se utilizaron precursores de médula ósea de ratones salvajes.

Como puede observarse en la figura $12 \mathrm{~A}$ los precursores provenientes de ratones TNFRp55KO presentan una menor diferenciación a osteoclastos que sus contrapartes provenientes de ratones salvajes al ser estimulados con sobrenadantes de cultivo de macrófagos y esplenocitos tratados con $\mathrm{CBE}$, siendo esta diferencia solo significativa en el caso de los precursores que fueron estimulados con sobrenadantes de esplenocitos $(p<0,05)$ 
En concordancia, los resultados de actividad osteolítica mostraron el mismo perfil (Fig.12 B).

Por lo tanto TNF- $\alpha$ jugaría un rol importante en la inducción de osteoclastogénesis en modelo in vitro murino de la enfermedad de Gaucher.

Los resultados obtenidos en esta sección demuestran una buena correlación con los resultados observados para el modelo in vitro humano, reforzando estos últimos. Por otro lado esta correlación abre la posibilidad para futuros estudios in vivo utilizando el modelo murino condicional de la enfermedad de Gaucher.
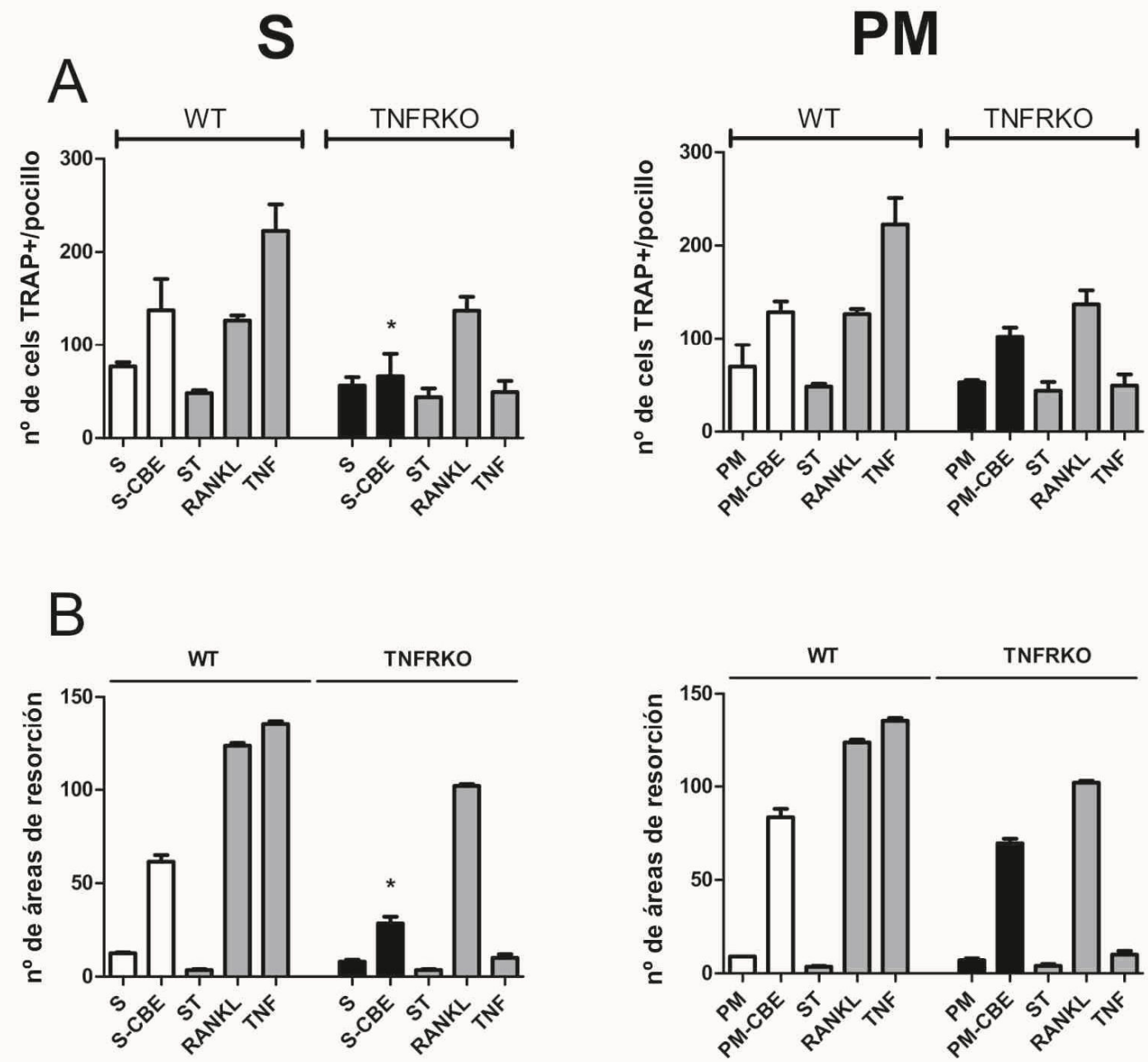

Fig.12 Rol del TNF- $\alpha$ en la inducción de osteoclastogénesis. Se llevaron a cabo los experimentos de osteoclastogénesis (A) y osteólisis (B) inducidos por sobrenadantes condicionados de esplenocitos (S) y macrófagos peritoneales (PM), sobre precursores provenientes de ratones WT o TNFRp55KO. *p $<0,05$ test $\mathrm{t}$.

\section{Actividad de osteoblastos}

Como se mencionó en la introducción general el metabolismo del hueso es un proceso complejo y muy controlado. En condiciones fisiológicas existe un balance continuo entre la degradación y la formación de hueso nuevo. 
Los osteoblastos son células óseas especializadas en producir los componentes de la matriz del hueso y se originan a partir de células mesenquimales pluripotenciales de la médula ósea (Pittenger et al., 1999). La vida de un osteoblasto consiste en múltiples pasos de diferenciación (osteoblastogénesis). En primer lugar ocurre la diferenciación de las células mesenquimales al linaje osteogénico, llamadas células osteoprogenitoras. Luego, estas últimas proliferan y se diferencian a pre-osteoblastos. En esta etapa los pre-osteoblastos comienzan a producir los componentes orgánicos de la matriz ósea, principalmente colágeno tipo I y se diferencian a osteoblastos maduros, los cuales continúan sintetizando proteínas de la matriz extracelular hasta que en última instancia inician la mineralización de la misma a través de la deposición de cristales de hidroxiapatita (fosfato de calcio cristalino con la fórmula $\left(\mathrm{Ca}_{10}\left(\mathrm{PO}_{4}\right)_{6}(\mathrm{OH})_{2}\right)$. Finalmente, una fracción de los osteoblastos maduros queda embebida por la matriz mineralizada y se convierte en osteocitos, mientras que la otra fracción permanece tapizando la superficie del hueso o muere por apoptosis.

Cada uno de los múltiples pasos de la osteoblastogenesis se encuentra regulado por hormonas, factores de crecimiento, citoquinas y proteínas de la matriz extracelular (Neve et al., 2011). Estas señales exógenas inician cascadas de señalización y activan factores de transcripción que median y controlan la osteoblastogénesis.

Los osteoblastos totalmente diferenciados se caracterizan por la expresión de fosfatasa alcalina y colágeno tipo I, ambos importantes para la síntesis de la matriz ósea y la posterior mineralización (Murshed et al., 2005). Los osteoblastos maduros también secretan factores reguladores de la mineralización como osteocalcina y osteopontina, cuya máxima expresión es detectada en el inicio de la etapa de mineralización (Hauschka et al., 1989; Yamate et al., 1997).

Dado que los osteoblastos son las células especializadas en la formación de la matriz ósea la inhibición de la diferenciación y actividad de los mismos provocaría una alteración del balance óseo disminuyendo así la densidad del hueso.

Existen evidencias que demuestran que las citoquinas proinflamatorias TNF- $\alpha$ e IL-1 $\beta$ (Lacey et al., 2009; Tomomatsu et al., 2009) como así también distintos antígenos bacterianos (Claro et al., 2011; Kadon et al., 1999) son capaces de inhibir la diferenciación y mineralización de los osteoblastos. Esto sugiere que los procesos inflamatorios juegan un rol importante en la disminución de la formación del hueso.

Por lo tanto nos propusimos evidenciar si los sobrenadantes condicionados de nuestro modelo in vitro, además de producir un aumento en el número y activación de los osteoclastos, tenían algún efecto sobre la funcionalidad de los osteoblastos. Para esto se trataron osteoblastos de la línea murina MC3T3 con 3-fosfoglicerato y ácido ascórbico, de modo de inducir la actividad de mineralización, con los medios 
condicionados de ambos modelos de la enfermedad. Luego de 14 días de cultivo se realizaron las tinciones para fosfatasa alcalina la cual, está involucrada en el proceso de mineralización, la tinción de Rojo Sirio que permite evidenciar niveles de colágeno secretados por los osteoblastos hacia la matriz extracelular, y la tinción con alizarina roja que permite la medida del calcio depositado durante la mineralización de la matriz extracelular.

En la figura 13 puede observarse que los tres parámetros de actividad de formación ósea estudiados se redujeron significativamente cuando los osteoblastos fueron cultivados en presencia de sobrenadante condicionado proveniente de macrófagos peritoneales/CBE con respecto a su control.

Estos resultados indicarían la existencia de factores solubles en los sobrenadantes condicionados de nuestro modelo que inhiben la actividad de mineralización de los osteoblastos, lo que podría derivar en un desequilibrio óseo hacia la disminución de la densidad ósea. 

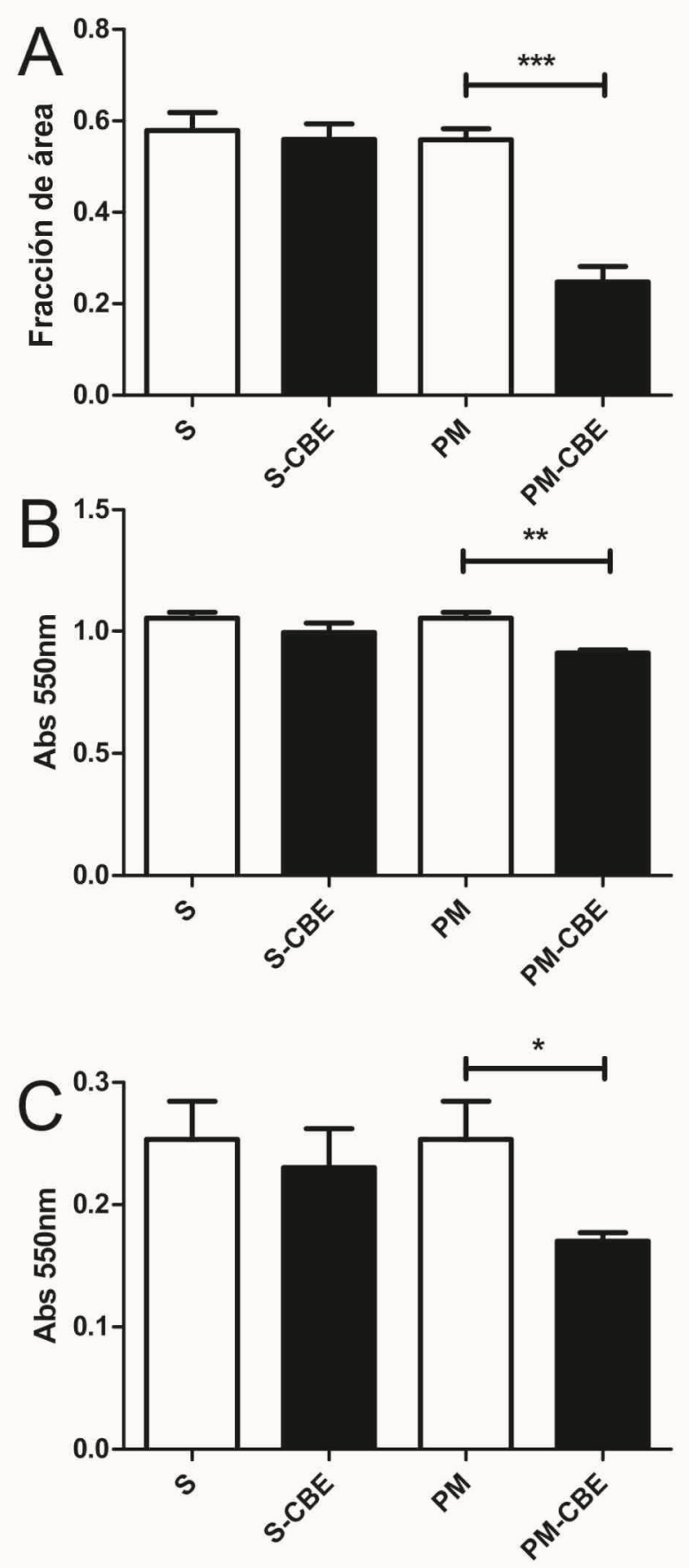

Fig.12 Medida de la actividad de osteoblastos tratados con sobrenadante condicionado proveniente de esplenocitos (S) y macrófagos peritoneales (PM) tratados con CBE. (A) Fosfatasa alcalina (B) Rojo Sirio (C) Alizarína Roja. *p $<0,05 * * p<0,01$ $* * * \mathrm{p}<0,001$ test $\mathrm{t}$.

\section{Discusión y conclusiones}

En la primera parte de nuestro trabajo demostramos que la deficiencia en la actividad de la GCasa y la concomitante acumulación de su sustrato, glucosilceramida, genera mediadores solubles que inducen la diferenciación de osteoclastos y un aumento en su actividad en nuestro modelo in vitro. Demostramos además que uno de los 
mediadores involucrados es TNF- $\alpha$, el cual ha sido previamente descripto como el principal inductor de osteoclastogénesis independiente de RANKL.

Como mencionamos decidimos comparar el modelo realizado con células humanas con un modelo in vitro murino de modo de revelar si el ratón reflejaba los efectos observados en el modelo humano partiendo, además, de otros tipos celulares. Estos experimentos se realizaron como una primera aproximación, en vista de la posibilidad de trabajar con el modelo murino condicional en células hematopoyéticas, que mejor refleja los problemas óseos de la enfermedad (Enquist et al., 2006; Mistry et al., 2010). Mediante una colaboración con el Dr. Karlsson este modelo se encuentra en este momento en nuestro laboratorio.

Los experimentos realizados en esta parte mostraron una buena correlación entre ambos modelos. En todos los casos se observó que el tratamiento de precursores de osteoclastos con sobrenadantes condicionados de células expuestas a CBE genera un número mayor de osteoclastos maduros como también una mayor actividad de los mismos en comparación a sus respectivos controles.

Como en la primera sección, también observamos que los precursores de osteoclastos/osteoclastos producían mayores niveles de TNF- $\alpha$ al ser expuestos a los sobrenadantes condicionados con $\mathrm{CBE}$, si bien estos niveles no fueron significativos estadísticamente, decidimos estudiar esta citoquina ya que ha sido la principal involucrada en osteoclastogénesis independiente de RANKL. Por lo tanto para poner de manifiesto el rol del TNF- $\alpha$ en la osteoclastogénesis inducida por los sobrenadantes condicionados de los modelos murinos, se partió de una estrategia distinta a la utilizada para el modelo humano. Se utilizaron células de médula ósea provenientes de ratones deficientes en el receptor de TNF- $\alpha$ para generar los precursores de osteoclastos empleados luego para los ensayos de osteoclastogénesis. Tal como se había observado utilizando células humanas, TNF- $\alpha$ es una citoquina involucrada en los fenómenos de osteoclastogénesis observados aunque el mediador soluble que inicia el proceso de osteoclastogénesis y producción de citoquinas por los precursores de osteoclastos aún no se ha dilucidado.

El hueso se encuentra en un equilibrio dinámico entre la resorción mediada por los osteoclastos y la formación mediada por los osteoblastos. Por lo tanto un desbalance en dicho equilibrio hacia una menor densidad ósea podría deberse tanto a una mayor actividad de los osteoclastos como a una menor actividad de los osteoblastos. Por lo tanto decidimos también analizar los efectos producidos por mediadores solubles sobre la diferenciación y actividad de los osteoblastos. 
El tratamiento de los osteoblastos con sobrenadante condicionado proveniente de macrófagos peritoneales/CBE produjo una disminución en la actividad de regeneración de la matriz ósea, mientras que para el modelo de esplenocitos no se presentaron diferencias. Estos resultados se encuentran en concordancia con los presentados por Mistry en 2010 donde demostró, en el modelo murino condicional de enfermedad de Gaucher, que los problemas óseos presentes en el modelo podrían deberse a una menor diferenciación y actividad de los osteoblastos.

Como conclusiones de esta parte demostramos que el modelo murino químico de la enfermedad de Gaucher refleja los mismos resultados observados para el modelo humano y refuerza nuestra hipótesis de que existen mediadores solubles secretados por células deficientes en la actividad de la GCasa que inducen la diferenciación y activación de osteoclastos.

Por otro lado en esta parte mostramos también que para uno de los modelos in vitro murinos existirían moléculas secretadas que tendrían un efecto negativo sobre la actividad de formación ósea llevada a cabo por los osteoblastos. A partir de estos resultados, se podría inferir que un déficit en actividad de los osteoblastos junto al aumento en la osteoclastogénesis podrían contribuir a la osteopenia observada en pacientes. 


\section{Osteoclastogénesis en pacientes con Enfermedad de Gaucher}

En esta sección nos propusimos analizar el posible estado pro-osteoclastogénico e inflamatorio en pacientes. Para esto se partió de sangre de pacientes con enfermedad de Gaucher bajo tratamiento de reemplazo enzimático con enzima recombinante. La toma de muestra se realizó en el momento previo a la infusión de la enzima de modo de minimizar los niveles de ésta en circulación.

\section{Datos demográficos y clínicos de los pacientes estudiados}

En las tablas 2 y 3 se presentan los síntomas clínicos de los pacientes estudiados. En las mismas se registran los datos demográficos y de manifestaciones clínicas al momento de la toma de muestra como así también al momento del diagnóstico de la enfermedad. En la tabla 2 se presenta un resumen con los datos clínicos como porcentaje de pacientes que presentaban el síntoma evaluado sobre el total de pacientes evaluados para dicho síntoma. En la tabla 3 se presentan los datos completos para cada paciente como presencia (1) o ausencia (0) del síntoma. En los casos en los que se carece de la evaluación se designó como ND.

Se incluyeron 24 pacientes, 11 mujeres y 13 varones. Los pacientes presentaban un rango etario entre 10 y 77 años con un promedio de $32,16 \pm 19,66$ años, todos ellos bajo tratamiento de TRE con Imiglucerasa (I) o Velaglucerasa (V).

Se muestran los porcentajes de pacientes que presentaban anemia, trombopenia, esplenomegalia, hepatomegalia, niveles aumentados de actividad quitotriosidasa (quito) en plasma y síntomas óseos, al momento del diagnóstico y al momento de la toma de muestra. De esta manera puede observarse que los problemas óseos fueron los más refractarios al efecto de la terapia de reemplazo enzimático con mejoras apreciables en un $25 \%$ de los casos. 


\begin{tabular}{|c|c|c|c|c|}
\hline Rango etario (años) & $32,16 \pm 19,66$ & $(10-77)$ & & \\
\hline Mujeres ( $n$ ) & 11 & & & \\
\hline Varones (n) & 13 & & & \\
\hline Esplenectomía previa (n) & 4 & & & \\
\hline \multicolumn{5}{|l|}{ Genotipo (n) } \\
\hline c. $1448 \mathrm{~T}>\mathrm{C}(\mathrm{L} 444 \mathrm{P}) / \mathrm{c} .1226 \mathrm{~A}>\mathrm{G}(\mathrm{N} 370 \mathrm{~S})$ & 2 & & & \\
\hline c. $1226 \mathrm{~A}>\mathrm{G} / \mathrm{c} .481 \mathrm{C}>\mathrm{T}$ & 1 & & & \\
\hline c. $1226 \mathrm{~A}>\mathrm{G} / \mathrm{RecNcil}$ & 4 & & & \\
\hline c. $245 C>T /$ unknown & 2 & & & \\
\hline c. $1226 \mathrm{~A}>\mathrm{G} / \mathrm{c} .1226 \mathrm{~A}>\mathrm{G}$ & 4 & & & \\
\hline RecNcil/c.1348T>A & 1 & & & \\
\hline c. $1226 \mathrm{~A}>\mathrm{G} / \mathrm{c} .703 \mathrm{~T}>\mathrm{C}$ & 1 & & & \\
\hline c. $1342 \mathrm{G}>\mathrm{C} / \mathrm{c} .1348 \mathrm{~T}>\mathrm{A}$ & 2 & & & \\
\hline RecNcil/c.1226A>G & 1 & & & \\
\hline RecNcil/c.1504C>T & 1 & & & \\
\hline TRE & Velaglucerasa & & Imiglucerasa & \\
\hline (n) & 5 & & 19 & \\
\hline Rango (años) & $10,79 \pm 5,89$ & $(1-20)$ & & \\
\hline Parámetros clínicos (\%) & Al diagnóstico & & Actual & \\
\hline Anemia & 70,83 & $(17 / 24)$ & 8,70 & $(2 / 23)$ \\
\hline Trombopenia & 62,50 & $(15 / 24)$ & 26,09 & $(6 / 23)$ \\
\hline Esplenomegalia & 94,44 & $(17 / 18)$ & 27,78 & $(5 / 18)$ \\
\hline Hepatomegalia & 91,30 & $(21 / 23)$ & 27,27 & $(6 / 22)$ \\
\hline Quitotriosidasa elevada & 80,00 & $(12 / 15)$ & 25,00 & $(4 / 16)$ \\
\hline Compromiso óseo & 79,17 & $(19 / 24)$ & 61,90 & $(13 / 21)$ \\
\hline \multicolumn{5}{|l|}{ Mejora en los parámetros (\%) } \\
\hline Anemia & 93,75 & $(15 / 16)$ & & \\
\hline Trombopenia & 64,28 & $(9 / 14)$ & & \\
\hline Esplenomegalia & 68,75 & $(11 / 16)$ & & \\
\hline Hepatomegalia & 70,00 & $(14 / 20)$ & & \\
\hline Quitotriosidasa elevada & 90,00 & $(9 / 10)$ & & \\
\hline Compromiso óseo & 25,00 & $(4 / 16)$ & & \\
\hline
\end{tabular}

Tabla 2 Resumen de datos demográficos y clínicos de los pacientes estudiados 


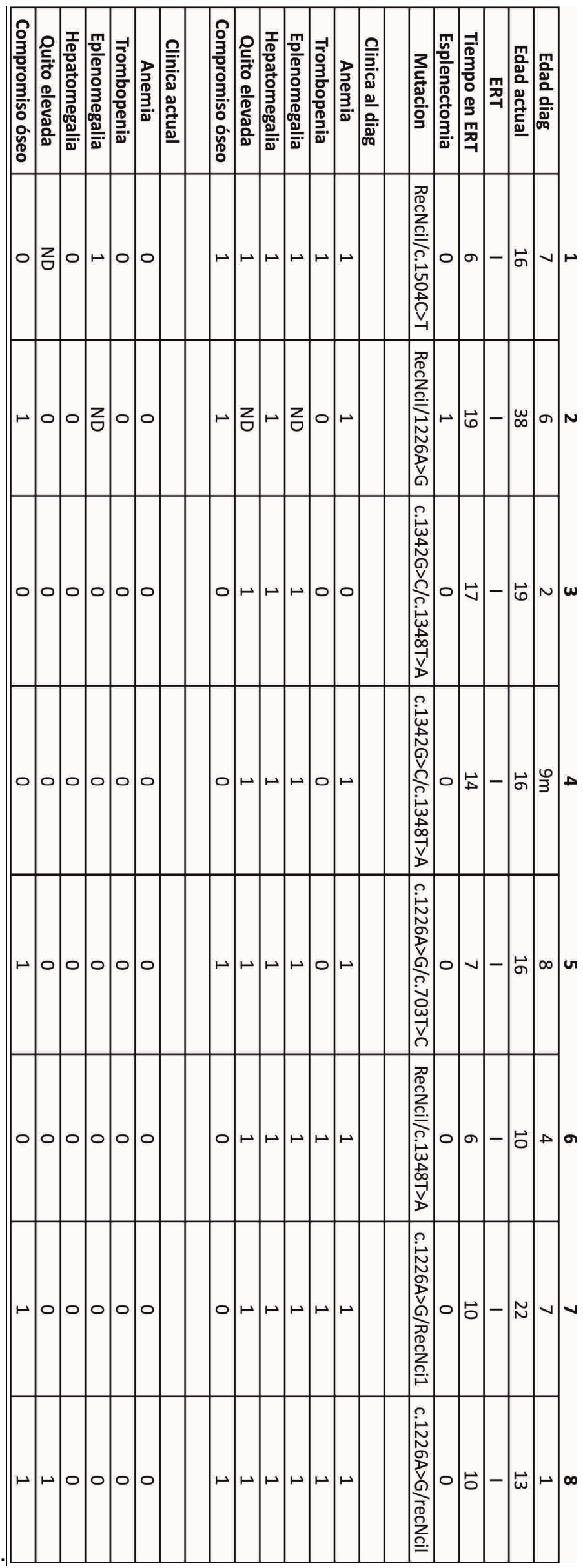




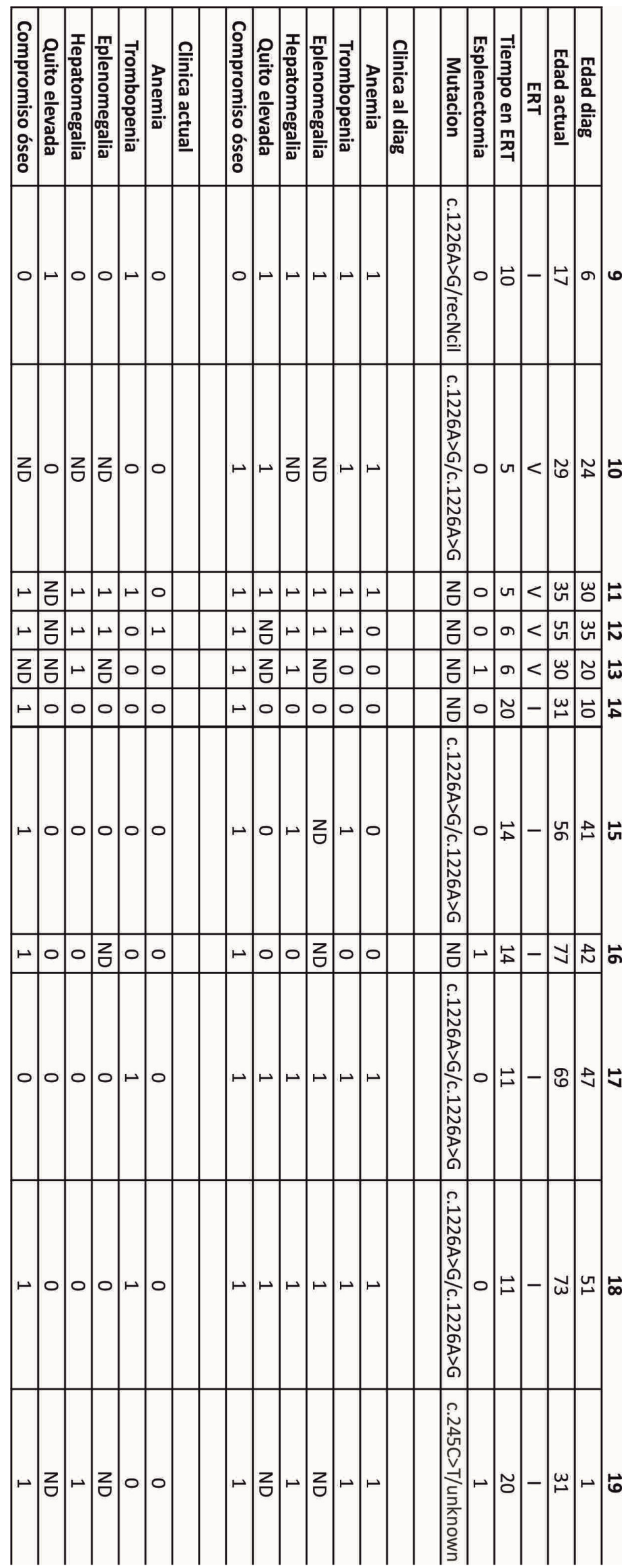




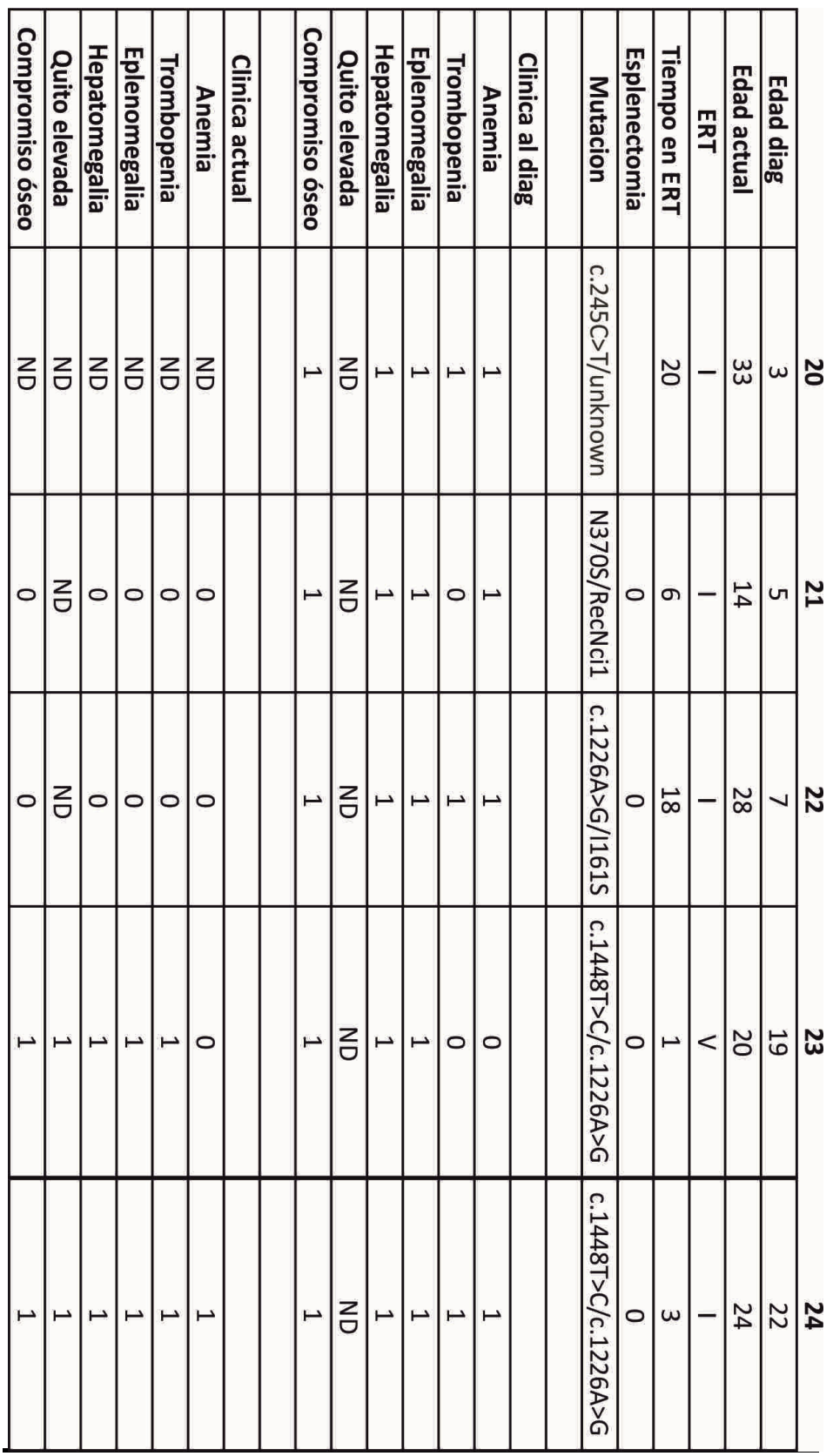

Tabla 3 Datos demográficos y clínicos de los pacientes estudiados. 1 y 0 significan presencia y ausencia del síntoma respectivamente. ND: no determinado 


\section{Perfíl inflamatorio de poblaciones en circulación de pacientes con EG}

Varios reportes han descripto aumentos en los niveles séricos de distintas moléculas involucradas en procesos inflamatorios en pacientes con enfermedad de Gaucher (Allen et al., 1997; Campeau et al., 2009a; Hollak et al., 1994; Pandey et al., 2013) como también alteraciones en las poblaciones y función de células en circulación (Braudeau et al., 2013; Burstein et al., 1987; Micheva et al., 2006; Pandey et al., 2013). Por otro lado es conocido el hecho de que la presencia de un estado inflamatorio crónico es una de las causas que lleva al aumento en la problemática ósea en enfermedades como artritis reumatoidea (Kotake et al., 1996; Mclnnes et al., 2007).

Las células del linaje monocito/macrófago son las más afectadas en la enfermedad de Gaucher (Guggenbuhl et al., 2008; Pandey et al., 2013), por lo tanto nos propusimos evaluar el estado de dos poblaciones de monocitos en PBMC de pacientes. Por un lado, las células CD14 ${ }^{+} \mathrm{CD} 16^{-}$las denominadas "monocitos clásicos" en base a su expresión de citoquinas pro y anti-inflamatorias (Ziegler-Heitbrock, 2007). Y por otro

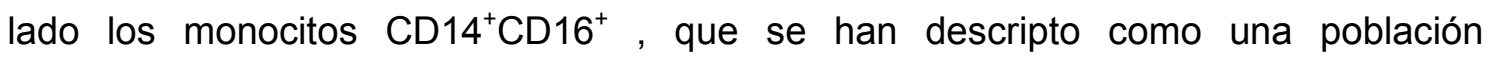
minoritaria dentro de los monocitos circulantes y potencialmente inflamatoria debido a su alta producción de citoquinas inflamatorias como TNF- $\alpha$, a la ausencia de producción de IL-10 y a una mayor capacidad de presentación antigénica junto con la expresión aumentada de moléculas presentadoras (Ziegler-Heitbrock, 2007).Esta población se incrementa en enfermedades inflamatorias crónicas (Kawanaka et al., 2002; Ramírez et al., 2011; Scherberich et al., 1999). Por lo tanto, se evaluaron ambas poblaciones en circulación de pacientes con enfermedad de Gaucher.

PBMC de pacientes y controles sanos fueron separadas mediante gradiente de ficoll Hypaque y se realizó la tinción de CD14 y CD16 utilizando anticuerpos específicos conjugados a distintos fluorocromos. Los resultados se analizaron mediante citometría de flujo.

Los pacientes presentaron menores niveles de monocitos CD14 ${ }^{+} \mathrm{CD} 16^{-}$(Fig. $14 \mathrm{~A}$ ), en cambio los monocitos $\mathrm{CD} 14^{+} \mathrm{CD} 16^{+}$se vieron significativamente aumentados hasta 4 veces con respecto a los controles sanos (Fig. 14 B). El incremento en esta población podría explicar, al menos en parte, el estado inflamatorio de los pacientes. 

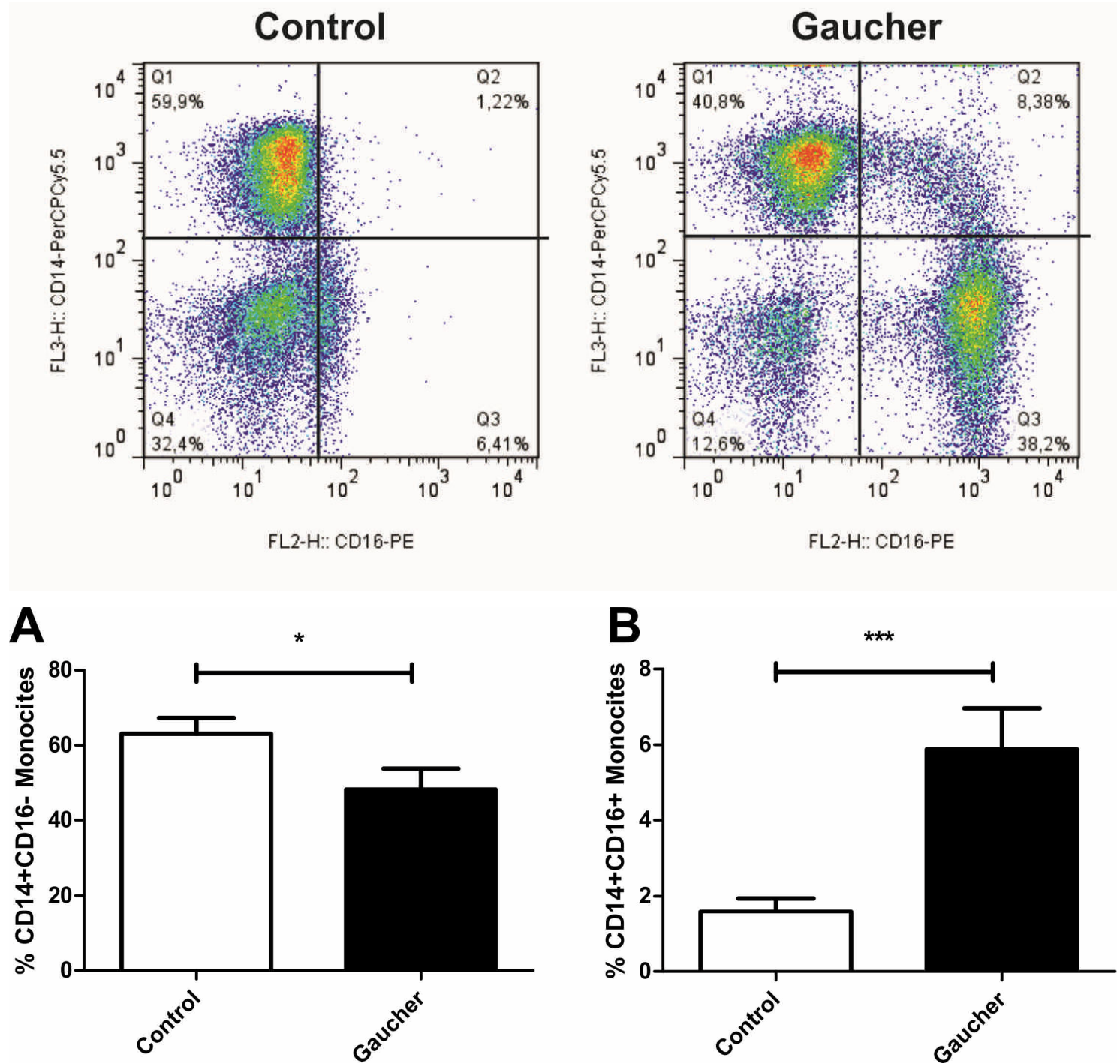

Fig. 14 Porcentaje de monocitos $\mathrm{CD} 14^{+} \mathrm{CD} 16^{-}(\mathrm{A})$ y $\mathrm{CD} 14^{+} \mathrm{CD} 16^{+}$(B) en PBMC de pacientes con enfermedad de Gaucher mediante citometría de flujo. ${ }^{*} \mathrm{p}<0,05 * * * \mathrm{p}<0,001$ test-t

Para continuar con el estudio de la participación de las distintas poblaciones circulantes en el estado inflamatorio crónico de los pacientes con enfermedad de Gaucher decidimos evaluar la producción de citoquinas inflamatorias en distintas poblaciones.

Para esto se realizó la marcación intracelular de las citoquinas IL-1 $\beta$, IL-6 y TNF- $\alpha$ utilizando anticuerpos específicos conjugados a fluorocromos, sobre las PBMC aisladas de pacientes y controles, junto con la marca de superficie para las moléculas CD3, CD14 y CD16, para evaluar linfocitos T y monocitos, y HLA-DR y LIN-1, para evaluar células dendríticas.

Los resultados se muestran en las figuras 15 y 16 como porcentaje de células positivas para cada citoquina o como aumento relativo de la intensidad de fluorescencia media para cada citoquina dentro de cada población. 
Para el caso de las células dendríticas pudo observarse un aumento en el número de células IL-6 positivas en las células de los pacientes respecto de los controles sanos, aunque el mismo no fue significativo (Fig. 15), mientras que los niveles de fluorescencia media no variaron para ninguna de las tres citoquinas (Fig. 16).

Los linfocitos $T$, en cambio, presentaron mayores niveles de producción para IL-6 y TNF- $\alpha$ (Fig. 16) mientras que el porcentaje de células para las tres citoquinas no se observó alterado (Fig. 15).

En el caso de los monocitos se diferenciaron las poblaciones $\operatorname{CD}_{14}^{+} \mathrm{CD}_{16}{ }^{+}$y CD14 ${ }^{+}$CD16- Para la población de monocitos $\mathrm{CD}^{-} 4^{+} \mathrm{CD} 16^{+}$se observaron niveles aumentados en el número de células positivas para IL-6 y TNF- $\alpha$ (Fig. 15) aunque esta diferencia no fue significativa. Mientras que no se presentaron diferencias en los niveles de fluorescencia media para ninguna de las citoquinas estudiadas (Fig. 16).

En el caso de los monocitos $C D 14^{+} \mathrm{CD} 16^{-}$se observó un aumento significativo en el porcentaje de monocitos que expresan IL-6 y TNF- $\alpha$ (Fig. 15), como también un aumento en los niveles de fluorescencia media para IL-6 (Fig. 16) aunque el mismo no llegó a ser significativo.

Estos resultados demostrarían la participación de los monocitos, linfocitos $\mathrm{T}$ y, en menor medida, las células dendríticas en la producción aumentada de citoquinas que había sido descripta en bibliografía en el suero de pacientes con enfermedad de Gaucher. 
IL-1 $\beta$
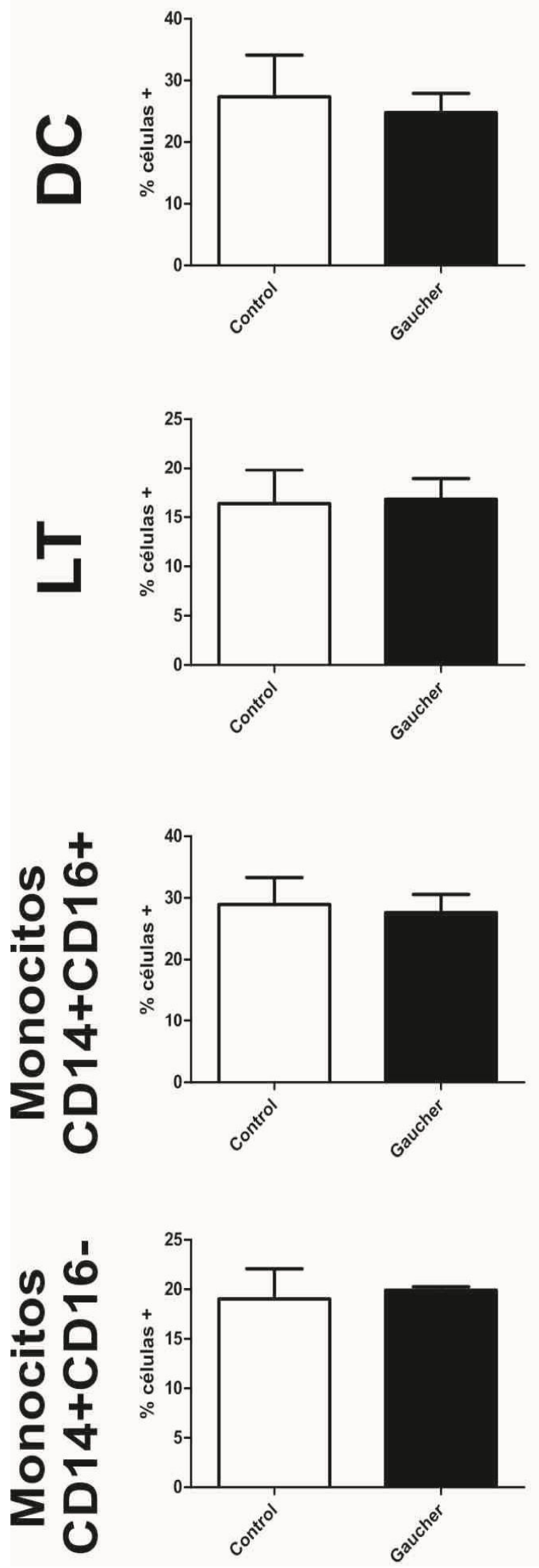

IL-6
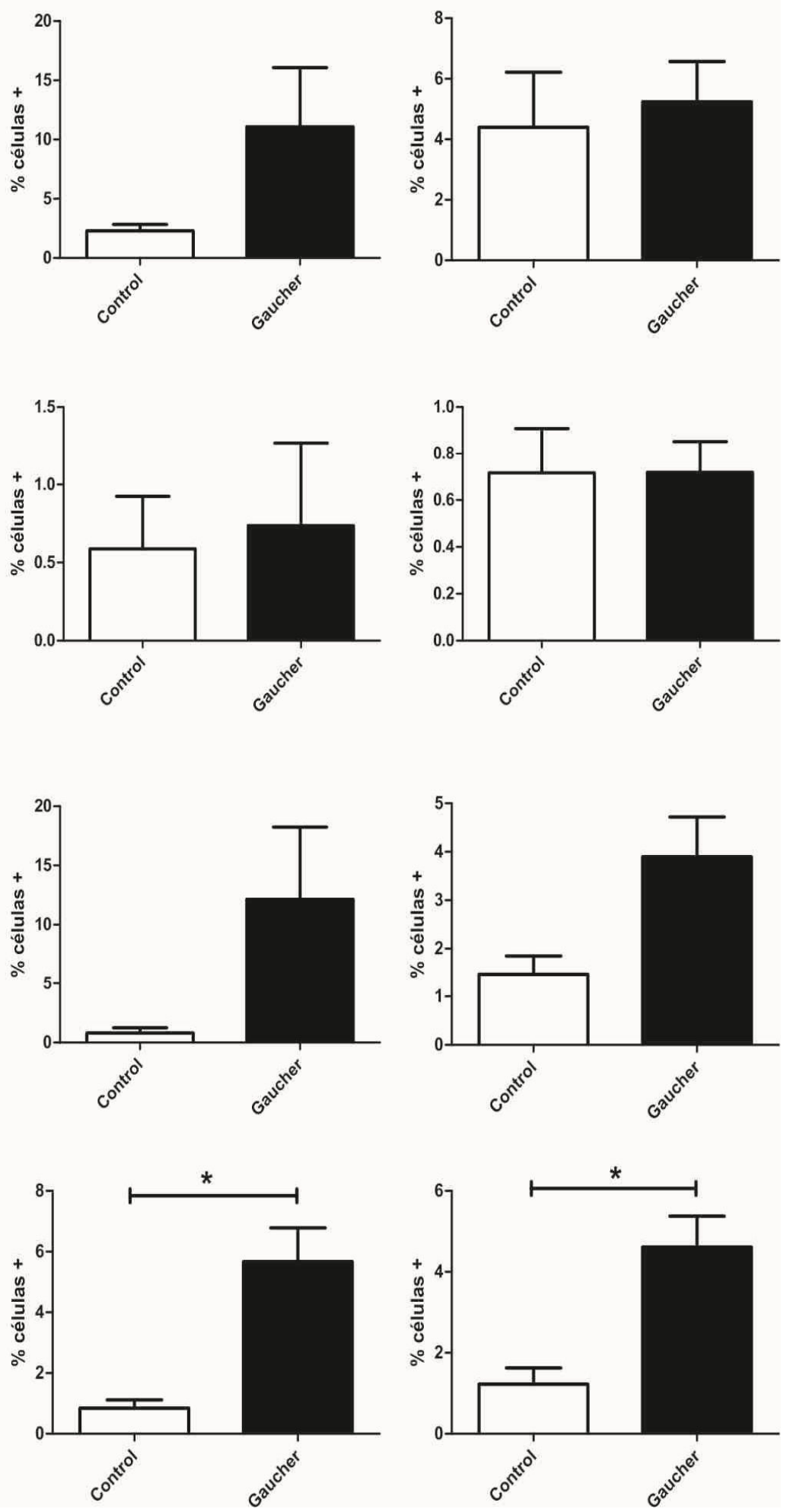

Fig.15 Porcentaje de células positivas para IL-1 $\beta$, IL-6 y TNF- $\alpha$ dentro de las distintas poblaciones determinado mediante citometría de flujo. $* \mathrm{p}<0,05$ test-t 
IL-1 $\beta$
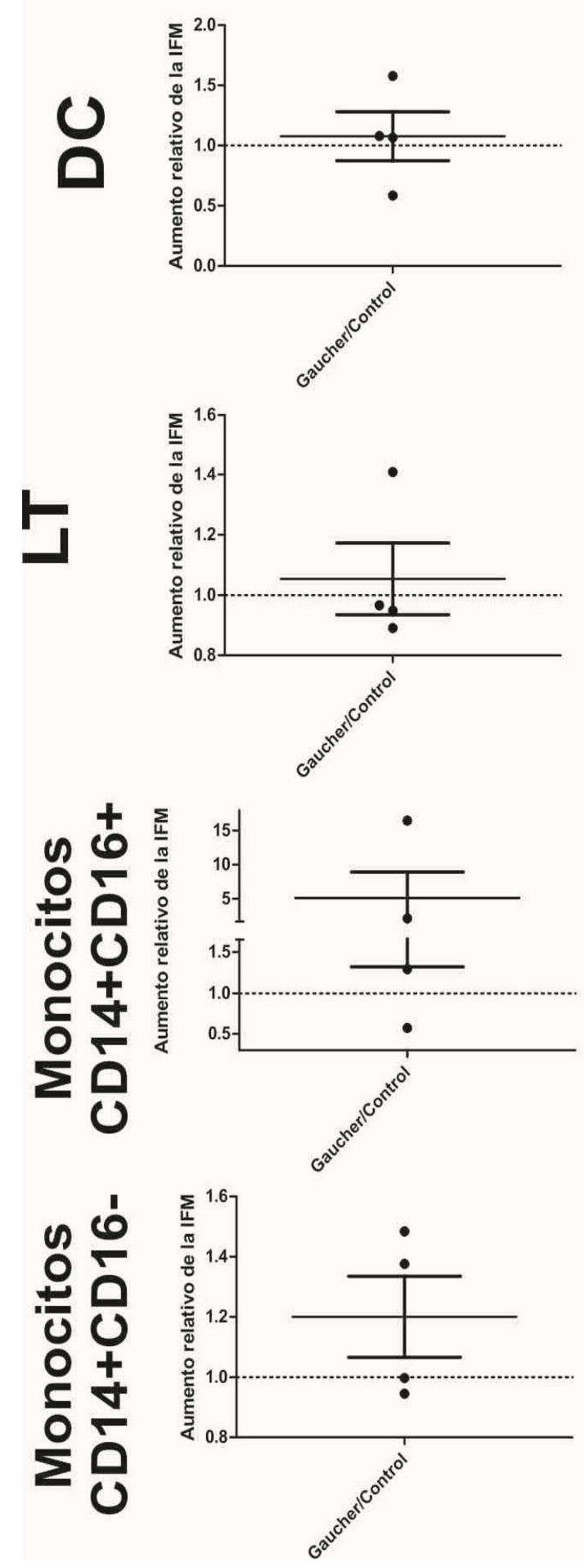

IL-6
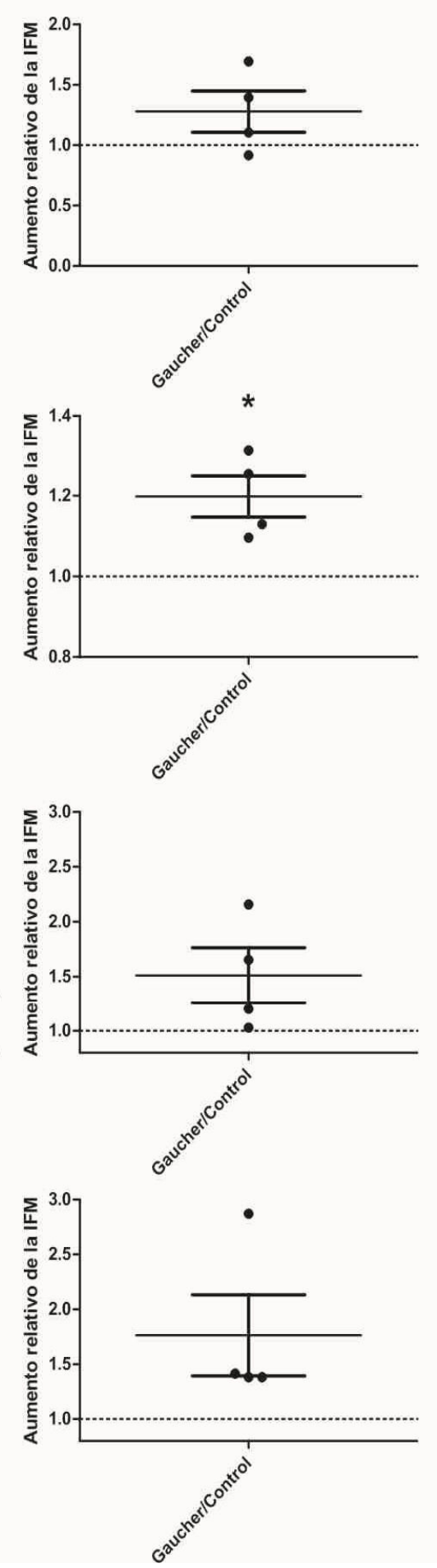
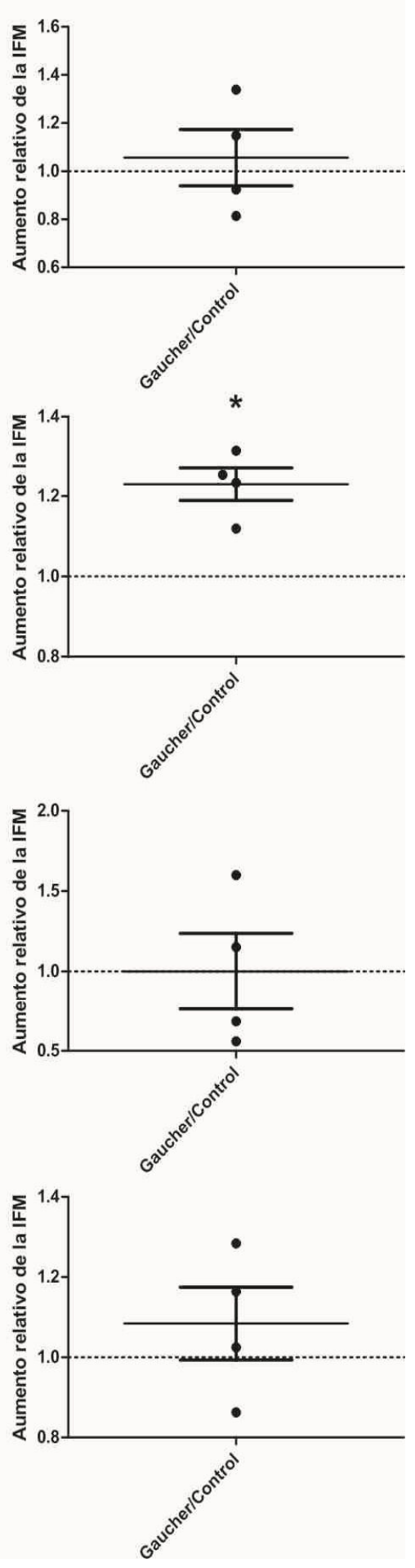

Fig. 16 Aumento relativo en la intensidad de fluorescencia media para las citoquinas IL-1 $\beta$, IL-6 y TNF- $\alpha$ dentro de las poblaciones determinadas. ${ }^{*} \mathrm{p}<0,05$ test $\mathrm{t}$ de una muestra. 
Como previamente demostramos que los LT participan en el proceso de inducción de osteoclastogénesis en nuestro modelo in vitro de enfermedad de Gaucher, decidimos evaluar la presencia de LT activados en PBMC de pacientes. Las células T activadas fueron evidenciadas como linfocitos $\mathrm{CD} 4^{+} \mathrm{CD} 25^{+}$mediante citometría de flujo.

El número de LT activados no mostró diferencias entre los entre pacientes con enfermedad de Gaucher y los controles sanos. (Fig. 17).
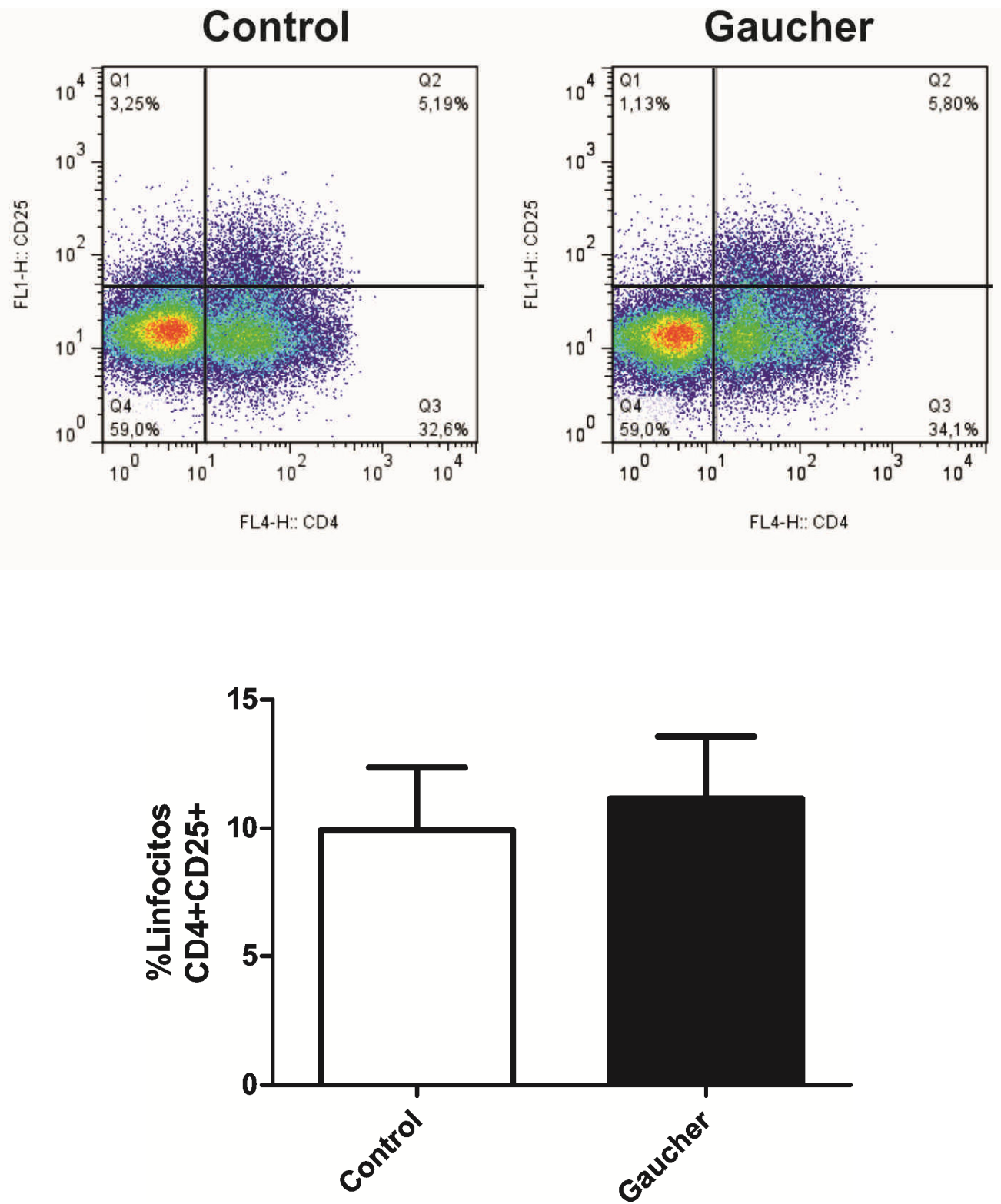

Fig. 17 Porcentaje de células T activadas definidas como CD4+CD25+ en circulación de pacientes con enfermedad de Gaucher

Por último nos propusimos evaluar los niveles de células $T$ regulatorias (Treg) en circulación de pacientes con enfermedad de Gaucher. Las células Treg son críticas para el mantenimiento de la tolerancia y homeostasis inmunológica contrarrestando los efectos inflamatorios generados por las células Th1/Th17 (Dingle et al., 2013; Lee et 
al., 2009). Por otro lado esta población celular se ha visto alterada en patologías que poseen un perfil inflamatorio (Arandi et al., 2014; van Leeuwen et al., 2013). Por último las células Treg han sido implicadas como inhibidoras del proceso de osteoclastogénesis (Zaiss et al., 2007). Por lo tanto nuestra hipótesis fue que la población de células Treg podría estar alterada en la enfermedad de Gaucher debido, por un lado a la acumulación de glucosilceramida en sí, o como un mecanismo fisiológico de respuesta ante el estado inflamatorio crónico presente en los pacientesA partir de PBMC de pacientes y controles se realizó la marca de superficie para las moléculas CD4 y CD25, y la marca intracitoplasmática del factor de transcripción Foxp3, el cual es clave en la generación de Tregs. En la figura 18 puede observarse que tanto el porcentaje de células Treg (Fig.18 A), definidas como CD4 ${ }^{+} \mathrm{CD} 25^{+} \mathrm{Foxp}^{+}$, como la intensidad de fluorescencia media para Foxp3 (Fig. 18 B), medida en linfocitos $\mathrm{CD} 4^{+} \mathrm{CD} 25^{+}$, no se presentaron alterados en los pacientes con respecto a los controles sanos.

Por lo tanto, las células Treg parecerían no desempeñar un papel en el estado inflamatorio en pacientes con enfermedad de Gaucher.

Control

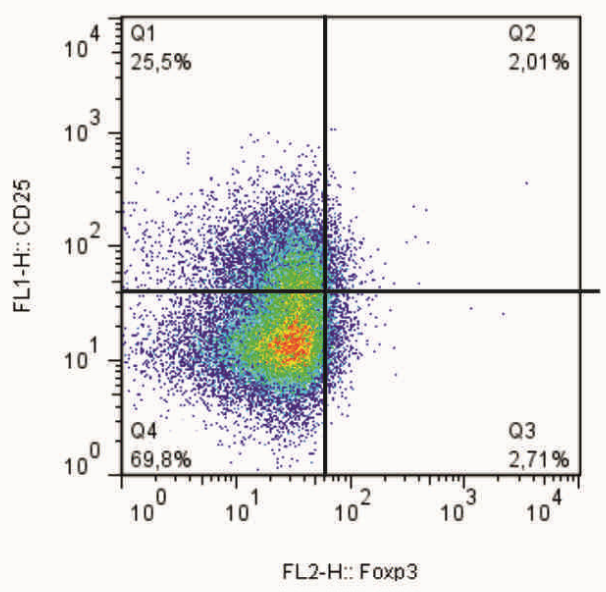

Gaucher

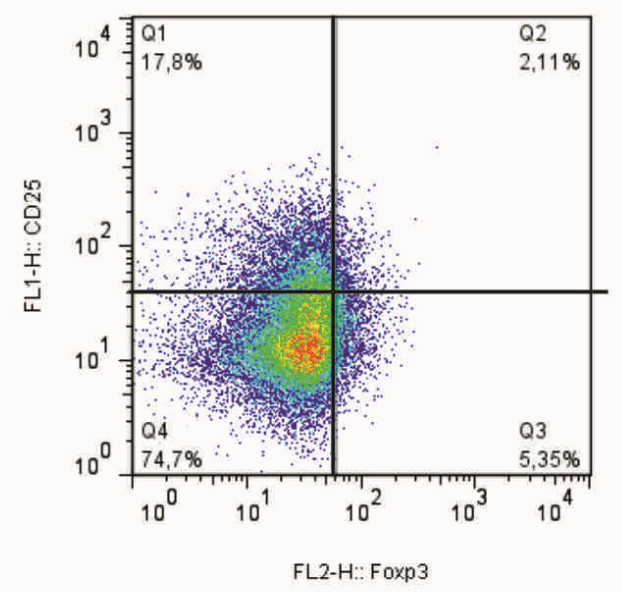

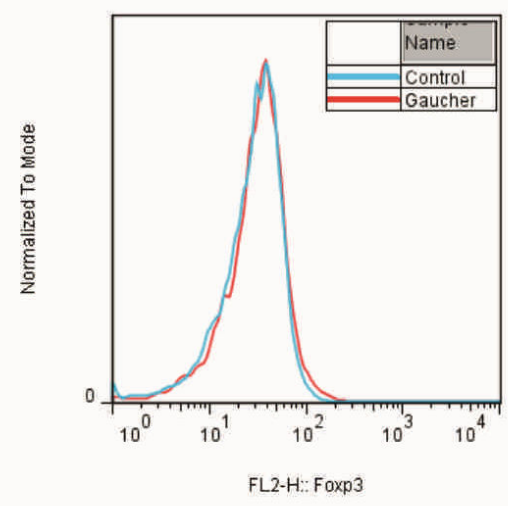



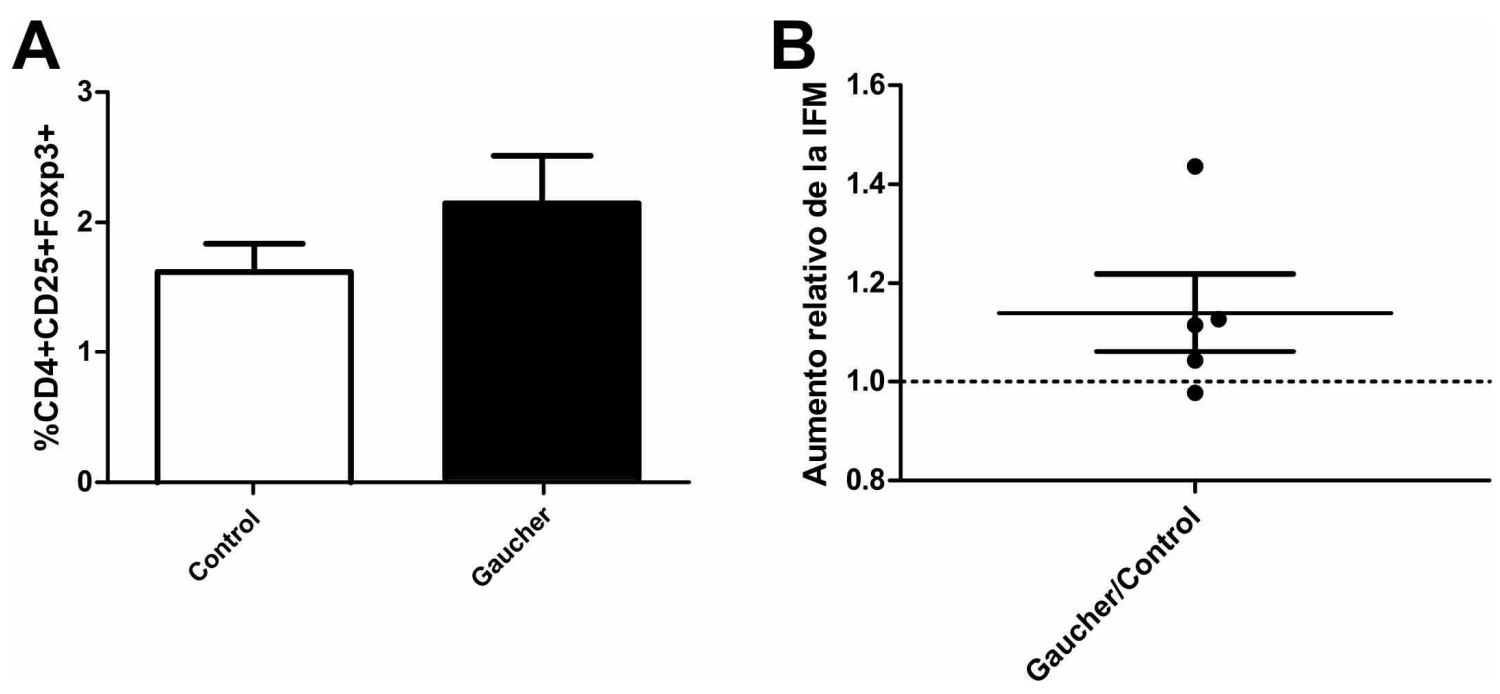

Fig. 18 Porcentaje de células Treg (A) y aumento relativo de la fluorescencia media para Foxp3 en linfocitos $\mathrm{CD} 4^{+} \mathrm{CD} 25^{+}(\mathbf{B})$ en PBMC de pacientes con enfermedad de Gaucher

\section{Niveles de precursores de osteoclastos en circulación de pacientes con enfermedad de Gaucher}

En condiciones fisiológicas los precursores de osteoclastos generados en la médula ósea migran hacia la sangre para luego retornar al hueso donde completan su diferenciación para cumplir su función de resorción (Ishii et al., 2010).

La pérdida de hueso, se ha correlacionado con un aumento en el número de precursores de osteoclastos en circulación en varias enfermedades, como fenilcetonuria, osteoporosis postmenopáusica y metástasis ósea de cáncer de próstata (Roato et al., 2008, 2010).

Las principales citoquinas que participan en la regulación de la diferenciación y función de osteoclastos son: M-CSF, el cual induce la proliferación y diferenciación de los precursores de osteoclastos; RANKL, el cual promueve la actividad y diferenciación de osteoclastos a partir de sus precursores (Eghbali-Fatourechi et al., 2003); y la osteoprotegerina (OPG) la cual funciona como un receptor soluble señuelo para RAKNL (Grundt et al., 2009).

Por lo tanto nos propusimos evaluar la presencia de precursores en circulación de pacientes con enfermedad de Gaucher. Mediante citometría de flujo (FACS). Se utilizaron anticuerpos anti-CD14, -CD16 y -CD51, definiéndose a las células $\mathrm{CD} 14^{+} \mathrm{CD} 16^{+} \mathrm{CD} 51^{+}$como precursores de osteoclastos (Roato et al., 2010). En el dot plot y el histograma que se muestran en la figura 19 se realizó una estrategia de selección de poblaciones sobre la población de monocitos CD14 ${ }^{+}$. 
Control

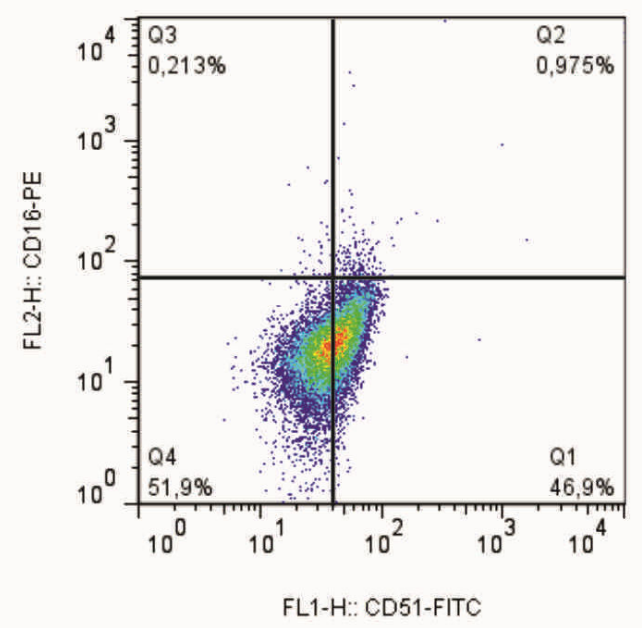

A

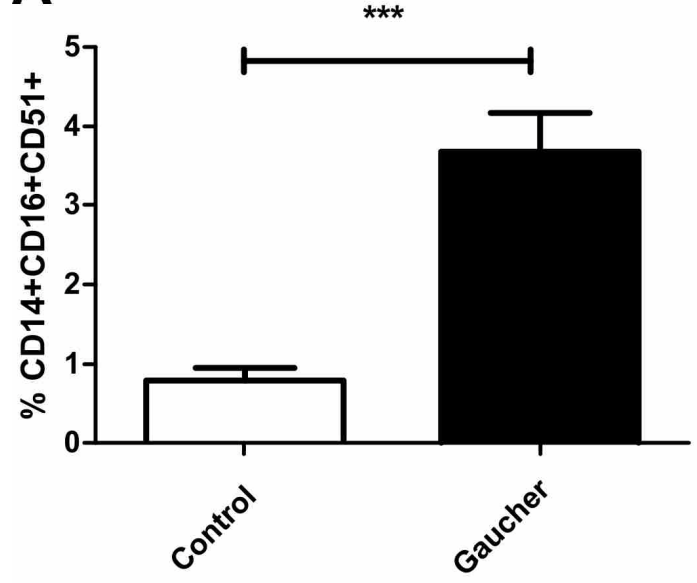

Gaucher

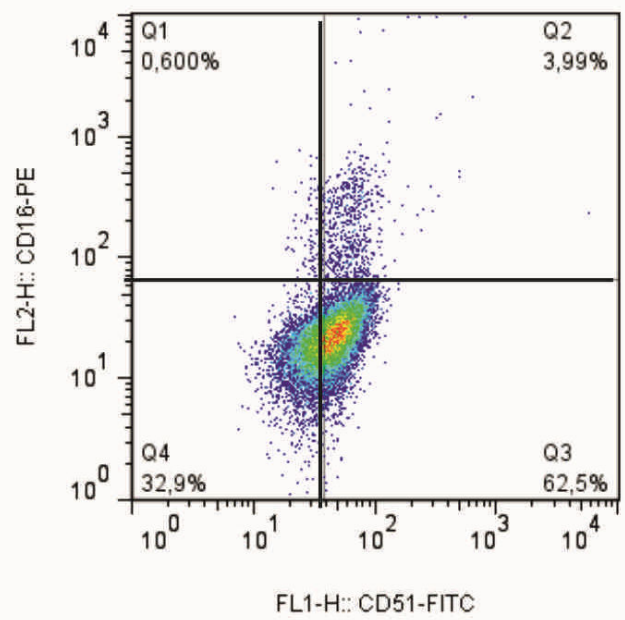

B

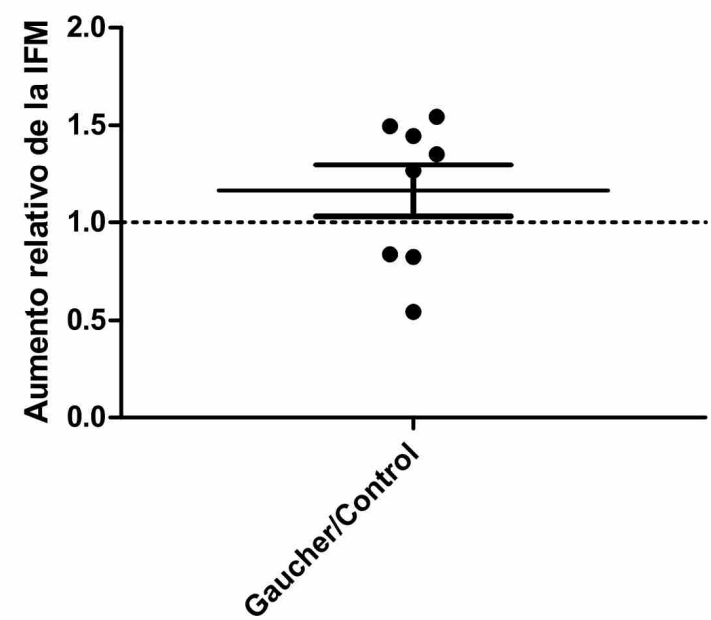

Fig.19 Precursores de osteoclastos definidos como células $\mathrm{CD} 14^{+} \mathrm{CD} 16^{+} \mathrm{CD} 51^{+}(\mathrm{A})$ en circulación de pacientes con enfermedad de Gaucher y medida de la intensidad relativa de CD51 en superficie (B). ${ }^{* * *}$ p $<0,001$ test-t

Como se observa en la Fig. 19 los pacientes tienen un porcentaje significativamente mayor de células $\mathrm{CD} 16^{+} \mathrm{CD} 14^{+} \mathrm{CD} 51^{+}$que los controles sanos. Por lo tanto los pacientes con enfermedad de Gaucher presentan un mayor número de precursores de osteoclastos en circulación con respecto a los controles sanos.

\section{Medida de niveles de marcadores involucrados en la osteoclastogénesis en pacientes con enfermedad de Gaucher}

Para continuar con la caracterización del potencial osteoclastogénico en PBMC de pacientes, realizamos la medida de distintos marcadores relacionados, directa 0 indirectamente, con el proceso de diferenciación de osteoclastos mediante PCR en tiempo real. 
Se midieron los niveles de los RNA mensajero codificantes para moléculas directamente relacionadas con la diferenciación de osteoclastos RANK, RANKL, OPG y catepsina K (CtsK). Los resultados de estas medidas se muestran en la figura 20. Los niveles de RNA mensajero de RANK, RANKL y CtsK se vieron aumentados en algunos pacientes con respecto a los controles sanos, aunque la variabilidad dentro del grupo de pacientes es muy grande presentándose valores por debajo de los controles. Para OPG no se presentaron niveles detectables (datos no mostrados).

Se midieron también los niveles de los mRNA codificantes para las citoquinas proinflamatorias IL-1 $\alpha$, IL-1 $\beta$, TNF- $\alpha$, IL- 6 y de la quemoquina atractante de monocitos CCL2. No se presentaron diferencias significativas (Fig.20).

Por último se realizó la medida de los niveles de expresión de NLRP3 presentándose significativamente aumentados $(p=0,017)$ (Fig.20). NLRP3 es una molécula relacionada con la maquinaria proinflamatoria conocida como el inflamasoma, la cual ha demostrado estar involucrada en diferentes procesos inflamatorios que no involucran patógenos, conocidos como "inflamación estéril". La posible importancia de este proceso en la enfermedad de Gaucher se discute más adelante. 


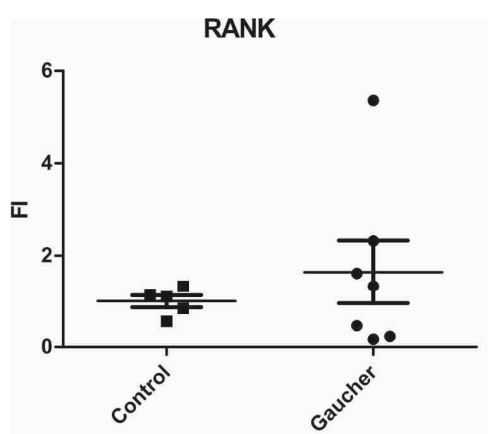

IL-1 $\alpha$

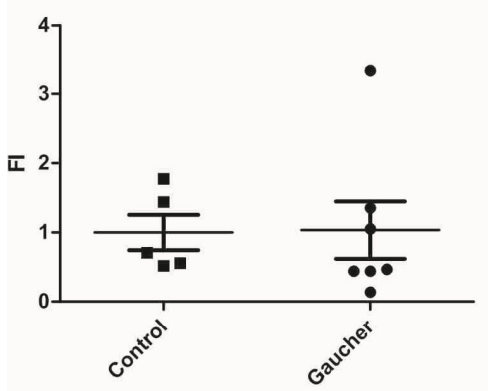

TNF- $\alpha$

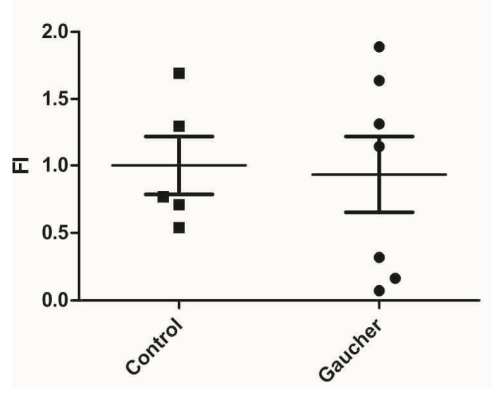

RANKL

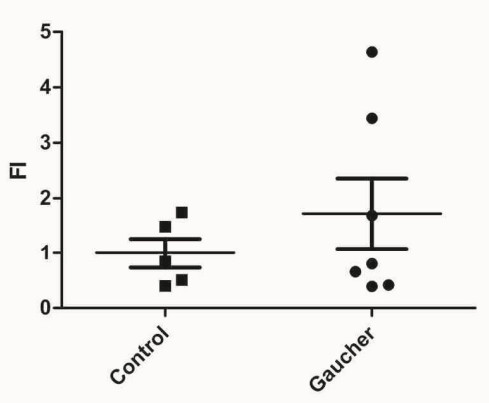

IL-1 $\beta$

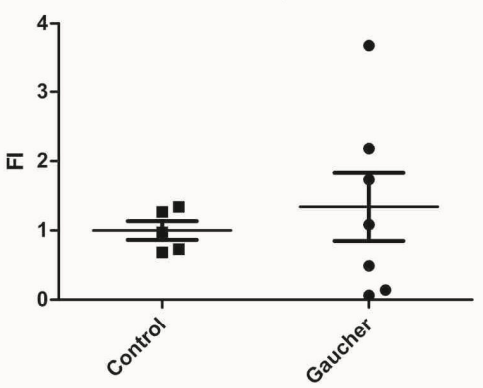

CCL2

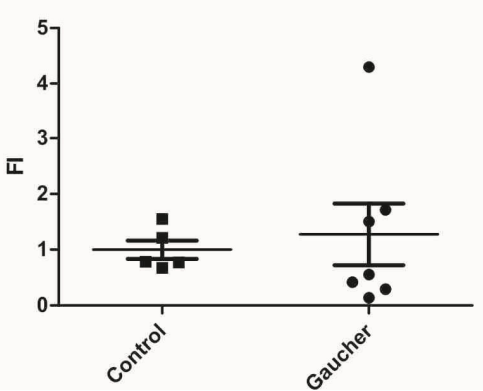

CtsK

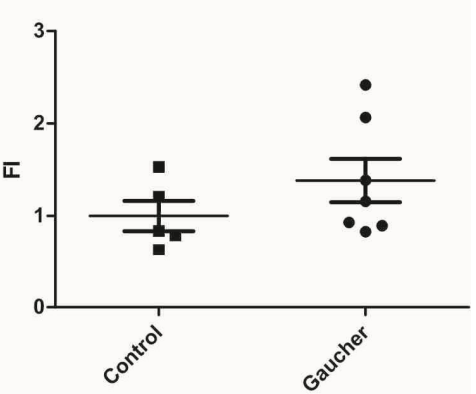

IL-6

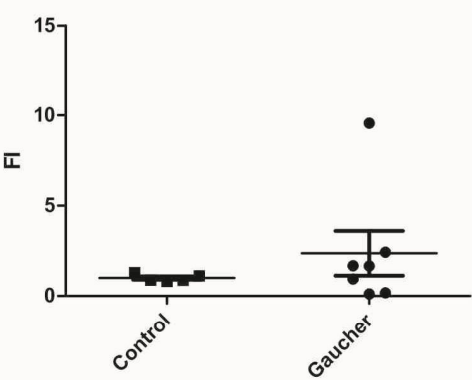

NLRP3

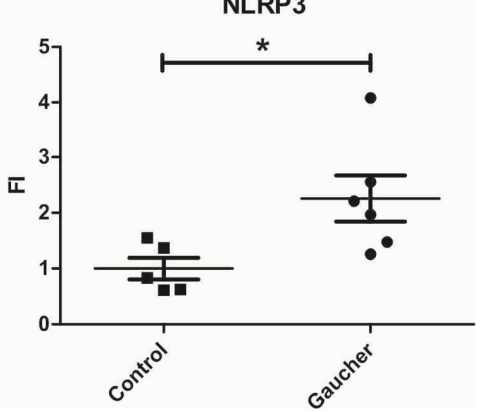

Fig.20 Niveles de RNA mensajero en PBMC de pacientes normalizado con respecto a los controles mediante PCR en tiempo real. ${ }^{*} \mathrm{p}<0,05$ test t.

\section{Presencia de RANKL en células en circulación}

Como mencionamos el hueso se encuentra en un equilibrio dinámico regulado principalmente por el eje RANK/RANKL/OPG. La molécula RANKL es la responsable, junto con el M-CSF, de la inducción de la osteoclastogénesis. Esta molécula puede expresarse en la superficie de osteoblastos, pero también sobre otros tipos celulares presentes en circulación, principalmente linfocitos $T$ y $B$, y células dendríticas (Lorenzo et al., 2008). Por lo tanto decidimos investigar los niveles de expresión de RANKL sobre estos tipos celulares circulantes en pacientes con enfermedad de Gaucher, mediante citometría de flujo.

Los pacientes presentaron niveles elevados de RANKL en la superficie de LT, mientras que para los LB y DC no se observaron diferencias (Fig. 21). 

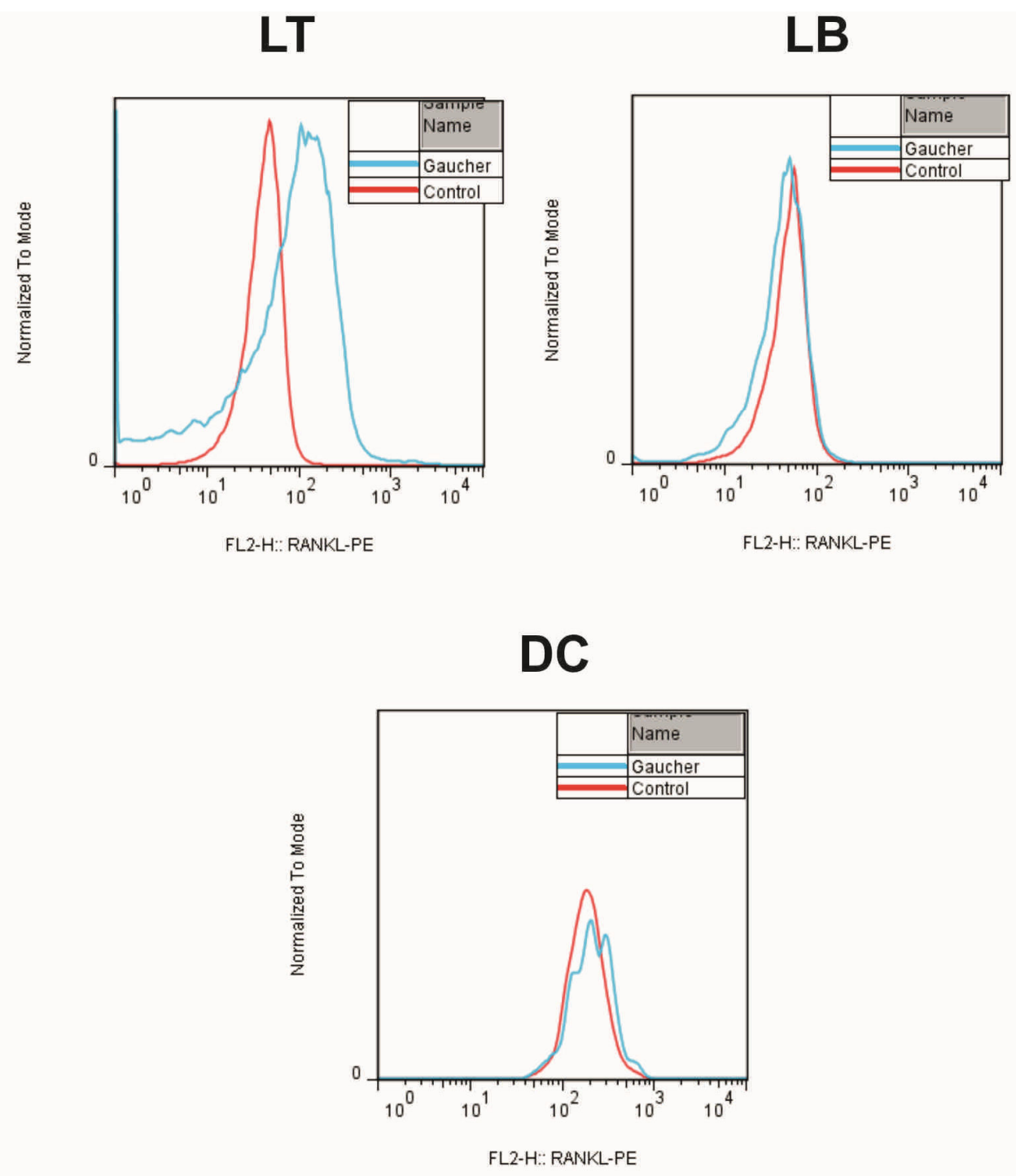
LT

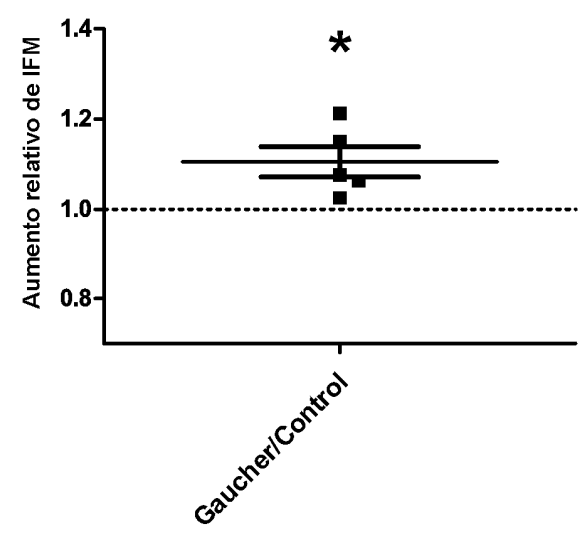

LB

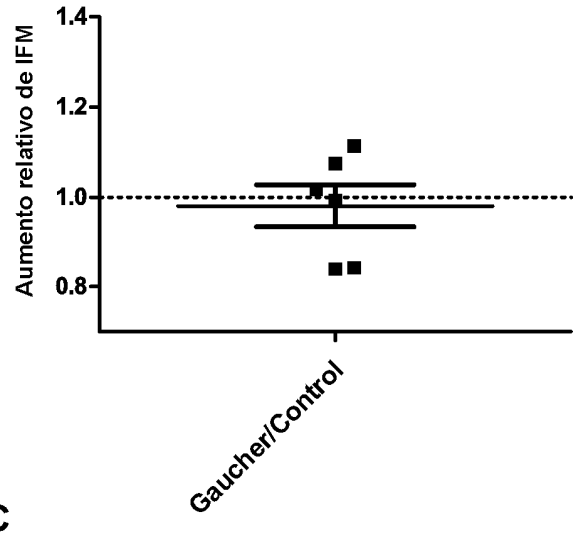

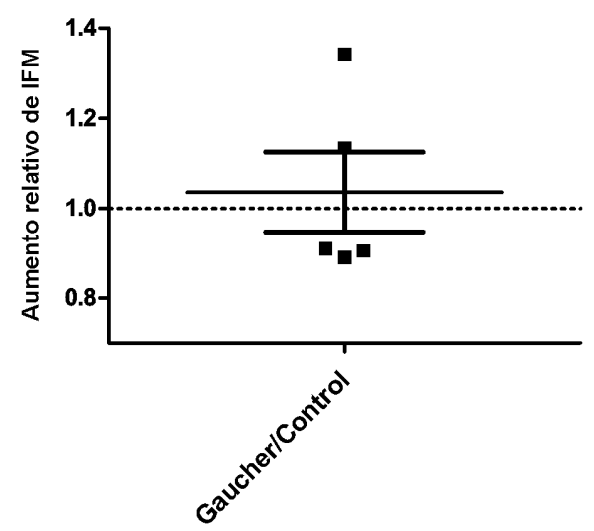

Fig.21 Niveles de RANKL en la superficie de LT, LB y DC. Se muestran los gráficos como una relación entre los niveles de intensidad de fluorescencia media (IFM) para los pacientes y sus respectivos controles. ${ }^{\mathrm{p}} \mathrm{p}<0,05$ test $\mathrm{t}$ de una muestra.

\section{Diferenciación de precursores obtenidos de circulación}

Hemos mostrado que los pacientes con Enfermedad de Gaucher presentaban un mayor porcentaje de precursores de osteoclastos en circulación. Para determinar si estos precursores podían diferenciarse a osteoclastos maduros y activos realizamos experimentos de osteoclastogénesis y resorción cultivando PBMC de pacientes en presencia de M-CSF.
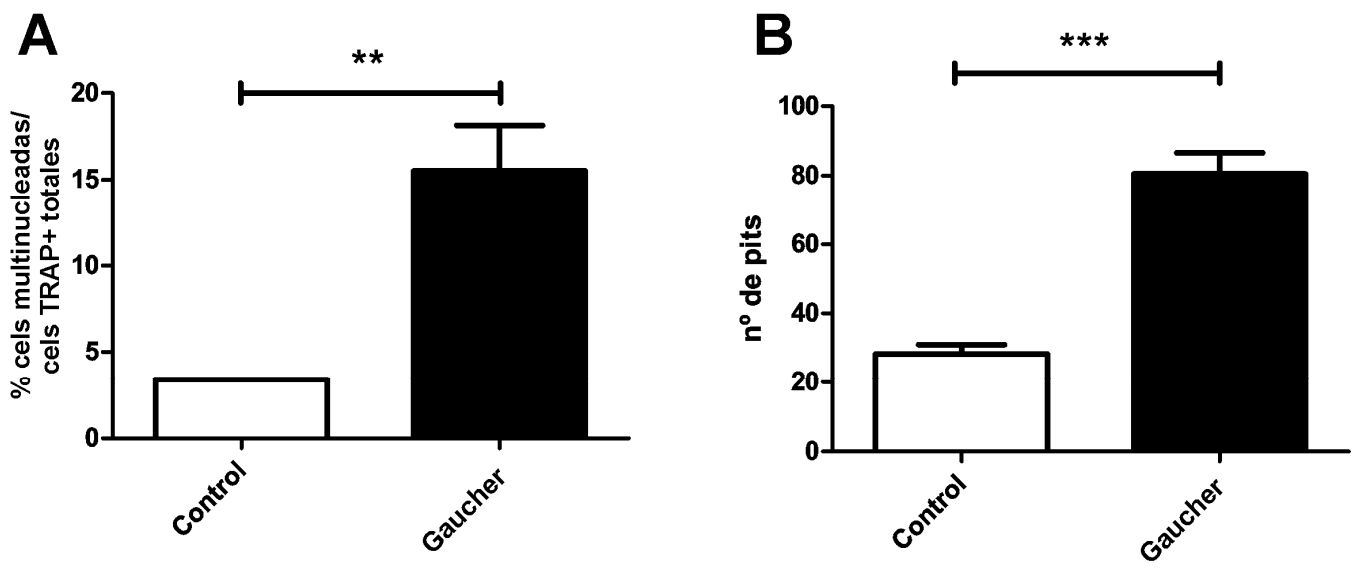

Fig.22 Osteoclastogénesis (A) y actividad de resorción (B) de PBMCs de pacientes y controles estimulados con MCSF. $* * \mathrm{p}<0,01 * * * \mathrm{p}<0,001$ test $\mathrm{t}$. 
En la figura 22 podemos observar que tanto el número de osteoclastos $(A)$ como su actividad de resorción (B) fueron estadísticamente mayores en el caso de las PBMC de pacientes estimuladas con M-CSF. Esto indicaría que los pacientes presentan en circulación células con una mayor tendencia a la diferenciación a osteoclastos.

\section{Osteoclastogénesis mediada por moléculas solubles}

Nos propusimos evaluar la posible secreción de mediadores secretados por PBMC que pudieran generar la diferenciación de osteoclastos. Para ello se cultivaron las PBMC de pacientes y controles durante tres días en un medio completo luego de los cuales se reservó el sobrenadante para los análisis posteriores.

La medida de citoquinas proinflamatorias fue realizada en los sobrenadantes de cultivo de pacientes y controles mediante ELISA (Fig. 23).
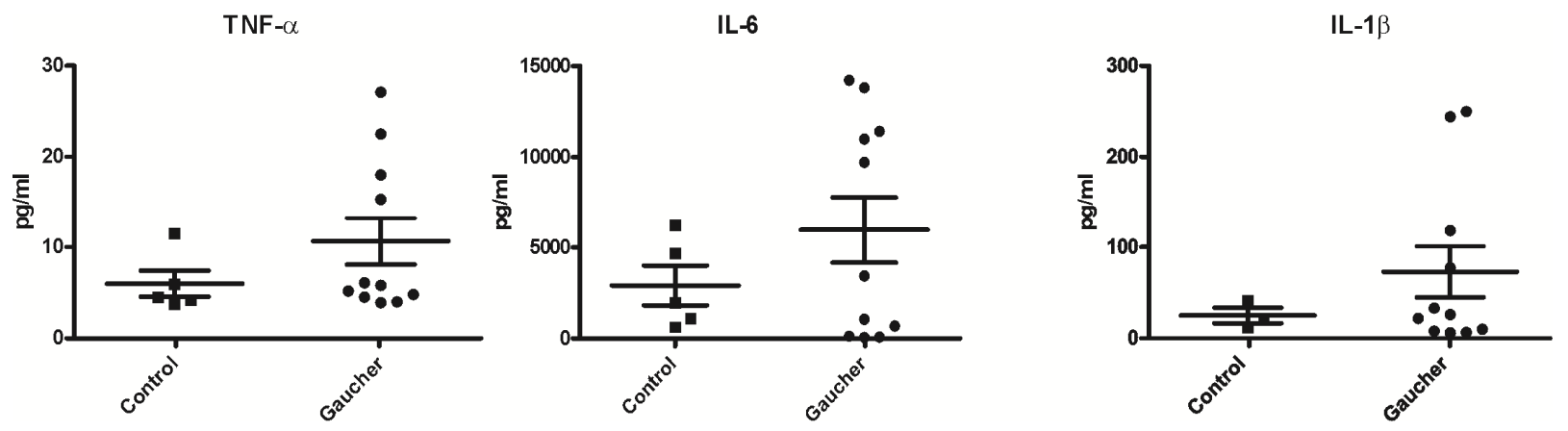

Fig.23 Niveles de citoquinas mediante ELISA.test $\mathrm{t}$.

Aunque se observó una tendencia al aumento en los niveles de las tres citoquinas analizadas para los sobrenadantes de cultivo de PBMC de pacientes, esta diferencia no fue significativa.

Para continuar con los estudios de osteoclastogénesis mediada por moléculas solubles se realizaron los experimentos de diferenciación de osteoclastos y de actividad de resorción estimulando precursores provenientes de THP-1 con sobrenadantes provenientes de pacientes Gaucher o controles en presencia de MCSF. Se evaluó el papel de TNF- $\alpha$ en el proceso de diferenciación utilizando un anticuerpo neutralizante. Por otro lado, el mismo experimento se llevó a cabo en presencia de OPG, el receptor soluble señuelo de RANKL para neutralizar específicamente el RANKL que podría encontrarse en los sobrenadantes de cultivo. 

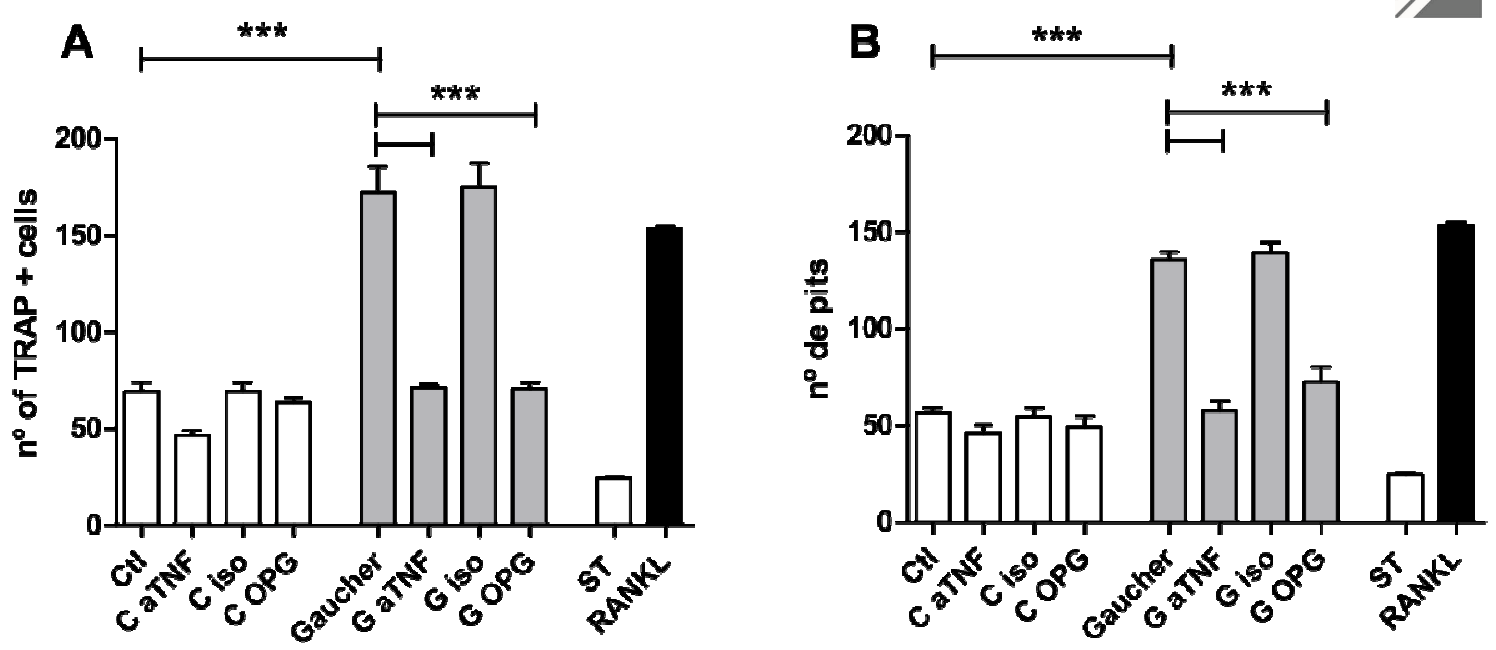

Fig.24 Osteoclastogénesis (A) y actividad de resorción (B) inducidos por tratamiento de precursores con sobrenadantes de PBMC de pacientes Gaucher (G) y sobrenadantes de PBMC de individuos control (C). Los mismos experimentos se realizaron en presencia de un anticuerpo neutralizante para TNF- $\alpha$ o un control de isotipo (iso) y en presencia de OPG recombinante. Como control positivo se trataron los precursores con RANKL recombinante y como control negativo con medio mínimo (ST). ${ }^{* * *}<<0,001$ ANOVA de una vía.

El tratamiento de precursores con sobrenadante de cultivo de células de pacientes indujo un número significativamente mayor de células multinucleadas TRAP positivas (Fig. 24 A) como también un aumento en la actividad de resorción de las mismas (Fig. $24 \mathrm{~B}$ ). Por otra parte la adición del anticuerpo neutralizante del TNF- $\alpha$ (pero no su control de isotipo) produjo una disminución de la inducción de osteoclastos y de su actividad, en el caso del tratamiento con sobrenadante Gaucher, a niveles comparables con los de los controles. El agregado de OPG tuvo el mismo efecto generando una disminución igualmente significativa (Fig. 24 A y B). El agregado de las dos moléculas neutralizantes juntas no mostró un efecto mayor que el presente para cada molécula por separado (datos no mostrados).

\section{Efecto del tratamiento in vitro con Velaglucerasa (rhGCasa) sobre la osteoclastogénesis en pacientes}

Actualmente se dispone de tres productos comerciales para la terapia de reemplazo enzimático aplicada a pacientes con enfermedad de Gaucher: Cerezyme (Genzyme Corporation, Cambridge, USA), Velaglucerase (VPRIV) (Shire, Lexington, USA) y taliglucerasa alfa (Protalix BioTherapeutics, Israel) (Aviezer et al., 2009; Barton et al., 1991; Pastores et al., 2007). La enzima ingresa a las células y es transportada a los lisosomas para degradar el sustrato acumulado. Por otro lado la terapia por vía oral de reducción de sustrato (Miglustat, Actelion Pharmaceuticals, Switzerland) se basa en la inhibición de una enzima clave que participa en la biosíntesis de glucosilceramida (Heitner et al., 2002). 
La aplicación de terapia de reemplazo enzimático y terapia de reducción de sustrato en pacientes Gaucher son efectivas frente a la reducción en el número de macrófagos que infiltran la médula ósea y el hígado, revierten las citopenias (anemia y trombopenia), reducen los episodios de osteonecrosis y mejoran la mineralización ósea (Pastores et al., 2007; Sims et al., 2008; Weinreb et al., 2002). Sin embargo, las manifestaciones relacionadas a la injuria ósea no son totalmente eliminadas (Sims et al., 2008).

Por esta razón decidimos evaluar el efecto del tratamiento con rhGCasa sobre la inducción de osteoclastogénesis de los precursores de osteoclastos en circulación. Para esto realizamos el agregado de rhGCasa durante los ensayos de osteoclastogénesis y medida de resorción. Agregamos en este ensayo el tratamiento con RANKL recombinante para evaluar si éste producía una inducción mayor a la ya observada con M-CSF, ya que el RANKL es uno de los principales inductores en el proceso de diferenciación de osteoclastos y, como demostramos en esta sección, su neutralización en los experimentos de osteoclastogénesis inducida por sobrenadantes de PBMC de pacientes, reduce los niveles de diferenciación y actividad de osteoclastos (Fig. 24)

Como puede observarse en los resultados mostrados en la figura 25 , la presencia de RANKL además de M-CSF en el cultivo, induce un mayor número de osteoclastos metabólicamente activos con respecto al inducido con M-CSF solo. Por otro lado la incubación con rhGCasa redujo significativamente el número de osteoclastos por parte de las células de pacientes prácticamente a los niveles observados para los controles tanto en el caso del tratamiento con M-CSF como con M-CSF+RANKL.
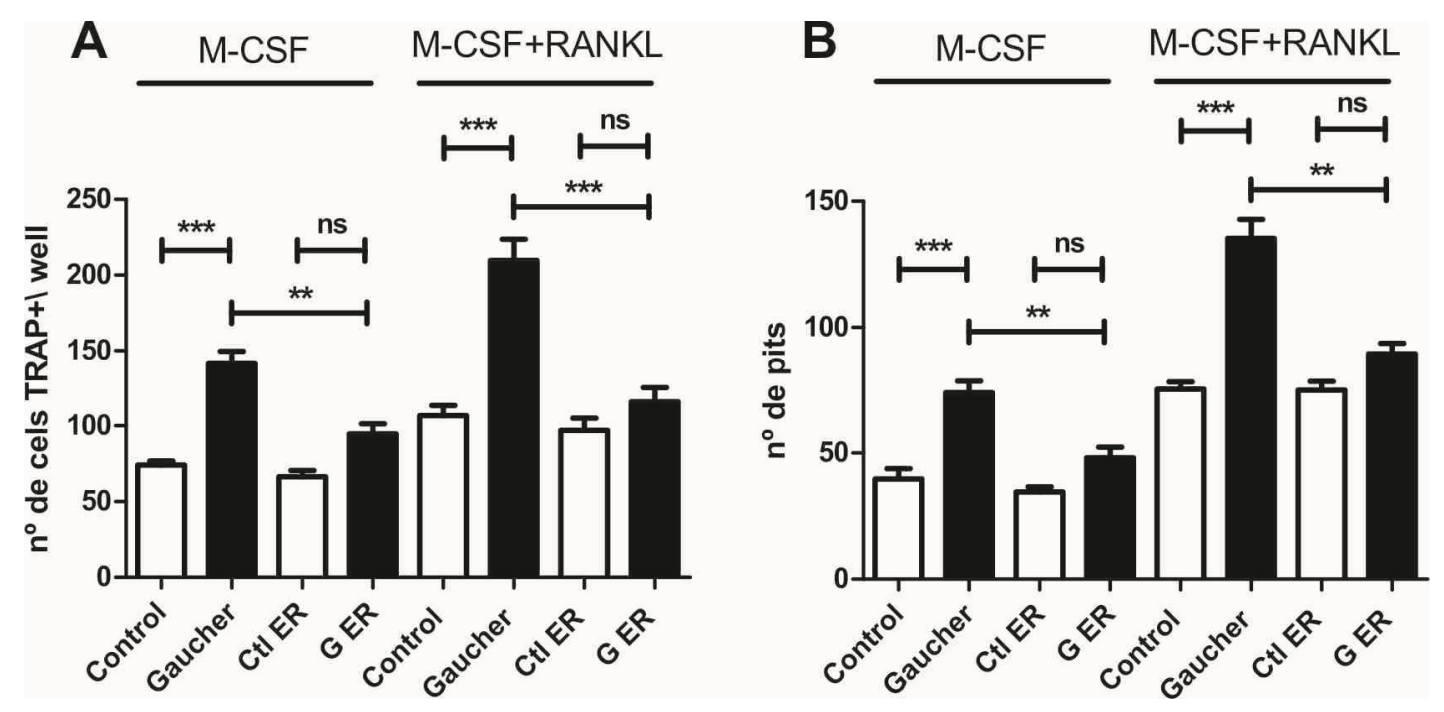

Fig.25 Osteoclastogénesis (A) y actividad de resorción (B) inducidos pos tratamiento de PBMCs de pacientes y controles con M-CSF o M-CSF y RANKL en presencia o ausencia de rhGCasa (ER). ${ }^{* *} \mathrm{p}<0,01 * * * \mathrm{p}<0,001$ ANOVA de una vía. 
Por lo tanto la utilización de rhGCasa inhibiría la diferenciación de osteoclastos a partir de sus precursores en circulación de pacientes con enfermedad de Gaucher. Por lo tanto, las mejoras observadas en el daño óseo en aquellos pacientes que recibieron tratamiento con rhGCasa, podrían deberse en parte a la inhibición de la diferenciación a osteoclastos a partir de sus precursores.

\section{Discusión y conclusiones}

En estudios realizados en células de pacientes Gaucher, se detectó el aumento en la expresión de marcadores fenotípicos de resorción ósea mediada por osteoclastos tales como Catepsina $\mathrm{K}$ en suero de pacientes (Moran et al., 2000) o el RNA mensajero de TRAP en células mesenquimales de médula ósea de pacientes (Campeau et al., 2009a). Se demostró, además, un aumento en la expresión génica en células mesenquimales de la metaloproteasa de matriz MMP-2, que está involucrada en procesos de daño óseo por destrucción de la matriz extracelular (Campeau et al., 2009). La expresión de la quemoquina CCL2 (o MCP-1) está elevada y podría producir alteraciones óseas indirectamente al atraer monocitos al hueso. Estos monocitos generarían daño mediante la secreción de citoquinas proinflamatorias, así como también por su capacidad de diferenciarse ellos mismos a osteoclastos. Recientemente, el trabajo de Lecourt y col utilizando células mesenquimales mostró que esas células secretarían factores que promueven la resorción ósea (Lecourt et al., 2012).

Además se sabe que la inflamación es un factor clave en la patogénesis de la enfermedad de Gaucher (Shoenfeld et al., 1982), y que está caracterizada por la

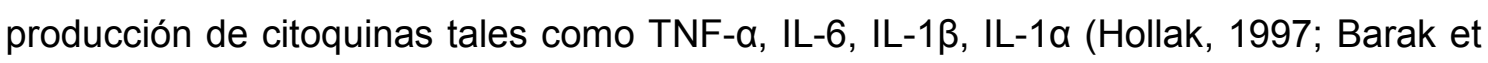
al., 1999; Hong et al., 2006) y las quemoquinas MIP-1 $\alpha$ y MIP-1 $\beta$ (van Breemenet al., 2007).

Dentro de este contexto decidimos establecer las causas posibles de las alteraciones óseas en los pacientes con enfermedad de Gaucher mediante el establecimiento de modelos in vitro que reflejaran, por lo menos en parte, la problemática en los pacientes. De esta manera demostramos que existirían mediadores solubles, secretados por células deficientes para la actividad de la GCasa, que generan una inducción en la diferenciación de osteoclastos. En esta última parte nos centramos en los pacientes, evidenciando la existencia de los mediadores solubles secretados por las células afectadas, los cuales inducen procesos de osteoclastogénesis. Por otra parte demostramos el rol del TNF- $\alpha$ y RANKL como moléculas clave en este proceso, apoyando los resultados obtenidos que involucran al TNF- $\alpha$ en los modelos in vitro. $\mathrm{Y}$ 
agregando a RANKL como otra de las posibles moléculas involucradas en la patogénesis ósea de la enfermedad.

Estudios realizados utilizando células mesenquimales de médula ósea, de pacientes con enfermedad de Gaucher (Campeau et al., 2009b) o células normales expuestas a CBE (Lecourt et al., 2012), han demostrado que existiría un microambiente inflamatorio en el hueso de pacientes con enfermedad de Gaucher que incluiría niveles aumentados de las citoquinas y quimoquinas tales como, IL-8, CCL-2, IL-6, MCP-1. Los resultados de nuestros modelos in vitro de la enfermedad de Gaucher muestran que los precursores de osteoclastos expuestos a sobrenadantes condicionados con CBE expresan mayores niveles de IL-1 $\beta$ y TNF- $\alpha$ lo que aportaría al microambiente inflamatorio en el hueso.

En esta sección demostramos la presencia aumentada de precursores de osteoclastos en circulación de pacientes con enfermedad de Gaucher, con capacidad de diferenciarse a osteoclastos maduros y activos. Estos precursores podrían migrar hacia el hueso donde encontrarían un microambiente propenso para completar su diferenciación generando un desbalance en el equilibrio normal.

Por otro lado demostramos una tendencia al aumento en los niveles de RNA mensajero para las moléculas RANKL, RANK y CtsK en PBMC de pacientes. Estos resultados apoyarían la hipótesis de que no solo existe un aumento en los niveles de precursores de osteoclastos en circulación sino que estos tendrían una mayor potencialidad para diferenciarse y se encontrarían en un ambiente que tiende a aumentar su diferenciación.

Se ha descripto que las células $T$ participan activamente en enfermedades con compromiso óseo tales como artritis reumatoidea, mieloma múltiple, enfermedad peridontal, etc. Dicha participación involucra tanto la expresión aumentada de RANKL en su superficie como un aumento en la producción de citoquinas (Kawai et al., 2006; Kong et al., 1999; Noonan et al., 2010)

En esta sección demostramos la expresión aumentada de RANKL en la superficie de linfocitos $\mathrm{T}$, lo cual podría aumentar el ambiente pro-osteoclastogénico al cual se encuentran sometidos los precursores y confirmaría la participación de las células T en este proceso, además de presentar mayores niveles de producción de IL-6 y TNF- $\alpha$. Por lo que el rol de las células $T$ en la patogénesis ósea e inflamatoria en la enfermedad de Gaucher sería importante.

Tanto la terapia de reemplazo enzimático como la terapia de reducción de sustrato reducen los episodios de osteonecrosis y mejoran la mineralización ósea (Pastores et al., 2007; Sims et al., 2008; Weinreb et al., 2002). Sin embargo, las manifestaciones 
relacionadas a la injuria ósea no son totalmente eliminadas manteniéndose las crisis de dolor óseo en casi un 40\% de los pacientes (Sims et al., 2008).

En esta sección obtuvimos resultados que demuestran que el tratamiento de las células de paciente con rhGCasa produce una disminución en la diferenciación a osteoclastos de los precursores presentes en circulación de pacientes. Esto sería beneficioso ya que disminuiría la cantidad de precursores con potencial osteoclastogénico que pueden migrar desde la circulación hacia el hueso, lo que podría explicar, al menos en parte, los efectos beneficiosos observados en los pacientes.

La inflamación es un factor clave en la patogénesis de la enfermedad de Gaucher (Shoenfeld et al., 1982), y está caracterizada por la producción de citoquinas tales

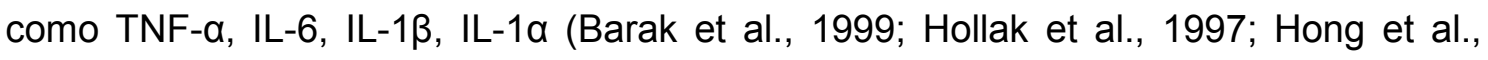
2006) las cuales se encuentran relacionadas también con el proceso de diferenciación de osteoclastos (Kim et al., 2009; Kobayashi et al., 2000; Kudo et al., 2003a).

Por lo tanto nos propusimos evaluar la posible contribución de diferentes poblaciones celulares en circulación de pacientes, a la generación del estado inflamatorio observado en los mismos. Demostramos entonces un aumento importante en el número de monocitos inflamatorios $\mathrm{CD} 14^{+} \mathrm{CD} 16^{+}$, como también un aumento en el número de células productoras de IL-6 y TNF- $\alpha$ en dicha población. Se ha demostrado que estos monocitos producen la expansión de células del linaje Th17 (Rossol et al., 2012), las cuales se han definido como el linaje T que apoya la osteoclastogénesis (Sato et al., 2006). Por lo que su rol en el estado inflamatorio y pro-osteoclastogénico podría ser central.

Por otro lado mostramos que los monocitos $\mathrm{CD} 14^{+} \mathrm{CD} 16^{-}$también contribuirían al estado inflamatorio en los pacientes presentando niveles aumentados de células productoras de IL-6 y TNF- $\alpha$ como también mayor producción de IL-6.

Debido al estado de inflamación crónico observado en pacientes nuestra hipótesis fue que las células $T$ regulatorias podrían estar aumentadas como respuesta fisiológica a este proceso. Sin embargo no se presentaron diferencias entre los pacientes y controles sanos tanto para el porcentaje de células Treg, como para los niveles del factor de transcripción Foxp3. Por lo que, en principio, estas células no se encontrarían alteradas como una respuesta al estado inflamatorio observado en los pacientes. Los pacientes con enfermedad de Gaucher presentan niveles aumentados de TGF- $\beta$ en plasma (Pandey et al., 2013). Como las células Treg son una de las principales productoras de TGF- $\beta$ se debería estudiar la expresión de esta citoquina en dicha población. 
Como conclusiones de esta parte hemos demostrado la presencia aumentada de precursores de osteoclastos en circulación de pacientes con enfermedad de Gaucher como también su mayor capacidad de diferenciación. Demostramos el rol del TNF- $\alpha$ y RANKL en el proceso de osteoclastogénesis inducido en pacientes. Revelamos los posibles efectos beneficiosos mediados por el tratamiento con glucocerebrosidasa recombinante. Encontramos el papel central que jugarían los LT y monocitos en el estado inflamatorio en pacientes. 


\section{Discusión General y Conclusiones}

Los objetivos propuestos para el presente trabajo se dirigieron a investigar la relación entre la deficiencia en la actividad de la enzima lisosomal beta-glucosidasa, y la consecuente acumulación de su sustrato la glucosilceramida, con los mecanismos que llevan a un aumento en el estado proinflamatorio y el daño óseo observado en pacientes con enfermedad de Gaucher.

Los pacientes con enfermedad de Gaucher sufren de dolor óseo el cual puede ser agudo o crónico. La deformidad radiológica en forma de "frasco de Erlenmeyer" es característica y se debe a una alteración en el remodelamiento de la metáfisis del fémur distal. El esqueleto sufre tumefacción, destrucción de hueso en lesiones osteolíticas, osteopenia, desmineralización generalizada, infartos medulares, expansión medular, adelgazamiento óseo cortical y osteoporosis con riesgo aumentado de fracturas. Los pacientes pueden tener osteosclerosis, como resultado del remodelamiento aberrante de un infarto óseo con deposición de calcio. La osteonecrosis o necrosis avascular se observa generalmente en cabeza femoral, húmero proximal, rodilla y cuerpos vertebrales, alterando la función de las grandes articulaciones de la cadera, hombro y rodilla.

Nuestra primer estrategia fue generar un modelo in vitro para evaluar las posibles alteraciones. Para esto se utilizó un inhibidor especifico de la enzima, el CBE, ya utilizado ampliamente en otros modelos de la enfermedad.

El modelo nos permitió demostrar que la ausencia de actividad enzimática y acumulación de sustrato genera alteraciones celulares que llevan a la secreción de factores solubles capaces de inducir la diferenciación de osteoclastos maduros y activos, y potencialmente, generar daño óseo por un desbalance en el equilibrio dinámico normal del hueso. Este aumento en la diferenciación y activación de los osteoclastos ha sido mostrada recientemente para otros modelos equivalentes al nuestro. En el trabajo de Lecourt y col., los autores utilizaron una estrategia equivalente a la nuestra en la cual tratan células mesenquimales de médula ósea con CBE. Demostraron que el tratamiento de precursores de osteoclastos con sobrenadantes condicionados de estas células generaron un aumento en la inducción de osteoclastos activos (Lecourt et al., 2012).

En nuestro trabajo utilizamos dos tipos de modelos distintos de modo de validar y reforzar los resultados obtenidos. Así los resultados observados para la diferenciación y actividad de osteoclastos pudieron observarse tanto en el caso del uso de células humanas como también para el modelo murino. En ambos casos también pudo 
verificarse que una de las moléculas centrales en el proceso es el TNF- $\alpha$, el cual se ha descripto aumentado en el suero de pacientes con enfermedad de Gaucher (Pandey et al., 2013).

Para el caso del modelo murino pudimos mostrar también que la actividad de los osteoblastos se encontraría alterada, llevando a una menor formación ósea. Estos resultados se encuentran en concordancia con los obtenidos para el único modelo murino con alteraciones óseas (Mistry et al., 2010). En este trabajo utilizan el modelo murino condicionado de la enfermedad de Gaucher en el cual el gen GBA en forma condicional luego del nacimiento. Los ratones presentan osteonecrosis avascular y osteopenia específicamente en el femur, la tibia y la columna vertebral lumbar. Los autores demuestran que los problemas óseos observados en estos ratones derivarían de una alteración en el proceso de diferenciación y actividad de los osteoblastos, mientras que la diferenciación y actividad de los osteoclastos no se presentaría alterada.

Las diferencias entre nuestro modelo murino in vitro y este modelo in vivo podrían deberse a la presencia de actividad de la GCasa en las células mesenquimales del modelo in vivo. Se ha demostrado que estas células juegan un rol en el proceso de inducción de osteoclastos como mencionamos antes y, por lo tanto, su aporte a la problemática ósea en el modelo murino condicional podría estar subestimada.

Experimentos equivalentes a los realizados con la línea MC3T3 utilizando líneas de osteoblastos de origen humano no pudieron realizarse debido a los requerimientos para el cultivo de éstos. Las líneas de osteoblastos humanas requieren una temperatura de $24^{\circ} \mathrm{C}$ para su crecimiento, en la actualidad no disponemos de una estufa de cultivo exclusiva para llevar a cabo un cultivo en estas condiciones.

Para evaluar la problemática desde una estrategia más cercana al estado fisiológico de los pacientes, se realizaron los experimentos de osteoclastogénesis utilizando células de pacientes con enfermedad de Gaucher. Mediante este trabajo pudimos corroborar y validar los resultados obtenidos para los modelos in vitro, nuevamente posicionando al TNF- $\alpha$ como molécula central en el proceso fisiopatogénico y agregando también a RANKL como otro factor soluble involucrado.

Además mostramos la presencia aumentada de precursores de osteoclastos en circulación de pacientes con enfermedad de Gaucher y su capacidad de diferenciarse a osteoclastos maduros y activos. Estos precursores se ha demostrado que pueden migrar desde la circulación hacia el hueso, donde terminan su diferenciación para ejercer su acción. Esta migración está dirigida, por lo menos en parte, por el lípido esfingosina-1-fostato (S1P) (Ishii et al., 2010; Ishii et al., 2011) mediante un gradiente de concentración del mismo que genera una quimiorepulsión de los precursores desde 
la circulación, donde se encuentra en mayor concentración, y un arresto en el hueso, donde está en bajas concentraciones. Recientemente Campeau y col. mostraron en un modelo de enfermedad de Gaucher niveles disminuidos de S1P en el microambiente óseo. Estos hallazgos en conjunto con nuestros resultados podrían indicar la existencia de un aumento en la migración de precursores hacia el hueso y subsecuente daño óseo.

La terapia de reemplazo enzimático y la terapia de reducción de sustrato logran reducir los episodios de osteonecrosis y mejoran la mineralización ósea (Pastores et al., 2007; Sims et al., 2008; Weinreb et al., 2002). Sin embargo, las manifestaciones relacionadas a la injuria ósea no son totalmente eliminadas manteniéndose los episodios de dolor óseo en casi un $40 \%$ de los pacientes bajo tratamiento (Sims et al., 2008). En la actualidad los especialistas ya no ven a la enfermedad de Gaucher como un desorden caracterizado por citopenias y visceromegalias sino como una patología principalmente esquelética con defectos en la estructura y metabolismo óseo (Deegan et al., 2011).

En nuestro trabajo obtuvimos resultados que demuestran que el tratamiento con glucocerebrosidasa recombinante generaría una disminución en el potencial de diferenciación de los precursores en circulación, atenuando de este modo los efectos nocivos de los mismos.

Resultados similares fueron obtenidos por el grupo de Reed et al. en 2013 simultáneamente con nuestro grupo. En este trabajo purificaron células CD14 ${ }^{+}$a partir de PBMC de pacientes con enfermedad de Gaucher y demostraron que las mismas presentaban una mayor diferenciación a osteoclastos activos en comparación con células de controles normales. Mientras que la presencia de otras formulaciones terapéuticas reducían el efecto en la diferenciación de osteoclastos. En este trabajo demuestran también que existe una alteración en la correlación entre el número de precursores de osteoblastos en circulación y los precursores de osteoclastos (definidos como células que se diferencian a osteoclastos in vitro) en pacientes con enfermedad de Gaucher.

A pesar de esto, como mencionamos antes, existe un importante número de pacientes bajo tratamiento en los cuales las manifestaciones óseas no son completamente revertidas. Las causas de este fenómeno no son comprendidas y, al día de la fecha, no han sido estudiadas. Una posible causa sería la accesibilidad de la enzima recombinante al microambiente óseo disminuyendo de esta manera la concentración efectiva de enzima en el hueso. Por otro lado podrían existir nichos dentro del sistema óseo donde se perpetúe un estado inflamatorio a pesar del tratamiento con enzima 
recombinante lo que llevaría al mantenimiento de un estado pro-osteoclastogénico en el microambiente óseo.

En la figura 26 se muestra un esquema de los posibles mecanismos que derivan en un desbalance de la dinámica ósea normal incluyendo tanto reportes de la bibliografía como resultados nuestros. Las flechas rojas indican moléculas que se han descripto aumentadas en pacientes con enfermedad de Gaucher o posibles mecanismos desregulados.

Se muestra cómo distintos mecanismos podrían actuar sobre los precursores de osteoclastos (OP) y/o sobre los osteoblastos llevando al desbalance. El aumento de citoquinas proinflamatorias podría actuar directamente sobre los precursores de osteoclasto, llevando a su diferenciación independiente de RANKL o aumentando los niveles de éste en la superficie de los osteoblastos y células Th17. Estas últimas han sido demostradas como la población linfocítica osteoclastogénica (Noonan et al., 2010; Sato et al., 2006). En nuestro trabajo demostramos un aumento de la expresión de RANKL en la superficie de linfocitos $T$ de pacientes con enfermedad de Gaucher, aunque más trabajo es necesario para evaluar la identidad de éstos como Th17. Todo esto se reflejaría en aumento en la diferenciación y actividad de los osteoclastos como demostramos tanto para los modelos in vitro como para el caso de los pacientes.

El aumento de las citoquinas proinflamatorias y otras moléculas podrían tener efectos sobre la actividad de los osteoblastos, como demostramos en el presente trabajo y los trabajos de Mistry y col. La actividad y diferenciación de osteoblastos se vería disminuida en la enfermedad de Gaucher. Por otro lado podría haber un aumento en la inducción de apoptosis mediada por moléculas solubles o disparada por señales intrínsecas debido a la acumulación de glucosilceramida.

Como conclusión nuestros resultados indican que los mecanismos fisiopatogénicos que derivarían en las alteraciones óseas en la enfermedad de Gaucher estarían mediados por un desbalance en el equilibrio dinámico óseo normal generado por un aumento en los niveles y actividad de los osteoclastos, con una importante contribución de TNF- $\alpha$ y RANKL como mediadores de este proceso. 
Por lo tanto las conclusiones generales de este trabajo son:

-Se encontró una inducción aumentada en la diferenciación de osteoclastos in vitro tanto en los modelos químicos como en las células mononucleares de pacientes con enfermedad de Gaucher.

-Este proceso estaría mediado por factores solubles liberados por las células deficientes en la actividad de GCasa.

-TNF- $\alpha$ sería una de las moléculas involucradas en el aumento de la osteoclastogénesis in vitro observado en nuestros modelos de enfermedad de Gaucher.

-Los linfocitos $T$ participarían en el estado proosteoclastogénico y proinflamatorio en pacientes con enfermedad de Gaucher.

-Los monocitos $\mathrm{CD}_{14}{ }^{+} \mathrm{CD} 16^{+}$y $\mathrm{CD}^{+} 4^{+} \mathrm{CD} 16^{-}$estarían involucrados en el estado proinflamatorio observado en los pacientes con enfermedad de Gaucher.

-Se reveló que factores solubles secretados por células deficientes en GCasa conducen a una menor actividad de formación ósea por parte de los osteoblastos en un modelo murino in vitro.

-El tratamiento in vitro con Velaglucerasa reduciría el potencial osteoclastogénico de los precursores en circulación de pacientes con enfermedad de Gaucher. 


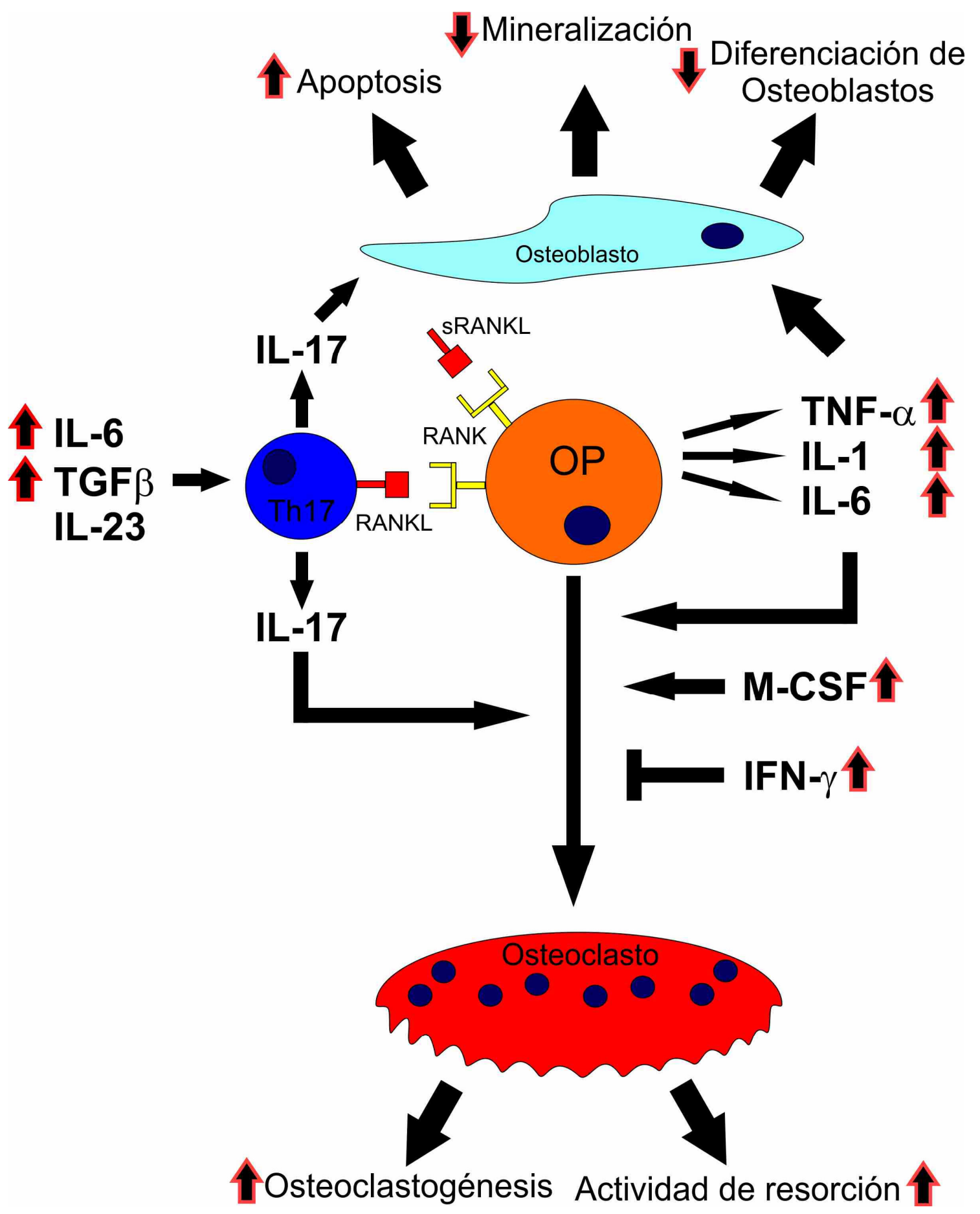

Fig. 26 Posibles mecanismos involucrados en la problemática ósea de la enfermedad de Gaucher. OP: Precursor de osteoclasto 


\section{Perspectivas a futuro}

Nuestro trabajo nos ha permitido demostrar varios aspectos sobre los mecanismos fisiopatogénicos involucrados en la problemática ósea de la enfermedad de Gaucher. Pero por otro lado nos ha abierto nuevos interrogantes para continuar con nuestros estudios.

Nos proponemos profundizar los estudios en osteoblastos para delinear los mecanismos involucrados en la disminución de su actividad y diferenciación, como también evaluar la posibilidad de un aumento en la apoptosis.

Para esto disponemos en la actualidad del modelo murino condicional de la enfermedad de Gaucher, que presenta las características óseas observadas en los pacientes. Este modelo nos permitirá evaluar los procesos de osteoclastogénesis, utilizando precursores de médula ósea que carezcan de actividad enzimática. Como también generar cultivos primarios de osteoblastos sobre los cuales investigar los mecanismos propuestos, como también el efecto del tratamiento con rhGCasa u otros coadyuvantes.

Por último sería importante poder definir el mecanismo molecular mediante el cual se genera el estado proinflamatorio observado en los pacientes, ya que, como hemos visto, las moléculas proinflamatorias serían en buena parte las causantes del daño óseo.

Un mecanismo posible para explicar el estado proinflamatorio podría ser la activación del sistema molecular conocido como el inflamosoma. Particularmente la activación del mismo a través de la molécula adaptadora NLRP3 se ha descripto como el receptor que interviene en la inflamación disparada por partículas como asbesto, cristales de ácido úrico, cristales de colesterol, etc. (Rock et al., 2010), conocida como "inflamación estéril". La activación y ensamble de la maquinaria del inflamosoma a través de NLRP3 puede generarse mediante distintos mediadores intracelulares. Se ha descripto que la ruptura de lisosomas y consecuente liberación de distintas moléculas activa a NLRP3 (Codolo et al., 2013; Hornung et al., 2008), por lo que la acumulación de glucosilceramida podría generar una inestabilidad en la estructura del lisosoma, llevando a una fuga de componentes del mismo hacia el citoplasma y la activación del inflamosoma.

Otra ruta de activación de NLRP3 es mediante la ceramida, la misma podría generarse por la liberación de la glucosilceramida acumulada en los lisosomas y la degradación de la misma mediante la enzima GBA2. La GBA2 (una isoenzima de GBA1) se ha descripto como una enzima asociada al retículo endoplásmico y al aparato de Golgi 
hacia la cara citoplasmática de los mismos (Körschen et al., 2013). Además estudios recientes muestran que su actividad se encontraría aumentada en fibroblastos y leucocitos de pacientes con enfermedad de Gaucher (Aureli et al., 2012; Burke et al., 2012).

Otros dos mecanismos posibles de activación son el aumento del calcio citosólico por liberación del mismo desde el retículo endoplasmático o por disfunción mitocondrial y generación de especies reactivas del oxígeno. Ambos mecanismos han sido descriptos en pacientes con enfermedad de Gaucher o en modelos de la misma (Cleeter et al., 2013; Osellame et al., 2013; Vitner el al., 2010).

La activación del inflamosoma lleva a la activación proteolítica de IL-1 $\beta$ y/o IL-18, la cual puede ser dependiente o independiente de caspasa-1. La liberación de ambas citoquinas promueve un proceso inflamatorio que puede autoperpetuarse llevando a un estado inflamatorio crónico. En la figura 27 se muestra un esquema sintetizando los posibles mecanismos propuestos.

El estudio de estos procesos en la enfermedad de Gaucher podría llevar a la utilización de tratamientos coadyuvantes apuntados a disminuir el estado inflamatorio en los pacientes. 


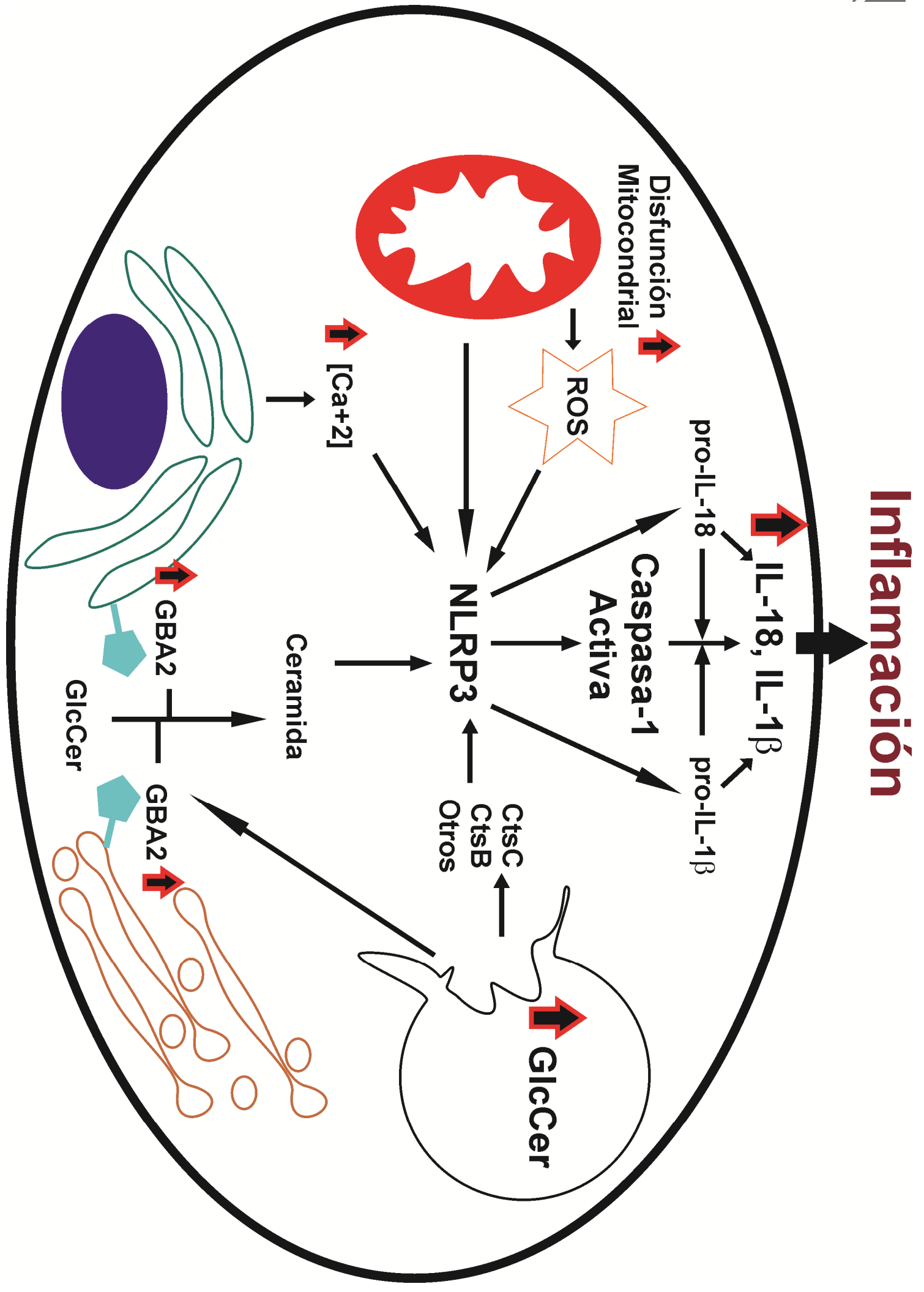

Fig.27 Posibles mecanismos involucrados en la generación de un estado proinflamatorio en la enfermedad de Gaucher 
Lic. Juan Marcos Mucci 


\section{$\underline{\text { Referencias }}$}

Adamopoulos, I. E., Sabokbar, A., Wordsworth, B. P., Carr, A., Ferguson, D. J., \& Athanasou, N. A. (2006). Synovial fluid macrophages are capable of osteoclast formation and resorption. The Journal of pathology, 208(1), 35-43. doi:10.1002/path.1891

Aerts, J. M. F. G., Hollak, C. E. M., van Breemen, M., Maas, M., Groener, J. E. M., \& Boot, R. G. (2005). Identification and use of biomarkers in Gaucher disease and other lysosomal storage diseases. Acta paediatrica (Oslo, Norway: 1992). Supplement, 94(447), 43-6; discussion 37-8. Retrieved from http://www.ncbi.nlm.nih.gov/pubmed/15895711

Aerts, J. M., \& Hollak, C. E. (1997). Plasma and metabolic abnormalities in Gaucher's disease. Baillière's clinical haematology, 10(4), 691-709. Retrieved from http://www.ncbi.nlm.nih.gov/pubmed/9497858

Allen, M. J., Myer, B. J., Khokher, A. M., Rushton, N., \& Cox, T. M. (1997). Proinflammatory cytokines and the pathogenesis of Gaucher's disease: increased release of interleukin-6 and interleukin-10. QJM : monthly journal of the Association of Physicians, 90(1), 19-25. Retrieved from http://www.ncbi.nlm.nih.gov/pubmed/9093585

Arandi, N., Mirshafiey, A., Jeddi-Tehrani, M., Shaghaghi, M., Sadeghi, B., Abolhassani, $\mathrm{H}$., ... Aghamohammadi, A. (2014). Alteration in Frequency and Function of CD4+CD25+FOXP3+ Regulatory T cells in Patients with Immune Thrombocytopenic Purpura. Iranian journal of allergy, asthma, and immunology, 13(2), 85-92. Retrieved from http://www.ncbi.nlm.nih.gov/pubmed/24338252

Aureli, M., Bassi, R., Loberto, N., Regis, S., Prinetti, A., Chigorno, V., ... Sonnino, S. (2012). Cell surface associated glycohydrolases in normal and Gaucher disease fibroblasts. Journal of inherited metabolic disease, 35(6), 1081-91. doi:10.1007/s10545-012-9478-x

Aviezer, D., Brill-Almon, E., Shaaltiel, Y., Hashmueli, S., Bartfeld, D., Mizrachi, S., ... Galun, E. (2009). A plant-derived recombinant human glucocerebrosidase enzyme--a preclinical and phase I investigation. PloS one, 4(3), e4792. doi:10.1371/journal.pone.0004792

Azuma, Y., Kaji, K., Katogi, R., Takeshita, S., \& Kudo, a. (2000). Tumor necrosis factoralpha induces differentiation of and bone resorption by osteoclasts. The Journal of biological chemistry, 275(7), 4858-64. Retrieved from http://www.ncbi.nlm.nih.gov/pubmed/10671521

Barak, V., Acker, M., Nisman, B., Kalickman, I., Abrahamov, A., Zimran, A., \& Yatziv, S. (1999). Cytokines in Gaucher's disease. European cytokine network, 10(2), 205-10. Retrieved from http://www.ncbi.nlm.nih.gov/pubmed/10400826

Barton, N. W., Brady, R. O., Dambrosia, J. M., Di Bisceglie, A. M., Doppelt, S. H., Hill, S. C., ... Argoff, C. E. (1991). Replacement therapy for inherited enzyme deficiency--macrophage-targeted glucocerebrosidase for Gaucher's disease. The New England journal of medicine, 324(21), 1464-70. doi:10.1056/NEJM199105233242104 
Beutler, E. (1995). Treatment regimens in Gaucher's disease. Lancet, 346(8974), 5812. Retrieved from http://www.ncbi.nlm.nih.gov/pubmed/7658807

Boot, R. G. (1998). The Human Chitotriosidase Gene. NATURE OF INHERITED ENZYME DEFICIENCY. Journal of Biological Chemistry, 273(40), 25680-25685. doi:10.1074/jbc.273.40.25680

Boven, PhD, L. a., Meurs, M. Van, Boot, PhD, R. G., Mehta, MD, A., Boon, PhD, L., Aerts, PhD, J. M., \& Laman, PhD, J. D. (2004). Gaucher Cells Demonstrate a Distinct Macrophage Phenotype and Resemble Alternatively Activated Macrophages. American Journal of Clinical Pathology, 122(3), 359-369. doi:10.1309/BG5VA8JRDQH1M7HN

Braudeau, C., Graveleau, J., Rimbert, M., Néel, A., Hamidou, M., Grosbois, B., ... Masseau, A. (2013). Altered innate function of plasmacytoid dendritic cells restored by enzyme replacement therapy in Gaucher disease. Blood cells, molecules \& diseases, 50(4), 281-8. doi:10.1016/j.bcmd.2013.01.001

Brinckerhoff, C. E., \& Matrisian, L. M. (2002). Matrix metalloproteinases: a tail of a frog that became a prince. Nature reviews. Molecular cell biology, 3(3), 207-14. doi:10.1038/nrm763

Bultron, G., Kacena, K., Pearson, D., Boxer, M., Yang, R., Sathe, S., ... Mistry, P. K. (2010). The risk of Parkinson's disease in type 1 Gaucher disease. Journal of inherited metabolic disease, 33(2), 167-73. doi:10.1007/s10545-010-9055-0

Burke, D. G., Rahim, A. a, Waddington, S. N., Karlsson, S., Enquist, I., Bhatia, K., ... Heales, S. (2012). Increased glucocerebrosidase (GBA) 2 activity in GBA1 deficient mice brains and in Gaucher leucocytes. Journal of inherited metabolic disease, 3-6. doi:10.1007/s10545-012-9561-3

Burstein, Y., Zakuth, V., Rechavi, G., \& Spirer, Z. (1987). Abnormalities of cellular immunity and natural killer cells in Gaucher's disease. Journal of clinical \& laboratory immunology, 23(3), 149-51. Retrieved from http://www.ncbi.nlm.nih.gov/pubmed/2959782

Campeau, P. M., Rafei, M., Boivin, M.-N., Sun, Y., Grabowski, G. a, \& Galipeau, J. (2009a). Characterization of Gaucher disease bone marrow mesenchymal stromal cells reveals an altered inflammatory secretome. Blood, 114(15), 3181-90. doi:10.1182/blood-2009-02-205708

Campeau, P. M., Rafei, M., Boivin, M.-N., Sun, Y., Grabowski, G. a, \& Galipeau, J. (2009b). Characterization of Gaucher disease bone marrow mesenchymal stromal cells reveals an altered inflammatory secretome. Blood, 114(15), 3181-90. doi:10.1182/blood-2009-02-205708

Capablo, J. L., Saenz de Cabezón, A., Fraile, J., Alfonso, P., Pocovi, M., \& Giraldo, P. (2008). Neurological evaluation of patients with Gaucher disease diagnosed as type 1. Journal of neurology, neurosurgery, and psychiatry, 79(2), 219-22. doi:10.1136/jnnp.2006.111518

Centrella, M., McCarthy, T. L., \& Canalis, E. (1991). Transforming growth factor-beta and remodeling of bone. The Journal of bone and joint surgery. American volume, 73(9), 1418-28. Retrieved from http://www.ncbi.nlm.nih.gov/pubmed/1918129 
Chakrabarti, S., \& Patel, K. D. (2005). Regulation of matrix metalloproteinase-9 release from IL-8-stimulated human neutrophils. Journal of leukocyte biology, 78(1), 27988. doi:10.1189/jlb.1004612

Chen, G., Deng, C., \& Li, Y.-P. (2012). TGF- $\beta$ and BMP signaling in osteoblast differentiation and bone formation. International journal of biological sciences, 8(2), 272-88. doi:10.7150/ijbs.2929

Chérin, P., Rose, C., de Roux-Serratrice, C., Tardy, D., Dobbelaere, D., Grosbois, B., ... Hartmann, A. (2010). The neurological manifestations of Gaucher disease type 1: the French Observatoire on Gaucher disease (FROG). Journal of inherited metabolic disease, 33(4), 331-8. doi:10.1007/s10545-010-9095-5

Chu, C. Q., Field, M., Allard, S., Abney, E., Feldmann, M., \& Maini, R. N. (1992). Detection of cytokines at the cartilage/pannus junction in patients with rheumatoid arthritis: implications for the role of cytokines in cartilage destruction and repair. British journal of rheumatology, 31(10), 653-61. Retrieved from http://www.ncbi.nlm.nih.gov/pubmed/1393370

Clarke, B. (2008). Normal bone anatomy and physiology. Clinical journal of the American Society of Nephrology: CJASN, 3 Suppl 3, S131-9. doi:10.2215/CJN.04151206

Claro, T., Widaa, A., O’Seaghdha, M., Miajlovic, H., Foster, T. J., O'Brien, F. J., \& Kerrigan, S. W. (2011). Staphylococcus aureus protein A binds to osteoblasts and triggers signals that weaken bone in osteomyelitis. PloS one, 6(4), e18748. doi:10.1371/journal.pone.0018748

Cleeter, M. W. J., Chau, K.-Y., Gluck, C., Mehta, A., Hughes, D. a, Duchen, M., ... Schapira, A. H. (2013). Glucocerebrosidase inhibition causes mitochondrial dysfunction and free radical damage. Neurochemistry international, 62(1), 1-7. doi:10.1016/j.neuint.2012.10.010

Codolo, G., Plotegher, N., Pozzobon, T., Brucale, M., Tessari, I., Bubacco, L., \& de Bernard, M. (2013). Triggering of inflammasome by aggregated $\alpha$-synuclein, an inflammatory response in synucleinopathies. PloS one, 8(1), e55375. doi:10.1371/journal.pone.0055375

Cox, T M. (2001). Gaucher disease: understanding the molecular pathogenesis of sphingolipidoses. Journal of inherited metabolic disease, 24 Suppl 2, 106-21; discussion 87-8. Retrieved from http://www.ncbi.nlm.nih.gov/pubmed/11758671

Cox, Timothy M, Amato, D., Hollak, C. E., Luzy, C., Silkey, M., Giorgino, R., \& Steiner, R. D. (2012). Evaluation of miglustat as maintenance therapy after enzyme therapy in adults with stable type 1 Gaucher disease: a prospective, open-label non-inferiority study. Orphanet journal of rare diseases, 7, 102. doi:10.1186/17501172-7-102

Deegan, P. B., Pavlova, E., Tindall, J., Stein, P. E., Bearcroft, P., Mehta, A., ... Cox, T. M. (2011). Osseous manifestations of adult Gaucher disease in the era of enzyme replacement therapy. Medicine, 90(1), 52-60.

doi:10.1097/MD.0b013e3182057be4 
Dickerson, T. J., Suzuki, E., Stanecki, C., Shin, H.-S., Qui, H., \& Adamopoulos, I. E. (2012). Rheumatoid and pyrophosphate arthritis synovial fibroblasts induce osteoclastogenesis independently of RANKL, TNF and IL-6. Journal of autoimmunity, 39(4), 369-76. doi:10.1016/j.jaut.2012.06.001

Dingle, B. M., Liu, Y., Fatheree, N. Y., Min, J., Rhoads, J. M., \& Tran, D. Q. (2013). FoxP3(+) Regulatory T Cells Attenuate Experimental Necrotizing Enterocolitis. PloS one, 8(12), e82963. doi:10.1371/journal.pone.0082963

Drake, F. H., Dodds, R. A., James, I. E., Connor, J. R., Debouck, C., Richardson, S., ... Gowen, M. (1996). Cathepsin K, but not cathepsins B, L, or S, is abundantly expressed in human osteoclasts. The Journal of biological chemistry, 271(21), 12511-6. Retrieved from http://www.ncbi.nlm.nih.gov/pubmed/8647859

Eghbali-Fatourechi, G., Khosla, S., Sanyal, A., Boyle, W. J., Lacey, D. L., \& Riggs, B. L. (2003). Role of RANK ligand in mediating increased bone resorption in early postmenopausal women. The Journal of clinical investigation, 111(8), 1221-30. doi:10.1172/JCl17215

Elstein, D., Abrahamov, A., Dweck, A., Hadas-Halpern, I., \& Zimran, A. (2002). Gaucher disease: pediatric concerns. Paediatric drugs, 4(7), 417-26. Retrieved from http://www.ncbi.nlm.nih.gov/pubmed/12083970

Enquist, I. B., Nilsson, E., Ooka, A., Månsson, J., Olsson, K., Ehinger, M., ... Karlsson, S. (2006). Effective cell and gene therapy in a murine model of Gaucher disease, 103(37), 13819-13824.

Eriksen, E. F. (2010). Cellular mechanisms of bone remodeling. Reviews in endocrine \& metabolic disorders, 11(4), 219-27. doi:10.1007/s11154-010-9153-1

Finkelstein, R., Nachum, Z., Reissman, P., Reiss, N. D., Besser, M., Trajber, I., \& Melamed, Y. (1992). Anaerobic osteomyelitis in patients with Gaucher's disease. Clinical infectious diseases : an official publication of the Infectious Diseases Society of America, 15(5), 771-3. Retrieved from http://www.ncbi.nlm.nih.gov/pubmed/1445974

Fuller, M., Rozaklis, T., Lovejoy, M., Zarrinkalam, K., Hopwood, J. J., \& Meikle, P. J. (2008). Glucosylceramide accumulation is not confined to the lysosome in fibroblasts from patients with Gaucher disease. Molecular genetics and metabolism, 93(4), 437-43. doi:10.1016/j.ymgme.2007.11.011

Grabowski, G. A. (2006). Delivery of lysosomal enzymes for therapeutic use: glucocerebrosidase as an example. Expert opinion on drug delivery, 3(6), 771-82. doi:10.1517/17425247.3.6.771

Grundt, A., Grafe, I. A., Liegibel, U., Sommer, U., Nawroth, P., \& Kasperk, C. (2009). Direct effects of osteoprotegerin on human bone cell metabolism. Biochemical and biophysical research communications, 389(3), 550-5. doi:10.1016/j.bbrc.2009.09.026

Guggenbuhl, P., Grosbois, B., \& Chalès, G. (2008). Gaucher disease. Joint, bone, spine : revue du rhumatisme, 75(2), 116-24. doi:10.1016/j.jbspin.2007.06.006 
Hauschka, P. V, Lian, J. B., Cole, D. E., \& Gundberg, C. M. (1989). Osteocalcin and matrix Gla protein: vitamin K-dependent proteins in bone. Physiological reviews, 69(3), 990-1047. Retrieved from http://www.ncbi.nlm.nih.gov/pubmed/2664828

Haynes, D. R. (2004). Bone lysis and inflammation. Inflammation research : official journal of the European Histamine Research Society ... [et al.], 53(11), 596-600. Retrieved from http://www.ncbi.nlm.nih.gov/pubmed/15693607

Heidinger, M., Kolb, H., Krell, H.-W., Jochum, M., \& Ries, C. (2006). Modulation of autocrine TNF-alpha-stimulated matrix metalloproteinase 9 (MMP-9) expression by mitogen-activated protein kinases in THP-1 monocytic cells. Biological chemistry, 387(1), 69-78. doi:10.1515/BC.2006.010

Hein, L. K., Meikle, P. J., Hopwood, J. J., \& Fuller, M. (2007). Secondary sphingolipid accumulation in a macrophage model of Gaucher disease. Molecular genetics and metabolism, 92(4), 336-45. doi:10.1016/j.ymgme.2007.08.001

Heitner, R., Elstein, D., Aerts, J., Weely, S. van, \& Zimran, A. (2002). Low-dose Nbutyldeoxynojirimycin (OGT 918) for type I Gaucher disease. Blood cells, molecules \& diseases, 28(2), 127-33. Retrieved from http://www.ncbi.nlm.nih.gov/pubmed/12064906

Hodge, J. M., Kirkland, M. A., \& Nicholson, G. C. (2007). Multiple roles of M-CSF in human osteoclastogenesis. Journal of cellular biochemistry, 102(3), 759-68. doi:10.1002/jcb.21331

Hollak, C. E., Evers, L., Aerts, J. M., \& van Oers, M. H. (1997). Elevated levels of MCSF, sCD14 and IL8 in type 1 Gaucher disease. Blood cells, molecules \& diseases, 23(2), 201-12. doi:10.1006/bcmd.1997.0137

Hollak, C. E., van Weely, S., van Oers, M. H., \& Aerts, J. M. (1994). Marked elevation of plasma chitotriosidase activity. A novel hallmark of Gaucher disease. The Journal of clinical investigation, 93(3), 1288-92. doi:10.1172/JCI117084

Hong, Y. Bin, Kim, E. Y., \& Jung, S.-C. (2004). Down-regulation of Bcl-2 in the fetal brain of the Gaucher disease mouse model: a possible role in the neuronal loss. Journal of human genetics, 49(7), 349-54. doi:10.1007/s10038-004-0155-2

Hong, Y. Bin, Kim, E. Y., \& Jung, S.-C. (2006). Upregulation of proinflammatory cytokines in the fetal brain of the Gaucher mouse. Journal of Korean medical science, 21(4), 733-8. Retrieved from http://www.pubmedcentral.nih.gov/articlerender.fcgi?artid=2729900\&tool=pmcentr ez\&rendertype=abstract

Hornung, V., Bauernfeind, F., Halle, A., Samstad, E. O., Kono, H., Rock, K. L., ... Latz, E. (2008). Silica crystals and aluminum salts activate the NALP3 inflammasome through phagosomal destabilization. Nature immunology, 9(8), 847-56. doi:10.1038/ni.1631

Horwood, N. J., Kartsogiannis, V., Quinn, J. M., Romas, E., Martin, T. J., \& Gillespie, M. T. (1999). Activated T lymphocytes support osteoclast formation in vitro. Biochemical and biophysical research communications, 265(1), 144-50. doi:10.1006/bbrc.1999.1623 
Hu, H., Hilton, M. J., Tu, X., Yu, K., Ornitz, D. M., \& Long, F. (2005). Sequential roles of Hedgehog and Wnt signaling in osteoblast development. Development (Cambridge, England), 132(1), 49-60. doi:10.1242/dev.01564

Ishii, M., Kikuta, J., Shimazu, Y., Meier-Schellersheim, M., \& Germain, R. N. (2010). Chemorepulsion by blood S1P regulates osteoclast precursor mobilization and bone remodeling in vivo. The Journal of experimental medicine, 207(13), 2793-8. doi:10.1084/jem.20101474

Ishii, T., Shimazu, Y., Nishiyama, I., Kikuta, J., \& Ishii, M. (2011). The role of sphingosine 1-phosphate in migration of osteoclast precursors; an application of intravital two-photon microscopy. Molecules and cells, 31(5), 399-403. doi:10.1007/s10059-011-1010-x

Jmoudiak, M., \& Futerman, A. H. (2005). Gaucher disease: pathological mechanisms and modern management. British journal of haematology, 129(2), 178-88. doi:10.1111/j.1365-2141.2004.05351.x

Kacher, Y., \& Futerman, A. H. (2009). Impaired IL-10 transcription and release in animal models of Gaucher disease macrophages. Blood cells, molecules \& diseases, 43(1), 134-7. doi:10.1016/j.bcmd.2009.03.006

Kadono, H., Kido, J., Kataoka, M., Yamauchi, N., \& Nagata, T. (1999). Inhibition of osteoblastic cell differentiation by lipopolysaccharide extract from Porphyromonas gingivalis. Infection and immunity, 67(6), 2841-6. Retrieved from http://www.pubmedcentral.nih.gov/articlerender.fcgi?artid=96590\&tool=pmcentrez \&rendertype=abstract

Kawai, T., Matsuyama, T., Hosokawa, Y., Makihira, S., Seki, M., Karimbux, N. Y., ... Taubman, M. A. (2006). B and T lymphocytes are the primary sources of RANKL in the bone resorptive lesion of periodontal disease. The American journal of pathology, 169(3), 987-98. doi:10.2353/ajpath.2006.060180

Kawanaka, N., Yamamura, M., Aita, T., Morita, Y., Okamoto, A., Kawashima, M., ... Makino, $H$. (2002). CD14+,CD16+ blood monocytes and joint inflammation in rheumatoid arthritis. Arthritis and rheumatism, 46(10), 2578-86. doi:10.1002/art.10545

Kim, J. H., Jin, H. M., Kim, K., Song, I., Youn, B. U., Matsuo, K., \& Kim, N. (2009). The mechanism of osteoclast differentiation induced by IL-1. Journal of immunology (Baltimore, Md. : 1950), 183(3), 1862-70. doi:10.4049/jimmunol.0803007

Kobayashi, K., Takahashi, N., Jimi, E., Udagawa, N., Takami, M., Kotake, S., ... Suda, T. (2000). Tumor necrosis factor alpha stimulates osteoclast differentiation by a mechanism independent of the ODF/RANKL-RANK interaction. The Journal of experimental medicine, 191(2), 275-86. Retrieved from http://www.pubmedcentral.nih.gov/articlerender.fcgi?artid=2195746\&tool=pmcentr ez\&rendertype $=$ abstract

Kong, Y., Feige, U., Sarosi, I., Bolon, B., Tafuri, A., Morony, S., ... I, L. T. N. (1999). Activated $T$ cells regulate bone loss and joint destruction in adjuvant arthritis through osteoprotegerin ligand, 402(November), 2-7. 
Kong, Y. Y., Feige, U., Sarosi, I., Bolon, B., Tafuri, A., Morony, S., ... Penninger, J. M. (1999). Activated T cells regulate bone loss and joint destruction in adjuvant arthritis through osteoprotegerin ligand. Nature, 402(6759), 304-9. doi: $10.1038 / 46303$

Körschen, H. G., Yildiz, Y., Raju, D. N., Schonauer, S., Bönigk, W., Jansen, V., ... Wachten, D. (2013). The non-lysosomal $\beta$-glucosidase GBA2 is a non-integral membrane-associated protein at the endoplasmic reticulum (ER) and Golgi. The Journal of biological chemistry, 288(5), 3381-93. doi:10.1074/jbc.M112.414714

Kotake, S., Sato, K., Kim, K. J., Takahashi, N., Udagawa, N., Nakamura, I., ... Kashiwazaki, S. (1996). Interleukin-6 and soluble interleukin-6 receptors in the synovial fluids from rheumatoid arthritis patients are responsible for osteoclast-like cell formation. Journal of bone and mineral research : the official journal of the American Society for Bone and Mineral Research, 11(1), 88-95. doi:10.1002/jbmr.5650110113

Kotake, S., Udagawa, N., Takahashi, N., Matsuzaki, K., Itoh, K., Ishiyama, S., ... Suda, T. (1999). IL-17 in synovial fluids from patients with rheumatoid arthritis is a potent stimulator of osteoclastogenesis. The Journal of clinical investigation, 103(9), 1345-52. doi:10.1172/JCI5703

Kudo, O., Sabokbar, a, Pocock, a, Itonaga, I., Fujikawa, Y., \& Athanasou, N. . (2003a). Interleukin- 6 and interleukin-11 support human osteoclast formation by a RANKLindependent mechanism. Bone, 32(1), 1-7. doi:10.1016/S8756-3282(02)00915-8

Kudo, O., Sabokbar, A., Pocock, A., Itonaga, I., Fujikawa, Y., \& Athanasou, N. A. (2003b). Interleukin-6 and interleukin-11 support human osteoclast formation by a RANKL-independent mechanism. Bone, 32(1), 1-7. Retrieved from http://www.ncbi.nlm.nih.gov/pubmed/12584029

Lacerda, L., Arosa, F. A., Lacerda, R., Amaral, O., Sousa, M. De, Fortuna, A., ... Sa, C. (1999). T Cell Numbers Relate to Bone Involvement in Gaucher Disease, 25, 130 138.

Lacey, D. C., Simmons, P. J., Graves, S. E., \& Hamilton, J. A. (2009). Proinflammatory cytokines inhibit osteogenic differentiation from stem cells: implications for bone repair during inflammation. Osteoarthritis and cartilage / OARS, Osteoarthritis Research Society, 17(6), 735-42. doi:10.1016/j.joca.2008.11.011

Lecourt, S., Vanneaux, V., Cras, A., Freida, D., Heraoui, D., Herbi, L., ... Larghero, J. (2012). Bone marrow microenvironment in an in vitro model of Gaucher disease: consequences of glucocerebrosidase deficiency. Stem cells and development, 21(2), 239-48. doi:10.1089/scd.2011.0365

Lee, Y. K., Mukasa, R., Hatton, R. D., \& Weaver, C. T. (2009). Developmental plasticity of Th17 and Treg cells. Current opinion in immunology, 21(3), 274-80. doi:10.1016/j.coi.2009.05.021

Li, X., Qin, L., Bergenstock, M., Bevelock, L. M., Novack, D. V, \& Partridge, N. C. (2007). Parathyroid hormone stimulates osteoblastic expression of MCP-1 to recruit and increase the fusion of pre/osteoclasts. The Journal of biological chemistry, 282(45), 33098-106. doi:10.1074/jbc.M611781200 
Li, Z., Kong, K., \& Qi, W. (2006). Osteoclast and its roles in calcium metabolism and bone development and remodeling. Biochemical and biophysical research communications, 343(2), 345-50. doi:10.1016/j.bbrc.2006.02.147

Liu, J., Halene, S., Yang, M., lqbal, J., Yang, R., Mehal, W. Z., ... Mistry, P. K. (2012). Gaucher disease gene GBA functions in immune regulation. Proceedings of the National Academy of Sciences of the United States of America, 109(25), 1001823. doi:10.1073/pnas.1200941109

Lorenzo, J., Horowitz, M., \& Choi, Y. (2008). Osteoimmunology: interactions of the bone and immune system. Endocrine reviews, 29(4), 403-40.

doi:10.1210/er.2007-0038

Machaczka, M., Hast, R., Dahlman, I., Lerner, R., Klimkowska, M., Engvall, M., \& Hägglund, H. (2012). Substrate reduction therapy with miglustat for type 1 Gaucher disease: a retrospective analysis from a single institution. Upsala journal of medical sciences, 117(1), 28-34. doi:10.3109/03009734.2011.641609

Malone, J. D., Teitelbaum, S. L., Griffin, G. L., Senior, R. M., \& Kahn, A. J. (1982). Recruitment of osteoclast precursors by purified bone matrix constituents. The Journal of cell biology, 92(1), 227-30. Retrieved from http://www.pubmedcentral.nih.gov/articlerender.fcgi?artid=2112000\&tool=pmcentr ez\&rendertype=abstract

Margalit, M., Ash, N., Zimran, A., \& Halkin, H. (2002). Enzyme replacement therapy in the management of longstanding skeletal and soft tissue salmonella infection in a patient with Gaucher's disease. Postgraduate medical journal, 78(923), 564-5. Retrieved from http://www.pubmedcentral.nih.gov/articlerender.fcgi?artid=1742495\&tool=pmcentr ez\&rendertype=abstract

Martin, T. J., Allan, E. H., Ho, P. W. M., Gooi, J. H., Quinn, J. M. W., Gillespie, M. T., ... Sims, N. A. (2010). Communication between ephrinB2 and EphB4 within the osteoblast lineage. Advances in experimental medicine and biology, 658, 51-60. doi:10.1007/978-1-4419-1050-9_6

McInnes, I. B., \& Schett, G. (2007). Cytokines in the pathogenesis of rheumatoid arthritis. Nature reviews. Immunology, 7(6), 429-42. doi:10.1038/nri2094

Merkel, K. D., Erdmann, J. M., McHugh, K. P., Abu-Amer, Y., Ross, F. P., \& Teitelbaum, S. L. (1999). Tumor necrosis factor-alpha mediates orthopedic implant osteolysis. The American journal of pathology, 154(1), 203-10. Retrieved from

http://www.pubmedcentral.nih.gov/articlerender.fcgi?artid=1853441\&tool=pmcentr ez\&rendertype=abstract

Micheva, I., Marinakis, T., Repa, C., Kouraklis-Symeonidis, a, Vlacha, V., Anagnostopoulos, N., ... Symeonidis, a. (2006). Dendritic cells in patients with type I Gaucher disease are decreased in number but functionally normal. Blood cells, molecules \& diseases, 36(2), 298-307. doi:10.1016/j.bcmd.2005.12.029

Mistry, P. K., Liu, J., Yang, M., Nottoli, T., McGrath, J., Jain, D., ... Zaidi, M. (2010). Glucocerebrosidase gene-deficient mouse recapitulates Gaucher disease displaying cellular and molecular dysregulation beyond the macrophage. 
Proceedings of the National Academy of Sciences of the United States of America, 107(45), 19473-8. doi:10.1073/pnas.1003308107

Mor, A., Abramson, S. B., \& Pillinger, M. H. (2005). The fibroblast-like synovial cell in rheumatoid arthritis: a key player in inflammation and joint destruction. Clinical immunology (Orlando, Fla.), 115(2), 118-28. doi:10.1016/j.clim.2004.12.009

Moran, M. T., Schofield, J. P., Hayman, A. R., Shi, G. P., Young, E., \& Cox, T. M. (2000). Pathologic gene expression in Gaucher disease: up-regulation of cysteine proteinases including osteoclastic cathepsin K. Blood, 96(5), 1969-78. Retrieved from http://www.ncbi.nlm.nih.gov/pubmed/10961902

Murshed, M., Harmey, D., Millán, J. L., McKee, M. D., \& Karsenty, G. (2005). Unique coexpression in osteoblasts of broadly expressed genes accounts for the spatial restriction of ECM mineralization to bone. Genes \& development, 19(9), 1093104. doi:10.1101/gad.1276205

Nair, S. P., Meghji, S., Wilson, M., Reddi, K., White, P., \& Henderson, B. (1996). Bacterially induced bone destruction: mechanisms and misconceptions. Infection and immunity, 64(7), 2371-80. Retrieved from http://www.pubmedcentral.nih.gov/articlerender.fcgi?artid=174085\&tool=pmcentre z\&rendertype=abstract

Nakashima, T., Kobayashi, Y., Yamasaki, S., Kawakami, A., Eguchi, K., Sasaki, H., \& Sakai, H. (2000). Protein expression and functional difference of membranebound and soluble receptor activator of NF-kappaB ligand: modulation of the expression by osteotropic factors and cytokines. Biochemical and biophysical research communications, 275(3), 768-75. doi:10.1006/bbrc.2000.3379

Neve, A., Corrado, A., \& Cantatore, F. P. (2011). Osteoblast physiology in normal and pathological conditions. Cell and tissue research, 343(2), 289-302. doi:10.1007/s00441-010-1086-1

Noonan, K., Marchionni, L., Anderson, J., Pardoll, D., Roodman, G. D., \& Borrello, I. (2010). A novel role of IL-17-producing lymphocytes in mediating lytic bone disease in multiple myeloma. Blood, 116(18), 3554-63. doi:10.1182/blood-201005-283895

Osellame, L. D., Rahim, A. a, Hargreaves, I. P., Gegg, M. E., Richard-Londt, A., Brandner, S., ... Duchen, M. R. (2013). Mitochondria and quality control defects in a mouse model of Gaucher disease--links to Parkinson's disease. Cell metabolism, 17(6), 941-53. doi:10.1016/j.cmet.2013.04.014

Pandey, M. K., \& Grabowski, G. a. (2013). Immunological cells and functions in Gaucher disease. Critical reviews in oncogenesis, 18(3), 197-220. Retrieved from http://www.ncbi.nlm.nih.gov/pubmed/23510064

Pandey, M. K., Jabre, N. a, Xu, Y.-H., Zhang, W., Setchell, K. D. R., \& Grabowski, G. a. (2013). Gaucher disease: Chemotactic factors and immunological cell invasion in a mouse model. Molecular genetics and metabolism, 1-9. doi:10.1016/j.ymgme.2013.09.002

Pandey, M. K., Rani, R., Zhang, W., Setchell, K., \& Grabowski, G. A. (2012). Immunological cell type characterization and Th1-Th17 cytokine production in a 
mouse model of Gaucher disease. Molecular genetics and metabolism, 106(3), 310-22. doi:10.1016/j.ymgme.2012.04.020

Pastores, G. M., Elstein, D., Hrebícek, M., \& Zimran, A. (2007). Effect of miglustat on bone disease in adults with type 1 Gaucher disease: a pooled analysis of three multinational, open-label studies. Clinical therapeutics, 29(8), 1645-54. doi:10.1016/j.clinthera.2007.08.006

Pittenger, M. F., Mackay, A. M., Beck, S. C., Jaiswal, R. K., Douglas, R., Mosca, J. D., ... Marshak, D. R. (1999). Multilineage potential of adult human mesenchymal stem cells. Science (New York, N.Y.), 284(5411), 143-7. Retrieved from http://www.ncbi.nlm.nih.gov/pubmed/10102814

Platt, F. M., Boland, B., \& van der Spoel, A. C. (2012). The cell biology of disease: Lysosomal storage disorders: The cellular impact of lysosomal dysfunction. The Journal of cell biology, 199(5), 723-734. doi:10.1083/jcb.201208152

Quinn, J. M., Elliott, J., Gillespie, M. T., \& Martin, T. J. (1998). A combination of osteoclast differentiation factor and macrophage-colony stimulating factor is sufficient for both human and mouse osteoclast formation in vitro. Endocrinology, 139(10), 4424-7. doi:10.1210/endo.139.10.6331

Ramírez, R., Carracedo, J., Merino, A., Soriano, S., Ojeda, R., Alvarez-Lara, M. A., ... Aljama, P. (2011). CD14+CD16+ monocytes from chronic kidney disease patients exhibit increased adhesion ability to endothelial cells. Contributions to nephrology, 171, 57-61. doi:10.1159/000327134

Reponen, P., Sahlberg, C., Munaut, C., Thesleff, I., \& Tryggvason, K. (1994). High expression of 92-kDa type IV collagenase (gelatinase) in the osteoclast lineage during mouse development. Annals of the New York Academy of Sciences, 732, 472-5. Retrieved from http://www.ncbi.nlm.nih.gov/pubmed/7978842

Rifas, L., Fausto, A., Scott, M. J., Avioli, L. V, \& Welgus, H. G. (1994). Expression of metalloproteinases and tissue inhibitors of metalloproteinases in human osteoblast-like cells: differentiation is associated with repression of metalloproteinase biosynthesis. Endocrinology, 134(1), 213-21. doi:10.1210/endo.134.1.8275936

Roato, I., D’Amelio, P., Gorassini, E., Grimaldi, A., Bonello, L., Fiori, C., ... Ferracini, R. (2008). Osteoclasts are active in bone forming metastases of prostate cancer patients. PloS one, 3(11), e3627. doi:10.1371/journal.pone.0003627

Roato, I., Porta, F., Mussa, A., D’Amico, L., Fiore, L., Garelli, D., ... Ferracini, R. (2010). Bone impairment in phenylketonuria is characterized by circulating osteoclast precursors and activated T cell increase. PloS one, 5(11), e14167. doi:10.1371/journal.pone.0014167

Rock, K. L., Latz, E., Ontiveros, F., \& Kono, H. (2010). The sterile inflammatory response. Annual review of immunology, 28, 321-42. doi:10.1146/annurevimmunol-030409-101311

Romas, E., Gillespie, M. T., \& Martin, T. J. (2002, February). Involvement of receptor activator of NFkappaB ligand and tumor necrosis factor-alpha in bone destruction 
in rheumatoid arthritis. Bone. Retrieved from

http://www.ncbi.nlm.nih.gov/pubmed/11856640

Rossol, M., Kraus, S., Pierer, M., Baerwald, C., \& Wagner, U. (2012). The CD14(bright) CD16+ monocyte subset is expanded in rheumatoid arthritis and promotes expansion of the Th17 cell population. Arthritis and rheumatism, 64(3), 671-7. doi:10.1002/art.33418

Sato, K., Suematsu, A., Okamoto, K., Yamaguchi, A., Morishita, Y., Kadono, Y., ... Takayanagi, H. (2006). Th17 functions as an osteoclastogenic helper T cell subset that links T cell activation and bone destruction. The Journal of experimental medicine, 203(12), 2673-82. doi:10.1084/jem.20061775

Sawkar, A. R., D’Haeze, W., \& Kelly, J. W. (2006). Therapeutic strategies to ameliorate lysosomal storage disorders--a focus on Gaucher disease. Cellular and molecular life sciences : CMLS, 63(10), 1179-92. doi:10.1007/s00018-005-5437-0

Scherberich, J. E., \& Nockher, W. A. (1999). CD14++ monocytes, CD14+/CD16+ subset and soluble CD14 as biological markers of inflammatory systemic diseases and monitoring immunosuppressive therapy. Clinical chemistry and laboratory medicine : CCLM / FESCC, 37(3), 209-13. doi:10.1515/CCLM.1999.039

Shoenfeld, Y., Gallant, L. A., Shaklai, M., Livni, E., Djaldetti, M., \& Pinkhas, J. (1982). Gaucher's disease: a disease with chronic stimulation of the immune system. Archives of pathology \& laboratory medicine, 106(8), 388-91. Retrieved from http://www.ncbi.nlm.nih.gov/pubmed/7049116

Sims, K. B., Pastores, G. M., Weinreb, N. J., Barranger, J., Rosenbloom, B. E., Packman, S., ... Rosenthal, D. (2008). Improvement of bone disease by imiglucerase (Cerezyme) therapy in patients with skeletal manifestations of type 1 Gaucher disease: results of a 48-month longitudinal cohort study. Clinical genetics, 73(5), 430-40. doi:10.1111/j.1399-0004.2008.00978.x

Takasugi, K., Yamamura, M., Iwahashi, M., Otsuka, F., Yamana, J., Sunahori, K., ... Makino, H. (2006). Induction of tumour necrosis factor receptor-expressing macrophages by interleukin-10 and macrophage colony-stimulating factor in rheumatoid arthritis. Arthritis research \& therapy, 8(4), R126. doi:10.1186/ar2015

Takayanagi, H, lizuka, H., Juji, T., Nakagawa, T., Yamamoto, A., Miyazaki, T., ... Tanaka, S. (2000). Involvement of receptor activator of nuclear factor kappaB ligand/osteoclast differentiation factor in osteoclastogenesis from synoviocytes in rheumatoid arthritis. Arthritis and rheumatism, 43(2), 259-69. doi:10.1002/15290131(200002)43:2<259::AID-ANR4>3.0.CO;2-W

Takayanagi, Hiroshi. (2007). Osteoimmunology: shared mechanisms and crosstalk between the immune and bone systems. Nature reviews. Immunology, 7(4), 292304. doi:10.1038/nri2062

Teitelbaum, S. L. (2000). Bone resorption by osteoclasts. Science (New York, N. Y.), 289(5484), 1504-8. Retrieved from http://www.ncbi.nlm.nih.gov/pubmed/10968780

Tomomatsu, N., Aoki, K., Alles, N., Soysa, N. S., Hussain, A., Nakachi, H., ... Amagasa, T. (2009). LPS-induced inhibition of osteogenesis is TNF-alpha 
dependent in a murine tooth extraction model. Journal of bone and mineral research : the official journal of the American Society for Bone and Mineral Research, 24(10), 1770-81. doi:10.1359/jbmr.090410

Ukai, T., Yumoto, H., Gibson, F. C., \& Genco, C. A. (2008). Macrophage-elicited osteoclastogenesis in response to bacterial stimulation requires Toll-like receptor 2-dependent tumor necrosis factor-alpha production. Infection and immunity, 76(2), 812-9. doi:10.1128/IAI.01241-07

Väänänen, H. K., \& Horton, M. (1995). The osteoclast clear zone is a specialized cellextracellular matrix adhesion structure. Journal of cell science, 108 ( Pt 8, 272932. Retrieved from http://www.ncbi.nlm.nih.gov/pubmed/7593313

Van Breemen, M. J., de Fost, M., Voerman, J. S. A., Laman, J. D., Boot, R. G., Maas, M., ... Rezaee, F. (2007). Increased plasma macrophage inflammatory protein (MIP)-1alpha and MIP-1beta levels in type 1 Gaucher disease. Biochimica et biophysica acta, 1772(7), 788-96. doi:10.1016/j.bbadis.2007.04.002

Van Leeuwen, M. a, du Pré, M. F., van Wanrooij, R. L., de Ruiter, L. F., Raatgeep, H. R. C., Lindenbergh-Kortleve, D. J., ... Samsom, J. N. (2013). Changes in natural Foxp3(+)Treg but not mucosally-imprinted CD62L(neg)CD38(+)Foxp3(+)Treg in the circulation of celiac disease patients. PloS one, 8(7), e68432. doi:10.1371/journal.pone.0068432

Varin, A., \& Gordon, S. (2009). Alternative activation of macrophages: immune function and cellular biology. Immunobiology, 214(7), 630-41. doi:10.1016/j.imbio.2008.11.009

Vitner, E. B., Platt, F. M., \& Futerman, A. H. (2010). Common and uncommon pathogenic cascades in lysosomal storage diseases. The Journal of biological chemistry, 285(27), 20423-7. doi:10.1074/jbc.R110.134452

Weinreb, N. J., Charrow, J., Andersson, H. C., Kaplan, P., Kolodny, E. H., Mistry, P., ... Zimran, A. (2002). Effectiveness of enzyme replacement therapy in 1028 patients with type 1 Gaucher disease after 2 to 5 years of treatment: a report from the Gaucher Registry. The American journal of medicine, 113(2), 112-9. Retrieved from http://www.ncbi.nlm.nih.gov/pubmed/12133749

Wenstrup, R. J., Roca-Espiau, M., Weinreb, N. J., \& Bembi, B. (2002). Skeletal aspects of Gaucher disease: a review. The British journal of radiology, 75 Suppl 1, A2-12. Retrieved from http://www.ncbi.nlm.nih.gov/pubmed/12036828

Yamate, T., Mocharla, H., Taguchi, Y., Igietseme, J. U., Manolagas, S. C., \& Abe, E. (1997). Osteopontin expression by osteoclast and osteoblast progenitors in the murine bone marrow: demonstration of its requirement for osteoclastogenesis and its increase after ovariectomy. Endocrinology, 138(7), 3047-55. doi:10.1210/endo.138.7.5285

Yasuda, H., Shima, N., Nakagawa, N., Mochizuki, S. I., Yano, K., Fujise, N., ... Higashio, K. (1998). Identity of osteoclastogenesis inhibitory factor (OCIF) and osteoprotegerin (OPG): a mechanism by which OPG/OCIF inhibits osteoclastogenesis in vitro. Endocrinology, 139(3), 1329-37. doi:10.1210/endo.139.3.5837 
Yeo, L., Toellner, K.-M., Salmon, M., Filer, A., Buckley, C. D., Raza, K., \& ScheelToellner, D. (2011). Cytokine mRNA profiling identifies B cells as a major source of RANKL in rheumatoid arthritis. Annals of the rheumatic diseases, 70(11), 20228. doi:10.1136/ard.2011.153312

Zaiss, M. M., Axmann, R., Zwerina, J., Polzer, K., Gückel, E., Skapenko, A., ... Schett, G. (2007). Treg cells suppress osteoclast formation: a new link between the immune system and bone. Arthritis and rheumatism, 56(12), 4104-12. doi:10.1002/art.23138

Zhao, C., Irie, N., Takada, Y., Shimoda, K., Miyamoto, T., Nishiwaki, T., ... Matsuo, K. (2006). Bidirectional ephrinB2-EphB4 signaling controls bone homeostasis. Cell metabolism, 4(2), 111-21. doi:10.1016/j.cmet.2006.05.012

Ziegler-Heitbrock, L. (2007). The CD14+ CD16+ blood monocytes: their role in infection and inflammation. Journal of leukocyte biology, 81(3), 584-92.

doi:10.1189/jlb.0806510

Zimran, A., Altarescu, G., Philips, M., Attias, D., Jmoudiak, M., Deeb, M., ... Elstein, D. (2010). Phase $1 / 2$ and extension study of velaglucerase alfa replacement therapy in adults with type 1 Gaucher disease: 48-month experience. Blood, 115(23), 4651-6. doi:10.1182/blood-2010-02-268649 